\title{
TÉCNICAS PARA ESTIMATIVA DE FRFS ANGULARES EM ANÁlISE MODAL EXPERIMENTAL COM APLICAÇÕES A ESTRUTURAS DO TIPO VIGA
}

\author{
Melina Lofrano
}

Dissertação apresentada à Escola de Engenharia de São Carlos da Universidade de São Paulo, como parte dos requisitos para obtenção do título de Mestre em Engenharia Mecânica

ORIENTADOR: Prof. Dr. Paulo Sergio Varoto

São Carlos 
Aos meus pais, José Roberto e

Silvia Ana, e aos meus irmãos,

Anabel e Micail, pelo eterno amor e compreensão. 


\section{Agradecimentos}

Agradeço a DEUS em primeiro lugar, por tudo.

Agradeço ao meu orientador, prof. Dr Paulo Sergio Varoto, pela confiança em mim depositada para que se iniciasse um trabalho de mestrado, pela sua ajuda e orientação que auxiliaram no meu crescimento intelectual no decorrer desses anos.

Aos funcionários do laboratório de Dinâmica, Cristina e Xina, pela ajuda sempre pronta.

À secretaria de pós-graduação pela resolução das questões burocráticas.

Aos Laboratórios, LaMAQ - Laboratório de Mecânica Aplicada e Computacionalpelo apoio com o software comercial de simulação computacional Ansys e ao Lamafe Laboratório de Máquinas Ferramentas - pela confecção das peças necessária para a realização deste trabalho.

À CAPES, pelo financiamento o qual tornou possível o desenvolvimento desse trabalho.

Aos meus pais pelo incondicional amor e eterno apoio o qual sem eles seria impossível a realização deste trabalho. Aos meus irmãos, Anabel e Micail, pela eterna compreensão nos muitos dias de ausência.

Aos amigos do laboratório de Dinâmica da EESC-USP, pela amizade, companheirismo, incentivo e colaboração. Ao Leopoldo o qual suas idéias e seus desenhos estão muitos presentes neste trabalho.

À minha amiga, Maria Alice, pelo carinho, dedicação e apoio que nunca me faltaram.

A todos os meus amigos que de forma diferente e em diversos momentos me ajudaram.

Ao Mariano pela paciência nos momentos difíceis e pela ajuda e carinho sempre presente em todos os momentos.

Ao Marcio pela força, coragem e incentivo para desbravar uma nova área de conhecimento.

À todos que contribuíram direta ou indiretamente para a realização deste trabalho. 


\section{Sumário}

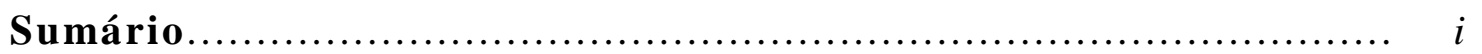

Lista de Abreviações............................................. iv

Lista de Símbolos................................................ v

Lista de Tabelas..............................................................

Lista de Figuras................................................... $x i$

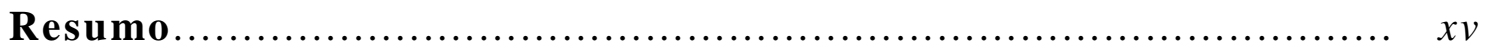

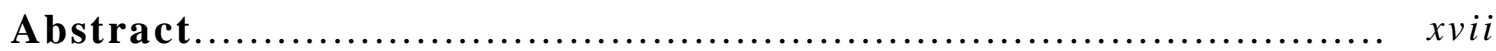

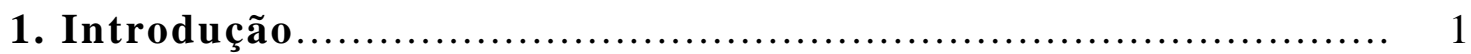

1.1Considerações Preliminares.................................... 2

1.2 Revisão Bibliográfica........................................ 3

1.2.1 Técnicas de Medida de Acelerações Angulares.......... 4

1.2.1.1 Medidas Baseadas em Sensores Piezelétricos....... 5

1.2.1.2 Medidas Utilizando Tecnologia a Laser............. 13

1.2.1.3 Medidas Através de Sensores Dedicados............ 15

1.2.2 Técnicas de Obtenção de Esforços Angulares............ 17

1.2.3 Aplicações de FRFs Angulares......................... 18

1.3 Objetivos.............................................. 20

1.4 Descrição da Dissertação.................................. 22

2. Modelo Contínuo para uma Viga de Euler - Bernoulli............ 24

2.1 Modelo Contínuo para uma Viga de Euler - Bernoulli........ 25

2.2 Análise para uma Viga Livre Livre............................ 29

2.3 Modelo Modal para Vibração Forçada........................... 42

2.4 FRF do Modelo Contínuo........................................ 45 
3. Técnicas de Estimação de Acelerações Angulares a Partir de Dados Experimentais............................................... 49

3.1 Definições Básicas de Entrada e Saída 50

3.2 Medidas de Aceleração Angular Utilizandoo Bloco T.

3.3 Medidas de Aceleração Angular Através da Técnica de Diferenças Finitas...

3.3.1 Matrizes de Transformação da Técnica de Diferenças Finitas 64

3.3.1.1 Aproximação de Primeira Ordem. 64

3.3.1.2 Aproximação de Segunda Ordem. 65

3.3.2 Aproximação baseada no Modelo de Resposta. 66

3.4 Medidas de Aceleração Angular obtida via Acelerômetro Angular Piezelétrico.

4. Simulação Numérica Através do Método dos Elementos Finitos para Viga de Euler - Bernoulli. 76

4.1 Introdução 77

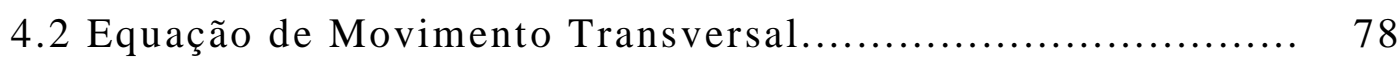

4.3 Transformação de Coordenada................................ 82

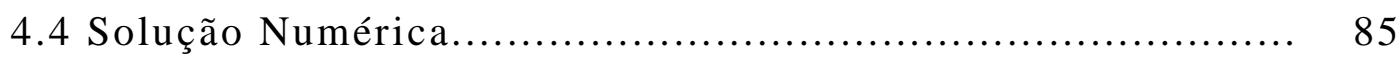

5. Resultados Experimentais..................................... 96

5.1 Consideração Prática para Realização de Ensaios Experimentais com o Bloco $\mathrm{T}$...

5.2 Utilização de Diversas Configurações de Blocos T 100

5.3 Resultados Experimentais Obtidos com o Bloco T........... 106

5.4 Resultados Experimentais Obtidos com Acelerômetro 109 Angular.

5.5 Resultados Experimentais Obtidos via Técnica das Diferenças Finitas de $1^{\text {a }}$ Ordem.

5.6 Resultados Experimentais Obtidos via Técnica das Diferenças Finitas de $2^{\text {a }}$ Ordem. 
7. Referências Bibliográficas e Bibliografia Consultada............ 131

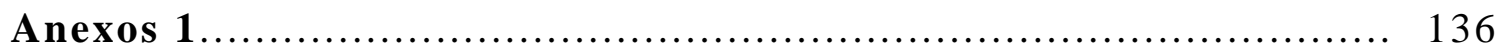

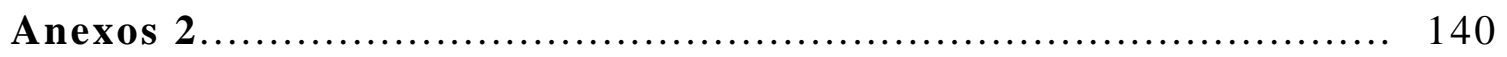

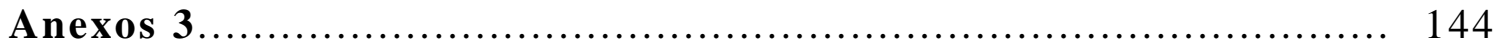




\section{Lista de Abreviações}

$\begin{array}{ll}\text { FFT - } & \text { Fast Fourier Transform } \\ \text { FRF - } & \text { Função de Resposta em Freqüência } \\ \text { GDL - } & \text { Graus De Liberdade } \\ \text { GDLR - } & \text { Graus De Liberdade de Rotação } \\ \text { GDLT - } & \text { Graus De Liberdade de Translação } \\ \text { MIMO - } & \text { Multiple Input Multiple Output } \\ \text { PZT - } & \text { Piezoelétrico } \\ \text { VLD - } & \text { Vibrômetro Laser Doppler } \\ \text { TAP - } & \text { Translation Angular Piezobeam }\end{array}$




\section{Lista de Símbolos}

\section{Romanas Maiúsculas}

Área da seção cruzada da viga $\left(\mathrm{m}^{2}\right)$

$A, B, C, D$

Constantes

$D_{p}$

Rigidez Dinâmica Modal (N/m)

E

Modulo de Young $(\mathrm{Pa})$

$F_{A}, F_{B}$ e $F_{C}$

Forças aplicadas nos pontos $a, b$ e $c$ respectivamente $(\mathrm{N})$

$F_{I}$

Força de Inércia (N)

F

Vetor de Força $(\mathrm{N})$

$H_{a b}$

FRF Ponto a Ponto

$H_{i j}$

FRF de relação entrada no ponto $j$ e saída no ponto $i$

$[H(\omega)]_{\text {est }}$

Matriz FRF estimada para a técnica de Diferenças Finitas

$\left[\mathrm{H}_{\mathrm{yy}}\right]$

Matriz FRF que relaciona saída e entrada lineares $(\mathrm{g} / \mathrm{N})$

$\left[\mathrm{H}_{\mathrm{y} \theta}\right]$

Matriz FRF que relaciona saída linear e entrada angular $(\mathrm{g} / \mathrm{Nm})$

$\left[\mathrm{H}_{\theta \mathrm{y}}\right]$

Matriz FRF que relaciona saída angular e entrada linear $\left(\left(\mathrm{rad} / \mathrm{s}^{2}\right) / \mathrm{N}\right)$

$\left[\mathrm{H}_{\theta \theta}\right]$

Matriz FRF que relaciona saída e entrada angulares $\left(\left(\mathrm{rad} / \mathrm{s}^{2}\right) /(\mathrm{Nm})\right)$

$[\mathrm{H}]_{\text {med }}$

Matriz FRF medida

$\left[\mathrm{H}_{\mathrm{AA}}\right]$

Matriz FRF medida com saída e entrada medidas no ponto A

$\left[\mathrm{H}_{\mathrm{BB}}\right]$

Matriz FRF medida com saída e entrada medidas no ponto B

$\left[\mathrm{H}_{\mathrm{CC}}\right]$

Matriz FRF medida com saída e entrada medidas no ponto C

$\left[\mathrm{H}_{\mathrm{BC}}\right]$

Matriz FRF medida com saída medida no ponto B e entrada medida no ponto $\mathrm{C}$

$\left[\mathrm{H}_{\mathrm{CB}}\right]$

Matriz FRF medida com saída medida no ponto $\mathrm{C}$ e entrada medida no ponto $\mathrm{B}$

$\left[\mathrm{H}_{\mathrm{CA}}\right]$

Matriz FRF medida com saída medida no ponto $\mathrm{C}$ e entrada medida no ponto $\mathrm{A}$ 
$\left[\mathrm{H}_{\mathrm{AC}}\right]$

$\left[\mathrm{H}_{\mathrm{AB}}\right]$

$\left[\mathrm{H}_{\mathrm{BA}}\right]$

$\left[\mathrm{H}_{\text {est }}(\omega)\right]_{1 f}$

$\left[\mathrm{H}_{\text {est }}(\omega)\right]_{1 b}$

$\left[\mathrm{H}_{\text {est }}(\omega)\right]_{2 f}$

$\left[\mathrm{H}_{\text {est }}(\omega)\right]_{2 b}$

$\left[\mathrm{H}_{\text {est }}(\omega)\right]_{2 c}$

$I(x)$

$I_{p}$

M

P

$P_{a}$

$P_{j}$

$Q_{p}$

$[\mathrm{T} *]$

$\left[\mathrm{T}_{1 f}\right]$

$\left[\mathrm{T}_{2 f}\right]$

$\left[\mathrm{T}_{1 \mathrm{~b}}\right]$

$\left[\mathrm{T}_{2 \mathrm{~b}}\right]$

$\left[\mathrm{T}_{2 \mathrm{c}}\right]$
Matriz FRF medida com saída medida no ponto A e entrada medida no ponto $\mathrm{C}$

Matriz FRF medida com saída medida no ponto A e entrada medida no ponto $\mathrm{B}$

Matriz FRF medida com saída medida no ponto B e entrada medida no ponto $\mathrm{A}$

Matriz FRF estimada usando matriz de transformação $[\mathrm{T}]_{1 f}$

Matriz FRF estimada usando matriz de transformação $[\mathrm{T}]_{1 b}$

Matriz FRF estimada usando matriz de transformação $[\mathrm{T}]_{2 f}$

Matriz FRF estimada usando matriz de transformação $[\mathrm{T}]_{2 b}$

Matriz FRF estimada usando matriz de transformação $[\mathrm{T}]_{2 c}$

Momento de Inércia da Viga de Seção Cruzada (Nm)

Momento de Inércia em relação a $P(\mathrm{Nm})$

Vetor Momento

Ponto de medida de Aceleração Angular

Distribuição Espacial de Carregamento Concentrado no ponto $a(\mathrm{~N})$

Vetor de excitação no ponto $j$

Força de Excitação Generalizada (N)

Matriz de Transformação

Matriz de Transformação para o ponto à frente do ponto de medida para a técnica de Diferenças Finitas $1^{\mathrm{a}}$ Ordem

Matriz de Transformação para o ponto à frente do ponto de medida para a técnica de Diferenças Finitas $2^{\mathrm{a}}$ ordem

Matriz de Transformação para o ponto atrás do ponto de medida para a técnica de Diferenças Finitas $1^{\mathrm{a}}$ ordem

Matriz de Transformação para o ponto à frente do ponto de medida para a técnica de Diferenças Finitas $2^{\mathrm{a}}$ ordem

Matriz de Transformação para o ponto do centro do ponto de medida para a técnica de Diferenças Finitas $2^{\mathrm{a}}$ ordem 


$\begin{array}{ll}U_{i} & \text { Vetor de movimento de saída no ponto } i \\ V & \text { Volume da Viga }\left(\mathrm{m}^{3}\right) \\ X(x) & \text { Movimento Linear }(\mathrm{m})\end{array}$

\section{Romanas Minúsculas}

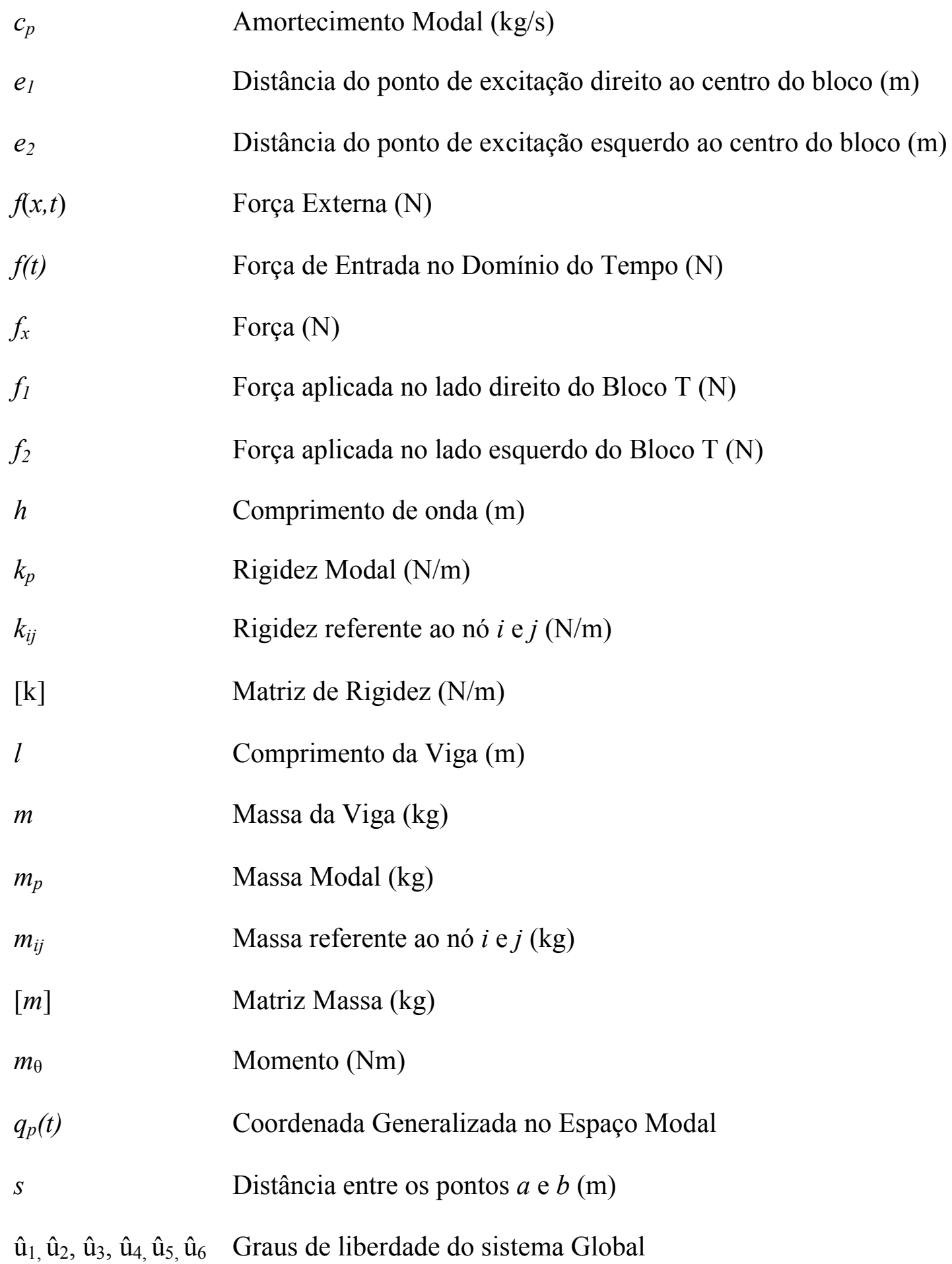




\begin{tabular}{|c|c|}
\hline$v(x, t)$ & Força de Cisalhamento $(\mathrm{N})$ \\
\hline$\ddot{x}_{P}$ & Aceleração linear no ponto $P\left(\mathrm{~m} / \mathrm{s}^{2}\right)$ \\
\hline$x_{A}$ & Deslocamento Linear no Ponto $a(\mathrm{~m})$ \\
\hline$\ddot{x}_{A}$ & Aceleração Linear no Ponto $a\left(\mathrm{~m} / \mathrm{s}^{2}\right)$ \\
\hline$x_{B}$ & Deslocamento Linear no Ponto $b(\mathrm{~m})$ \\
\hline$\ddot{x}_{B}$ & Aceleração Linear no Ponto $b\left(\mathrm{~m} / \mathrm{s}^{2}\right)$ \\
\hline$x_{C}$ & Deslocamento Linear no Ponto $c(\mathrm{~m})$ \\
\hline$\left(\ddot{x}_{P}\right)_{1}$ & $\begin{array}{l}\text { Aceleração Linear no ponto } P \text { devido a uma força aplicada no lado } \\
\text { direito do Bloco T }\left(\mathrm{m} / \mathrm{s}^{2}\right)\end{array}$ \\
\hline$\left(x_{P}\right)_{1}$ & $\begin{array}{l}\text { Deslocamento Linear no ponto } P \text { devido a uma força aplicada no } \\
\text { lado direito do Bloco } \mathrm{T}(\mathrm{m})\end{array}$ \\
\hline$\left(\ddot{x}_{P}\right)_{2}$ & $\begin{array}{l}\text { Aceleração Linear no ponto } P \text { devido a uma força aplicada no lado } \\
\text { esquerdo do Bloco } \mathrm{T}\left(\mathrm{m} / \mathrm{s}^{2}\right)\end{array}$ \\
\hline$\left(x_{P}\right)_{2}$ & $\begin{array}{l}\text { Deslocamento Linear no ponto } P \text { devido a uma força aplicada no } \\
\text { lado esquerdo do Bloco } \mathrm{T}(\mathrm{m})\end{array}$ \\
\hline$\dot{x}$ & Velocidade na superfície do corpo vibrante $(\mathrm{m} / \mathrm{s})$ \\
\hline$x_{i}, y_{i}$ & Coordenadas no nó $i$ \\
\hline$x_{j}, y_{j}$ & Coordenadas no nó $j$ \\
\hline$w(x, t)$ & Deslocamento (m) \\
\hline$w_{1} e w_{2}$ & Deslocamentos nodais \\
\hline
\end{tabular}

\section{Grega Maiúscula}

$\Theta(\theta) \quad$ Movimento Angular (rad)

\section{Gregas Minúsculas}
$\alpha(\omega)$
Matriz de Receptância
$\alpha_{\mathrm{xx}}$
Receptância devido à entrada e saída linear $(\mathrm{m} / \mathrm{s} / \mathrm{N})$
$\alpha_{\mathrm{x} \theta}$
Receptância devido a saída linear e entrada angular $((\mathrm{m} / \mathrm{s}) /(\mathrm{Nm}))$
$\alpha_{\theta \mathrm{x}}$
Receptância devido a saída angular e entrada linear ((rad/s)/N) 


\begin{tabular}{|c|c|}
\hline$\alpha_{\theta \theta}$ & Receptância devido à entrada e saída angular $((\mathrm{rad} / \mathrm{s}) /(\mathrm{Nm}))$ \\
\hline$\tau, \beta$ & Constantes \\
\hline$\gamma$ & Ângulo (rad) \\
\hline$\delta(x-a)$ & Função Delta de Dirac \\
\hline$\lambda$ & Auto valor \\
\hline$\theta$ & Deslocamento Angular no ponto $b$ (rad) \\
\hline$\ddot{\theta}_{P}$ & Aceleração Angular no ponto $P\left(\mathrm{rad} / \mathrm{s}^{2}\right)$ \\
\hline$\left(\theta_{P}\right)_{1}$ & $\begin{array}{l}\text { Rotação no ponto } P \text { devido a uma força aplicada no lado direito do } \\
\text { Bloco (rad) }\end{array}$ \\
\hline$\left(\ddot{\theta}_{P}\right)_{1}$ & $\begin{array}{l}\text { Aceleração Angular no ponto } P \text { devido a uma força aplicada no lado } \\
\text { direito do Bloco } \mathrm{T}\left(\mathrm{rad} / \mathrm{s}^{2}\right)\end{array}$ \\
\hline$\left(\theta_{P}\right)_{2}$ & $\begin{array}{l}\text { Rotação no ponto } P \text { devido a uma força aplicada no lado esquerdo } \\
\text { do Bloco (rad) }\end{array}$ \\
\hline$\left(\ddot{\theta}_{P}\right)_{2}$ & $\begin{array}{l}\text { Aceleração Angular no ponto } P \text { devido a uma força aplicada no lado } \\
\text { esquerdo do Bloco } \mathrm{T}\left(\mathrm{rad} / \mathrm{s}^{2}\right)\end{array}$ \\
\hline$\theta_{1}$ e $\theta_{2}$ & Rotações nodais \\
\hline$\rho$ & Densidade $\left(\mathrm{kg} / \mathrm{m}^{3}\right)$ \\
\hline$\omega$ & Freqüência Natural (Hz) \\
\hline$\psi_{1}, \psi_{2}, \psi_{3}$ & Função de Forma para a técnica de Elementos Finitos \\
\hline
\end{tabular}




\section{Lista de Tabelas}

TABELA 2.1 Autovalores da Equação Transcendental................ 35

TABELA $2.2 \quad$ Propriedades da viga estudada...................... 36

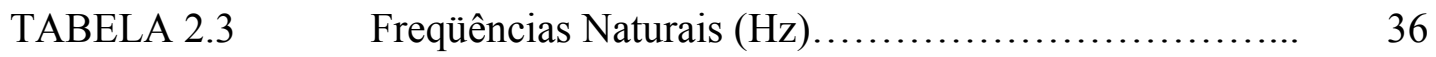

TABELA $4.1 \quad$ Propriedades da viga.............................. 88

TABELA 5.1 Descrição das propriedades dos diferentes blocos T...... 101

TABELA 5.2 Comparação das Freqüências Naturais das Técnicas Analisadas. .... 


\section{Lista de Figuras}

FIGURA 1.1 Esquema do bloco montado na estrutura de teste........... 6

FIGURA 1.2 (a) Transdutor de 6 GDL mostrando os acelerômetros lineares (A-F) e suas distâncias (r) do centro. (b) Vista lateral do Transdutor de 6 GDL,IVARSSON L. et al. (2000)

FIGURA 1.3 Sensor com posicionamento e orientação dos acelerômetros, HELDERWEIRT et al. (2001)..................... 11

FIGURA $1.4 \quad$ Sistema de laser BOKELBERG, et al. (1994).............. 15

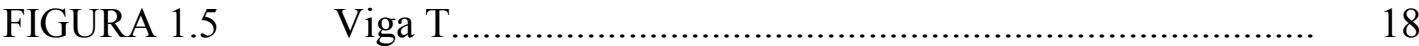

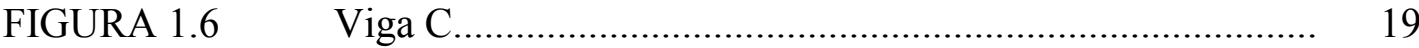

FIGURA 1.7 Vigas acopladas (a) formar viga maior, (b) utilização de juntas, LIU e EWINS (2000).

FIGURA 2.1 Viga sobre movimento transversal (a). Diagrama de corpo livre (b). RAO (1981)

FIGURA 2.2 Modo de vibrar de corpo rígido........................................... 38

FIGURA 2.3 Primeiro Modo de Vibrar...................................................... 38

FIGURA 2.4 Segundo Modo de Vibrar........................................................ 39

FIGURA 2.5 Terceiro Modo de Vibrar....................................................... 40

FIGURA 2.6 Quarto modo de vibrar.......................................................... 40

FIGURA 2.7 Quinto Modo de Vibrar....................................................... 41

FIGURA 2.8 $\quad$ Excitação de Força Concentrada, McCONNELL (1995)..... 45

FIGURA $2.9 \quad$ FRF Linear/Linear.......................................................... 47

FIGURA 2.10 FRF Angular/Linear...................................................... 47

FIGURA 3.1 Posição de entradas e saídas para medidas experimentais de FRF da estrutura em termos das coordenadas globais.... 50

FIGURA 3.2 Esquema do bloco montado na estrutura de teste................. 54

FIGURA 3.3 Montagem do bloco com entrada de força e momento......... 55

FIGURA 3.4 Método das diferenças Finitas para medidas de GDLR....... 63 
FIGURA 3.5 Acelerômetro formado de chapas piezelétricas, INSALACO (2002)

FIGURA 3.6 Deformações das vigas piezoelétricas quando expostas às acelerações lineares (A) e angulares (B), INSALACO (2002)

FIGURA 3.7 Elementos de viga separados no centróide, INSALACO (2002).

FIGURA 3.8 Distribuição de cargas para Aceleração linear (a) e angular (b)

FIGURA 3.9 Circuito elétrico de Soma e Diferença.

FIGURA 3.10 Miniatura eletrônica contendo um pequeno sensor com pouca massa, INSALACO (2002)...

FIGURA 3.11 Acelerômetro angular com quartzo.

FIGURA 3.12 Acelerômetro Angular feito com cristais de quartzo, INSALACO (2002).....

FIGURA 4.1 Elemento de Viga de Euler - Bernoulli.

FIGURA 4.2 Função de Forma do Método dos Elementos Finitos para Elemento de Viga.

FIGURA 4.3 Transformação de Coordenadas para a Viga.

FIGURA 4.4 Diagrama para os deslocamentos

FIGURA 4.5 Primeiro Modo de Vibrar a 40,6021 Hz (a) Linear, (b) Angular.

FIGURA 4.6 Segundo Modo de Vibrar a 110,4344 Hz (a) Linear, (b) Angular.

FIGURA 4.7 Terceiro Modo de Vibrar a 216,5054 Hz (a) Linear, (b) Angular.

FIGURA 4.8 Quarto Modo de Vibrar a 357,9322 Hz (a) Linear, (b) Angular.

FIGURA 4.9 Quinto Modo de Vibrar a 534,6394 Hz (a) Linear, (b) Angular.

FIGURA 4.10 Primeiro modo de vibrar de flexão no plano XY .................. 91

FIGURA 4.11 Segundo modo de vibrar de flexão no plano XY ................. 91 
FIGURA 4.12 Primeiro modo de vibrar de flexão no plano XZ.................. 92

FIGURA 4.13 Terceiro modo de vibrar de flexão no plano XY.................. 92

FIGURA 4.14 Quarto modo de vibrar de flexão no plano XY.................... 93

FIGURA 4.15 Segundo modo de vibrar de flexão no plano XZ ................... 93

FIGURA 4.16 Primeiro modo de vibrar do Bloco T -6348 Hz................... 94

FIGURA 4.17 Segundo modo de vibrar do Bloco T - 9395 Hz.................. 94

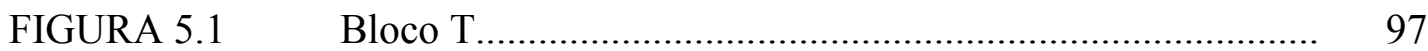

FIGURA 5.2 Aceleração e Ângulo de Fase dos Acelerômetros no Bloco T preso com parafuso e contra porca.................................... 99

FIGURA 5.3 Aceleração e Ângulo de Fase dos Acelerômetros no Bloco $\mathrm{T}$ preso com cera.

FIGURA 5.4 Diferentes configurações de Bloco T

FIGURA 5.5 Aparato experimental para ensaios dos blocos $\mathrm{T}$

102

FIGURA 5.6 FRF Angular/Linear no ponto de excitação com diferentes configurações Blocos $\mathrm{T}$.

FIGURA 5.7 FRF Angular/Linear de transferência com diferentes configurações de Blocos T

FIGURA 5.8 Aparato experimental da Técnica do Bloco T

FIGURA 5.9 Medida de FRF de ponto.

FIGURA 5.10

Aparato Experimental do Acelerômetro Angular.

FIGURA 5.11 FRF de ponto do Acelerômetro Angular e do modelo Teórico.

FIGURA 5.12 FRF de ponto do Acelerômetro Angular e do Bloco T.

FIGURA 5.13 Aparato Experimental para a Técnica de Diferenças Finitas de $1^{\text {a }}$ Ordem.

FIGURA 5.14 Resultados das FRFs com todos os Graus de Liberdade via Diferenças Finitas $1^{\text {a }}$ Ordem.

FIGURA 5.15 FRF diferenças finitas $1^{\mathrm{a}}$ ordem e modelo teórico.

FIGURA 5.16 Comparação dos resultados obtidos via diferenças finitas e Acelerômetro Angular... 
FIGURA 5.17 Comparação dos resultados obtidos via Diferenças Finitas e BlocoT.....

FIGURA 5.18 Aparato Experimental para a Técnica de Diferenças Finitas de $2^{\text {a }}$ Ordem......

FIGURA 5.19 FRFs Obtidas via técnica Diferenças Finitas 2a Ordem........ 119

FIGURA 5.20 FRF Diferenças Finitas 2a Ordem e FRF Modelo Teórico... 120

FIGURA 5.21 FRF das Diferenças Finitas de $1^{\mathrm{a}}$ e $2^{\mathrm{a}}$ ordem....................... 121

FIGURA 5.22 FRF Diferenças Finitas $2^{\mathrm{a}}$ ordem e FRF Acelerômetro Angular.

FIGURA 5.23 FRF Diferenças Finitas $2^{\mathrm{a}}$ ordem e FRF Acelerômetro Angular. 


\section{Resumo}

LOFRANO, M. (2003). Técnicas de estimativa de FRFs angulares em análise modal experimental com aplicações a estruturas do tipo viga, São Carlos, 2003. 152p. Dissertação (Mestrado) - Escola de Engenharia de São Carlos, Universidade de São Paulo.

Este trabalho realiza uma investigação sobre técnicas experimentais para a determinação de Funções de Resposta em Freqüência (FRFs) angulares com aplicações em estruturas do tipo viga. Estas FRFs são definidas considerando-se como variável de saída o movimento angular (deslocamento, velocidade ou aceleração) exibido pela estrutura sob estudo quando a mesma é excitada por uma força linear ou um momento puro. Dada a grande dificuldade em se aplicar um momento puro à estrutura sob estudo, este trabalho utiliza como forma de excitação apenas esforços lineares que podem ser aplicados através de técnicas usuais de excitação em análise modal, tais como o excitador eletrodinâmico e o martelo impulsivo. Portanto as FRFs obtidas descrevem relações de saída e entrada do tipo Angular/Linear. Uma das técnicas utilizadas na determinação das FRFs angulares consiste na excitação de uma estrutura com um excitador eletrodinâmico e utilização de um corpo rígido na forma de um bloco T que é montado sobre a estrutura sob estudo. Dois acelerômetros lineares devem ser montados sobre o bloco $\mathrm{T}$ e a partir das duas acelerações lineares medidas buscam-se estimar um sinal proporcional à aceleração angular da estrutura no ponto de conexão. Outra técnica utiliza uma formulação via diferenças finitas, onde dois ou três acelerômetros (de acordo com a formulação de diferenças finitas utilizada) igualmente espaçados são montados diretamente sobre a estrutura sob estudo e são usados para se derivar à 
aceleração angular. Os resultados obtidos a partir destas técnicas são comparados com resultados obtidos a partir da utilização de um acelerômetro angular piezelétrico recentemente disponível no mercado. Também foram desenvolvidos modelos analíticos e computacionais via método dos elementos finitos a fim de se gerar subsídios adicionais para a análise dos resultados. Foram feitas várias constatações e dentre elas destacam-se resultados onde as FRFs angulares/lineares resultantes podem sofrer alterações significativas dependendo de como os dados experimentais são processados.

Palavras-chave: Análise Modal Experimental, FRF angular, Bloco-T, Aceleração Angular, Diferenças Finitas, Graus de liberdade de rotação. 


\section{Abstract}

LOFRANO, M. (2003). Techniques for the estimation of angular FRFs in modal testing with applications to beam type structures, São Carlos, 2003. 152p. Dissertação (Mestrado) - Escola de Engenharia de São Carlos, Universidade de São Paulo.

The present work aims to perform an investigation on experimental techniques for the determination of angular Frequency Response Functions (FRFs) in Modal Testing. Angular FRFs are those where the output variable is given by angular displacement, velocity or acceleration, whereas the input is given in terms of linear or angular quantities (a pure moment). Since the application of a pure moment as an excitation source still remains as a challenge, this work is focused in studying techniques to estimate angular/linear types of angular FRFs. One of these techniques consists of exciting the structure with a shaker and using a rigid T-block to measure the linear accelerations and then calculating the angular FRFs from these linear accelerations. Another technique employs finite differences formulations to get the angular motions. This technique uses the closely spaced accelerometers mounted directly to the structure under test, where at least two (according to the finite difference formula employed) accelerometers are used. The translational measurements are gathered and finite difference formulas are used to derive the necessary angular quantities. Additional tests are performed with an angular piezoelectric accelerometer recently available in the market in order to provide a comparison basis for the results obtained using the two techniques. The results are also compared whit theoretical models developed using analytical and Finite Element Formulations. Among all results obtained, it was understood that depending on the level of angular vibrations exhibited by the structure, 
and how the signals are processed, the resulting angular FRFs can suffer some significant changes.

Keyword: Experimental Modal Analysis, Angular FRF, T-block, Angular Acceleration, Finite Differences, Rotational Degrees of Freedom 


\section{Capítulo 1}

\section{INTRODUÇÃO}

No capítulo de Introdução dessa dissertação algumas considerações preliminares importantes para a área de Análise Modal serão abordadas. Ainda neste capítulo será apresentada uma revisão da literatura envolvendo os assuntos que abrangem técnicas de medidas de aceleração angular, bem como técnicas de excitação com momento e possíveis aplicações das FRFs que relacionam saídas angulares e entradas lineares e as FRFs puramente angulares. Ainda serão apresentados os objetivos principais deste trabalho e para fechar será discorrida a organização desta dissertação. 


\subsection{Considerações Preliminares}

A determinação das características dinâmicas de uma dada estrutura pode ser realizada através de dois procedimentos (EWINS, 2000). O primeiro é denominado de Análise Modal Teórica e consiste na formulação de um modelo matemático da estrutura em estudo através de uma técnica de discretização. Neste caso, o Método dos Elementos Finitos é largamente utilizado na obtenção das matrizes físicas de massa e rigidez da estrutura. Estas matrizes são então utilizadas na formulação de um problema de autovalores e autovetores cuja solução fornece as freqüências naturais e modos normais de vibração da estrutura. Estes resultados constituem o chamado modelo modal teórico e podem ser posteriormente utilizados na obtenção de níveis de resposta a carregamentos dinâmicos conhecidos, na determinação de características de resposta em freqüência e impulsiva e na correlação com dados experimentais.

O segundo procedimento é denominado de Análise Modal Experimental e busca através de dados experimentais a determinação das frequiências naturais, fatores de amortecimento modais e modos de vibrar. Dentre as aplicações da análise modal experimental, a mais comum é a validação de um modelo teórico para uma dada estrutura. Através de ensaios experimentais são obtidas as características da resposta do sistema, que são geralmente dadas através de Funções de Respostas em Freqüência (FRFs) ou resposta impulsiva, MAIA et al. (1997).

As FRFs relacionam a resposta do sistema geralmente expressa por deslocamentos, velocidades ou acelerações com as entradas aplicadas ao mesmo, que geralmente são dadas por forças lineares. Essas entradas e saídas podem ser referentes a graus de liberdade de 
translação, como, por exemplo, força e deslocamento, como também aos graus de liberdade de rotação, por exemplo, ângulo e momento, McCONNELL (1995).

Um dos maiores desafios da análise modal experimental é a identificação de FRFs angulares cujas entradas e saídas do sistema são dadas através de grandezas angulares. A dificuldade neste caso é a obtenção dessas grandezas angulares (deslocamento, velocidade ou aceleração para as saídas e momentos para as entradas) com precisão. Da mesma forma, as medidas de momentos também representam desafios no contexto da análise modal experimental. Por muitos anos este problema não tem sido de fácil solução e as medidas têm se limitado à excitação com forças lineares e resposta de aceleração translacional. O resultado destas medidas é um modelo experimental incompleto, onde a falta de informação das grandezas angulares pode representar mais da metade do modelo de resposta completo do sistema. Contudo, o aumento na necessidade de maior precisão nos modelos de resposta vem contribuindo para uma crescente importância de melhorias nas técnicas de medidas de grandezas angulares (MAIA et al., 1997).

\subsection{Revisão de Literatura}

Nesta seção é apresentada uma revisão da literatura envolvendo o assunto que abrange técnicas de medidas de aceleração angular, bem como técnicas de excitação com momento e possíveis aplicações das FRFs que relacionam saídas angulares e entradas lineares bem como as FRFs puramente angulares. Conforme será apresentado nos objetivos deste trabalho, será dada ênfase ao estudo de técnicas de medidas de acelerações angulares para a obtenção de FRFs do tipo saída angular por entrada força linear visto que a obtenção 
de medidas precisas de acelerações angulares por si só já oferece desafios significativos ao experimentalista em análise modal.

\subsection{1 - Técnicas de medidas de acelerações angulares}

O estudo experimental de vibração estrutural tem proporcionado uma grande contribuição para a identificação e também para a solução de problemas de engenharia. Neste contexto, a Análise Modal Experimental tornou-se uma poderosa ferramenta de análise para a determinação de características dinâmicas das estruturas a partir de medidas da resposta em frequiência da estrutura sob estudo. Desta forma, a pesquisa em Análise Modal Experimental está relacionada com um conjunto de técnicas que possibilitam a obtenção de modelos matemáticos precisos para uma determinada estrutura através de dados experimentais, EWINS (2000).

De acordo com MAIA et al. (1997) a análise modal foi aplicada pela primeira vez com sucesso em 1940, em um estudo que proporcionou o entendimento do comportamento dinâmico de uma estrutura de uma aeronave. Atualmente, a aplicação da análise modal cobre uma vasta área, como por exemplo, a identificação e avaliação dos fenômenos de vibração; validação e ajuste de modelos dinâmicos computacionais, modificação estrutural e detecção de falhas. Salienta-se também que a análise modal é parte integrante do processo de desenvolvimento de novos produtos bem como na avaliação de seu comportamento dinâmico. A análise modal também possui uma estreita relação com temas de pesquisa em acústica estrutural e análise vibroacústica de sistemas mecânicos, HEYLEN et al. (2000). 
De acordo com BREGANT e SANDERSON (2000) medidas e excitação levando em consideração os graus de liberdade de rotação (GDLR) têm uma história relativamente curta se comparado com os graus de liberdade de translação (GDLT), isto se devendo principalmente a dois motivos: (i) GDLR não eram considerados importantes e estes não eram vistos como necessários para o enriquecimento do modelo de resposta da estrutura. Isto poderia em princípio ser considerado verdade na determinação das freqüências naturais e fatores de amortecimento modais, mas não representa uma hipótese apropriada em questões de acoplamento estrutural (ii) movimentos em GDLR são mais difíceis de medir do que os movimentos dos GDLT, pois estas medidas requerem um grande esforço experimental e apresentam pouca precisão se comparado com as medidas diretas dos movimentos dos GDLT. Técnicas e métodos para medir GDLR vêm ganhando muita importância pela necessidade de maior precisão nas FRFs experimentais.

De acordo com vários autores importantes no contexto da análise modal experimental, os procedimentos para medidas de grandezas angulares podem ser classificados em três grupos: (i) medidas baseadas em acelerômetros piezelétricos; (ii) medidas baseadas em vibrômetros a laser e (iii) medidas usando sensores dedicados. Será feita em seguida uma descrição sucinta das principais contribuições científicas e tecnológicas nestes três grupos de métodos experimentais para medidas de GDLR.

\subsubsection{1- Medidas Baseadas em Sensores Piezelétricos}

A obtenção de dados de posição, velocidade ou aceleração angular pode ser feita de diferentes maneiras, EWINS (2000), MAIA (1997) e McCONELL (1995). As mais comuns são baseadas na utilização de dois ou mais acelerômetros de medidas lineares fixados 
diretamente sobre a estrutura ou usando um corpo rígido auxiliar na forma de um T que é conectado a mesma, EWINS (2000), MAIA (1997), McCONELL (1995) e YOSHIMURA (2000).

A técnica do bloco $\mathrm{T}$ esta baseada na medida da resposta dos acelerômetros lineares montados em um bloco T que é conectado à estrutura no ponto de interesse como mostrado na Figura (1.1), URGUEIRA (1989)

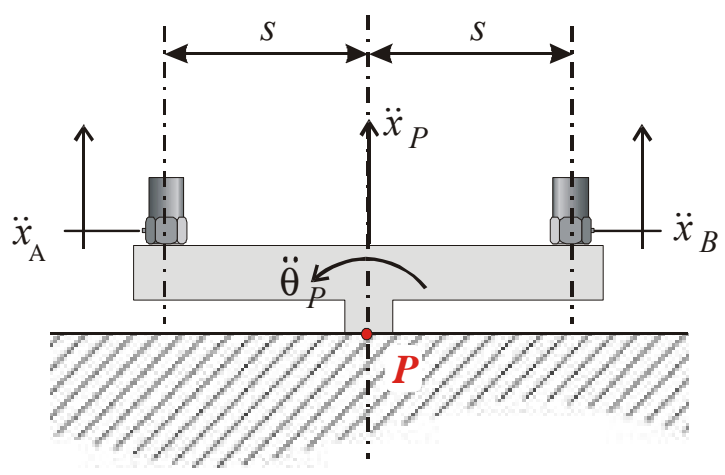

FIGURA 1.1 Esquema do bloco montado na estrutura de teste

O bloco é assumido como sendo rígido na faixa de freqüências de interesse e a sensibilidade cruzada dos acelerômetros tem que ser baixa, BREGANT e SANDERSON (2000). A principal vantagem dessa técnica é que o aparato experimental é relativamente simples, já que somente faz uso de acelerômetros lineares convencionais durante as medidas. Uma grande desvantagem desta técnica é a massa adicional (do bloco $\mathrm{T}$ e dos acelerômetros, principalmente) que é adicionada à estrutura sob estudo e que pode alterar as medidas significativamente em alguns casos. Outra desvantagem desta técnica é a presença de elevados níveis de ruído, já que a determinação da aceleração angular requer que os 
sinais dos acelerômetros sejam subtraídos um do outro. $\mathrm{O}$ funcionamento da técnica do Bloco T será detalhada no capítulo 3 desta dissertação.

YOSHIMURA et al. (2000) utilizam o bloco T em estruturas tipo viga para estimar FRFs angulares. Primeiramente o bloco é fixado na estrutura no ponto de interesse e é então excitado por um martelo de impacto convencional em três pontos diferentes onde são introduzidas na estrutura uma força e um momento a fim de se obter as acelerações dos GDLR como resposta do sistema. Após um procedimento numérico, são estimados as forças e os momentos aplicados no ponto onde o bloco $\mathrm{T}$ foi instalado bem como os movimentos lineares e angulares resultantes nestes pontos. Finalmente, as FRFs angulares e lineares são obtidas.

IVARSSON e SANDERSON (2000) usaram um corpo rígido na forma de triângulo com uso de acelerômetros lineares e desenvolveram um transdutor para medir simultaneamente todos os seis graus de liberdade de um corpo rígido. Esse mecanismo usou seis acelerômetros convencionais devidamente posicionados em uma peça triangular com um orifício em seu centro e este sendo o ponto de medição, como mostra a Figura (1.2) 


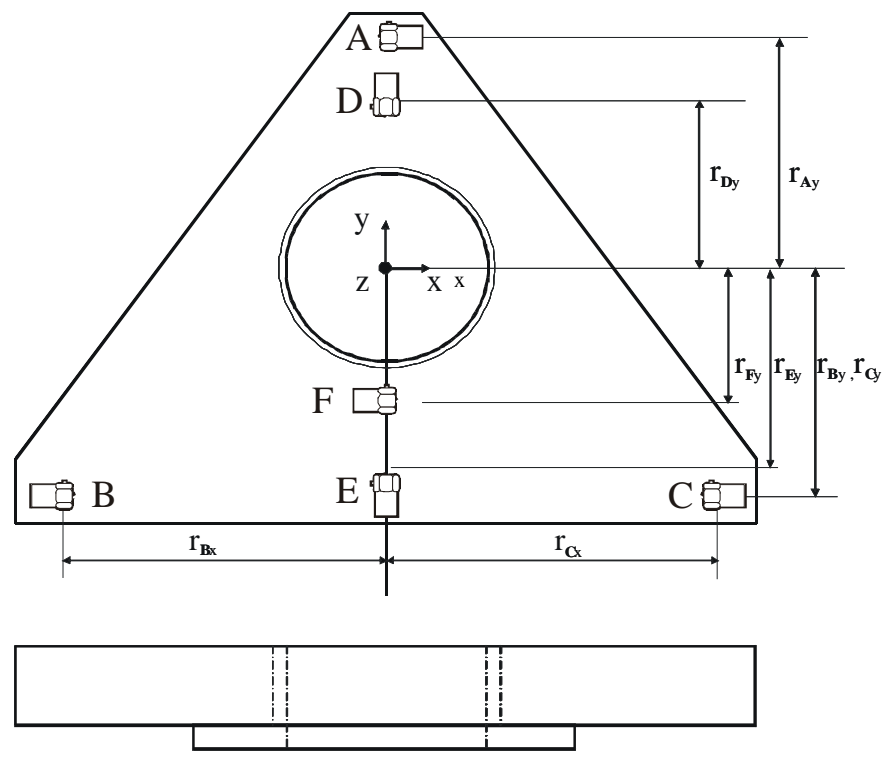

FIGURA 1.2 (a) Transdutor de 6 GDL mostrando os acelerômetros lineares (A-F) e suas distâncias (r) do centro. (b) Vista lateral do Transdutor de 6 GDL,IVARSSON L. et al. (2000).

O orifício na peça possibilita a medida de excitação e resposta no mesmo ponto, além de diminuir a massa do transdutor para minimizar o problema de carregamento de massa. Também para evitar este problema os acelerômetros usados são os de massa pequena. Apesar desse transdutor conter seis acelerômetros, ele foi projetado para ter pouca massa o que não leva a considerar o carregamento de massa na estrutura, cada acelerômetro possui cerca de $2 \mathrm{~g}$ de massa. Assumindo que o transdutor de 6 GDL se comporta como corpo rígido, as equações ordinárias para análise cinética dos corpos rígidos podem ser usadas.

Um método relativamente simples quanto à implementação para solucionar o problema da falta de medidas de graus de liberdade de rotação é apresentado por DUARTE e EWINS (2000). Este procedimento utiliza a técnica das diferenças finitas (formulação 
será apresentada no Capítulo 3), que consiste em posicionar acelerômetros lineares próximos uns dos outros na própria estrutura e através de manipulação algébrica dos dados obter as FRFs angulares. A quantidade de acelerômetros usada depende da aproximação desejada, esta pode ser de primeira ordem, onde se usa um par de acelerômetros, ou de segunda ordem, onde são necessários três acelerômetros lineares para completar as medidas. Por se tratar de uma técnica da qual se obtém movimentos nos GDLR com boa qualidade, os autores consideram seu uso como boa alternativa para se aplicar também na análise do acoplamento estrutural. A compensação residual na obtenção desses graus de liberdade é cuidadosamente tratada neste trabalho junto com a melhor aproximação da técnica. DUARTE e EWINS (2000), também enfocam que a qualidade das medidas depende do espaçamento entre os acelerômetros. Para aumentar a ordem de aproximação para FRFs que relacionam resposta rotacional e excitação com força é necessário que a distância entre os acelerômetros seja a menor possível.

ASHORY (1999), também utiliza a técnica das diferenças finitas juntamente com um método de correção para gerar FRFs angulares relacionada a dois diferentes pontos da estrutura. Para aplicar a técnica de diferenças finitas, dois ou três acelerômetros convencionais (de acordo com a fórmula de diferenças finitas empregada) são colocados próximos uns aos outros, com uma distância entre eles constante. Medem-se os movimentos nos GDLT e a partir das formulações dessa técnica, as FRFs angulares são obtidas. As FRFs angulares de transferência podem não apresentar bons resultados, para que se consiga essas FRFs com boa precisão, ASHORY (1999) utiliza um método de correção.

A principal vantagem da FRF baseada na técnica de diferenças finitas é que, como o nome sugere, as FRF são diretamente obtidas, além disso, nenhum aparato experimental 
especial é necessário, somente os transdutores normalmente usados em análise modal experimental. Porém alguns problemas são associados com o uso dessa técnica e alguns cuidados devem ser tomados para se ter o mínimo de suas influências. O primeiro problema é estabilizar o espaçamento entre os acelerômetros. A distância entre os acelerômetros tem uma relação direta na freqüência das anti-ressonâncias, ASHORY (1999). Outro problema é a ordem de aproximação usada. Para um dado espaçamento, a aproximação de segunda ordem é geralmente melhor que a aproximação de primeira ordem, com a FRF que relaciona entrada linear com resposta angular mais bem definida do que a FRF que relaciona entrada e resposta angulares, DUARTE (1996).

HELDERWEIRT et al (2001) utilizou técnicas indiretas e uma massa adicional para propor um método de obtenção de movimentos nos GDLR. Os autores propuseram uma técnica que usa vários acelerômetros lineares em uma massa adicional para derivar os correspondentes movimentos dos GDLR no ponto de excitação. Para essa finalidade, um sensor especial foi desenvolvido. Esse sensor consiste em um corpo rígido em forma de cruz onde são conectados acelerômetros lineares em diversas direções, como mostrado na Figura (1.3). 


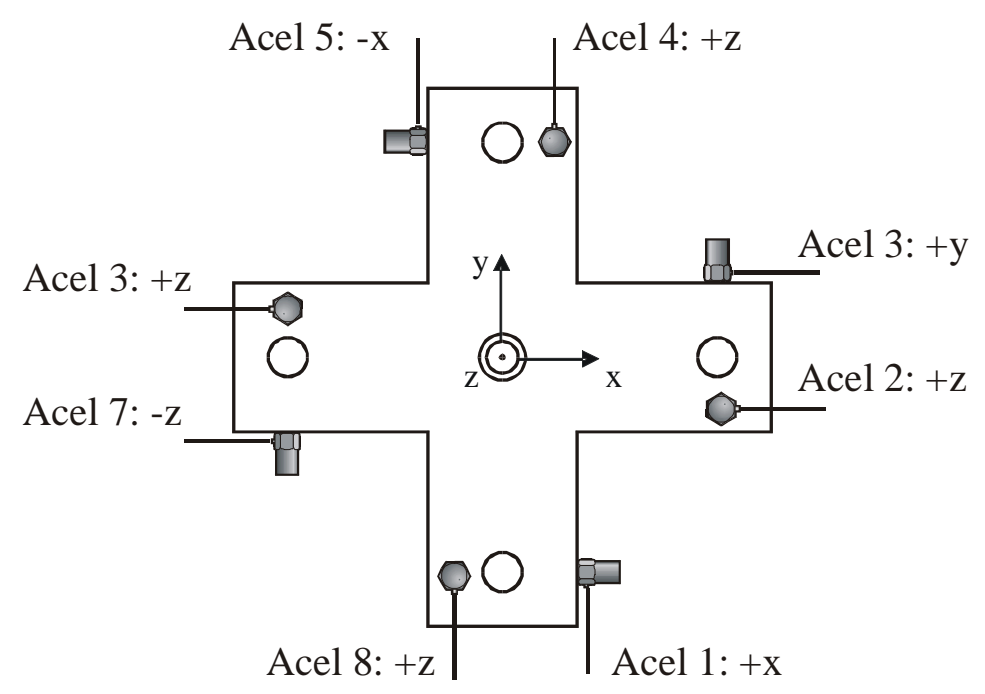

FIGURA 1.3 Sensor com posicionamento e orientação dos acelerômetros,

HELDERWEIRT et al. (2001)

Foi aplicada a técnica de cancelamento de massa, para eliminar erros ocasionados por essa técnica.

BELLO et al. (2000) apresenta uma maneira de se estimar grandezas angulares com a utilização de material piezelétrico na forma de pequenos retângulos finos (patches) que são colados à estrutura. Esse material quando em contato com a superfície deformada da estrutura também sofre uma deformação emitindo um sinal elétrico proporcional à variação da curvatura local da estrutura, possibilitando medidas de rotação. Os transdutores PZT's, como são chamados, são relativamente baratos e são considerados boas alternativas de medidas, pois interferem pouco nestas. Entretanto, os autores apontam para alguns problemas, tais como: montagem apropriada do sensor na estrutura, sensibilidade cruzada e procedimentos de calibração. Para o problema de sensibilidade cruzada conclui-se que quanto maior é a razão entre comprimento e a largura, isto é, a razão entre a sensibilidade ao longo dos eixos transversal e longitudinal, menor é a sensibilidade cruzada. Segundo os 
autores, a melhor maneira de conectar o sensor na estrutura é através de uma colagem, porém, um particular cuidado deve ser tomado quanto às camadas de cola utilizadas, pois estas interferem na deformação do PZT. Os autores desenvolvem um dispositivo de calibração que provê uma forma simples de calibração para cada sensor. Diferentemente dos extensômetros (strain-gages) que também são apropriados para medir curvatura, o PZT apresenta a vantagem de ser independente da estrutura em que ele é conectado, não precisando de informações da estrutura sob teste (tais como módulo de Young e Poisson). Para obter os movimentos nos GDLR é usada uma técnica de interpolação. Os autores apresentam uma comparação dessa técnica com outras técnicas, mostrando um bom resultado das medidas com o uso de sensores PZT's.

Ainda utilizando a tecnologia de materiais piezelétricos, recentemente foi projetado e construído um novo sensor piezelétrico angular que já se encontra disponível no mercado (KISTLER, 2001). Este sensor representa uma evolução de um sensor dedicado a medidas de aceleração angular denominado TAP, Translational Angular Piezobeam, (KISTLER, 2001) que foi comercializado em meados da década de 1990. McCONNELL, (1995) descreve o modelo mecânico e elétrico deste sensor que é bastante similar ao recentemente disponível. Este novo sensor será usado neste trabalho para efetuar medidas de aceleração angulares que servirão de padrão comparativo para os vários métodos usados. Por esta razão, será feita uma descrição mais detalhada deste sensor piezelétrico angular no Capítulo 3 desta dissertação. 


\subsubsection{2 - Medidas Utilizando Tecnologia a Laser}

Apesar de ainda não serem muito atrativas em relação ao fator custo, o uso de vibrômetros a laser em medidas de vibração vem ganhando popularidade tanto no meio acadêmico quanto nas empresas. Esta tecnologia teve seu início de forma mais acentuada no início da década de 1990 com os vibrômetros baseados em métodos interferométricos e pontuais, ou seja, a varredura na estrutura sob estudo era feita manualmente. $\mathrm{O}$ uso destes instrumentos tem sido bastante difundido, principalmente no setor acadêmico, especialmente devido à redução de seu custo. Em contrapartida, novas tecnologias surgiram nesta área, e hoje, os vibrômetros de varredura (scanning laser vibrometers) já equipam a maioria dos laboratórios de análise modal das grandes empresas (montadoras automobilísticas, empresas aeronáuticas, etc), mas ainda em poucas universidades.

O funcionamento do vibrômetro a laser Doppler (VLD) é baseado no efeito Doppler, ou seja, quando a luz entra em contato com uma superfície em movimento, a freqüência do feixe de luz refletida é alterada de uma determinada quantidade e o feixe de luz é então dividido em duas partes uma delas é guiada em direção a estrutura em um determinado ponto e a outra parte é usada como feixe de luz de referência para a formação de interferência construtiva ou destrutiva com relação ao feixe de luz medido, o qual é refletido pela estrutura, RATCLIFFE e LIEVEN (1996).

ZIAEI-RAD et al (2000) utilizam o vibrômetro Doppler para obter movimentos nos GDLR da estrutura sob estudo. Os autores descrevem o funcionamento dessa técnica levando em consideração os métodos discretos, lineares e circulares de medidas, ou seja, o vibrômetro pode mapear continuamente a superfície de uma estrutura vibrante ao longo de uma linha reta ou ao redor de um círculo, dando uma saída modulada que pode ser usada 
para analisar a vibração de uma estrutura com mais de um grau de liberdade. O vibrômetro é um instrumento que mede a componente da velocidade de vibração do ponto na direção do laser, e a partir de uma formulação algébrica pode-se derivar os movimentos nos GDL.

A principal vantagem dessa técnica é a ausência de contado com a estrutura sob teste, o qual permite não considerar o efeito de carregamento de massa, o qual, na maioria das técnicas que usa transdutores, deve ser levada em conta. As medidas são relativamente rápidas e fáceis, a resolução e a precisão das medidas são altas. Pode ser tirada medida de qualquer superfície, tais como superfícies quentes ou com altos campos eletromagnéticos. A principal desvantagem é o custo do equipamento, pois dentre todas as técnicas de obtenção de GDLR o uso do laser é o que apresenta a maior inviabilidade econômica por ainda possuir um alto custo dos equipamentos, ZIAEI-RAD et al. (2000). Além do fator custo outra desvantagem é o fato da saída do vibrômetro ser dada em velocidade tendo assim que passar por um procedimento algébrico no sinal analógico para se conseguir aceleração, que a forma mais utilizada na analise modal.

Outra técnica que usa o laser consiste em posicionar um conjunto de vibrômetros de tal maneira que o feixe de luz possa incidir num alvo com o formato de tetraedro localizado numa superfície vibrante. Cada feixe de luz refletida interceptará um fotodetector capaz de determinar as coordenada $\mathrm{X}$ e $\mathrm{Y}$ do alvo. Com alguns procedimentos algébricos é possível determinar a posição inicial do alvo em forma de tetraedro e seu movimento em seis direções, como mostrado na Figura (1.4).

Esse sistema possui um alto custo pelo fato dos números de laser usado. Outra desvantagem é a sobrecarga computacional e problemas relacionados ao posicionamento do alvo na estrutura, BOKELBERG, et al. (1994). 


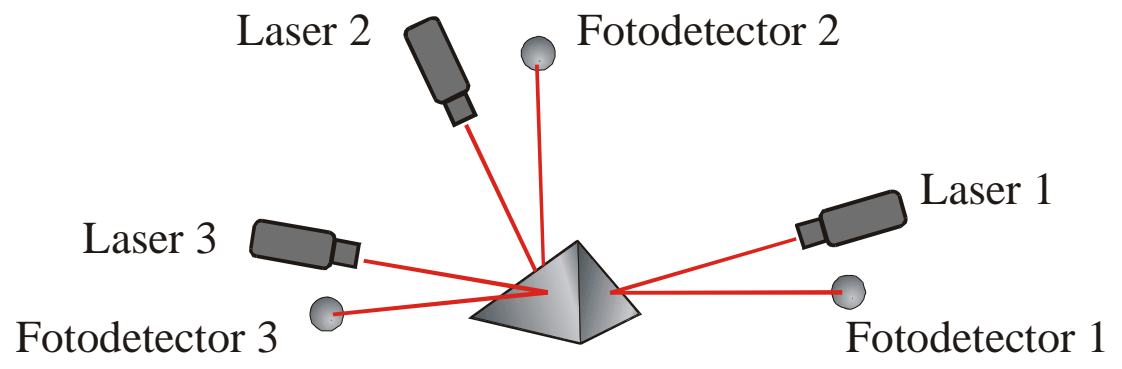

FIGURA 1.4 Sistema de laser BOKELBERG, et al. (1994)

\subsubsection{Medidas Através de Sensores Dedicados}

As medidas da resposta dinâmica de translação têm dominado os procedimentos da análise modal experimental desde seus primórdios, EWINS (2000). Uma razão para isto é a falta de um transdutor de medidas angulares que apresente desempenho satisfatório. Em seu trabalho RORRER et al. (1989) realiza medidas de movimentos nos GDLR fazendo uso de um transdutor angular Kistler obtendo medidas de aceleração angular e linear para uma viga livre-livre bem como os vetores modais para ambas medidas. Os autores comparam os resultados dos modos com a teoria da viga de Euler - Bernoulli. Os resultados destas comparações entre o modelo analítico e o experimental indicam resultados satisfatórios para as grandezas angulares identificadas. A principal desvantagem dessa técnica é o custo e a correspondente precisão relacionada a este transdutor.

McCONNELL (2001) também compara o uso do acelerômetro angular para uma determinada faixa de freqüência com a teoria de viga livre-livre via modelo contínuo, 
extraindo os modos de vibrar angulares. O acelerômetro em questão foi projetado pela Kistler sendo o modelo 8836M01. Esse tipo de comparação é considerada uma boa maneira de checar a eficiência e o desempenho do acelerômetro angular. Uma grande vantagem de usar sensores próprios para medidas de movimentos nos GDLR é o fato de se obter diretamente uma grandeza angular, porém esses sensores apresentam algumas desvantagens, uma delas esta relacionada às suas grandes dimensões, possibilitando erros de carregamento de massa na medida. Outra desvantagem é o fato de possuir um alto custo, DUARTE (1996).

Como pode ser observado há uma quantidade razoável de técnicas de obtenção de movimentos de GDLR. A escolha da técnica irá depender de alguns pontos, tais como: custo, precisão, facilidade na aplicação e a implementação. A partir do ponto de vista de custo, a técnica mais inviável economicamente é a técnica utilizando laser, porém é a mais precisa de todas as técnicas aqui relatadas e a de maior dificuldade de implementação. Transdutores de resposta angular são mais baratos, mas dependendo da quantidade necessária, pode resultar em um alto custo. Contudo esta é a única técnica que permite medir diretamente uma quantidade angular, todas as outras requerem uma manipulação algébrica dos dados para derivar esta informação, DUARTE (1996). As técnicas do bloco T e das diferenças finitas são de fácil implementação e relativamente baratas, pois utiliza somente acelerômetros lineares. 


\subsection{2- Técnicas de Obtenção de Esforços Angulares}

A maior dificuldade para medir mobilidade está na aplicação de um momento puro à estrutura sob estudo. A técnica proposta no trabalho de CHAMPOUX et al. (2000) consiste em excitar uma estrutura com um "momento puro", ou seja, sem que uma força linear associada seja aplicada simultaneamente. São utilizadas duas forças aplicadas, respectivamente, por dois martelos, sendo idênticas, porém atuando em linhas paralelas, direções opostas e separadas por uma distância conhecida. A distância impõe uma limitação nas altas freqüências. Neste trabalho também é mostrada a excelente correlação entre resultados experimentais e a teoria.

Freqüentemente, quando se tenta excitar uma estrutura com um momento puro, uma força indesejável aparece, com efeitos translacionais e rotacionais, levando a erros nas medidas de mobilidade. Utilizando a técnica MIMO (Multiple Input Multiple Output) prescrita por IVARSSON e SANDERSON (2000) pode-se aplicar na estrutura força e momento simultaneamente. Os autores aplicam essa técnica para uma estrutura tipo viga. A técnica MIMO é comparada com técnicas convencionais de aplicação de momento puro nos quais se usam dois excitadores eletrodinâmicos idênticos defasados de $180^{\circ}$ e com cálculos teóricos. Concluiu-se que a técnica MIMO, por excitar momento e força simultaneamente, é superior as técnicas convencionais e pode ser usada como método alternativo.

Deve-se observar que, a determinação precisa de esforços angulares representa um excelente tema de pesquisa tanto científico quanto tecnológico, visto que sensores piezoelétricos para medidas de esforços angulares com considerável faixa de freqüências ainda são inexistentes no mercado. 


\subsection{3 - Aplicações de FRFs Angulares}

As principais aplicações das FRFs angulares na análise modal estão voltadas para problemas de subestruturação, acoplamento estrutural e modificação estrutural. Entre os vários problemas envolvendo subestruturação, a ausência dos graus de liberdade angulares é a que acarreta mais problemas. DONG e MCCONNELL (2002) propõem um novo método para extrair o conjunto completo de FRFs incluindo todos os graus de liberdade, usando medidas indiretas em uma pequena estrutura chamada instrumento cluster. Este método também é estendido para se determinar matrizes de acelerância multi-direcionais de ponto e de transferência. A idéia chave é conectar um instrumento cluster no ponto de interface onde as matrizes de ponto e de transferência são investigadas, nestes instrumentos serão fixados acelerômetros que medem acelerações tangenciais e acelerômetros que medem acelerações normais e angulares TAP - Translational Angular Piezobeam, com relação à base. São feitos dois tipos diferentes de simulações que correspondem a um caso onde se consideram três graus de liberdade $\left(x, y, \theta_{z}\right)$, e o outro considera todos os seis graus de liberdade (x, y, z, $\left.\theta_{x}, \theta_{y}, \theta_{z}\right)$. Para o caso de se considera três GDL o instrumento em questão é uma viga $T$, Figura (1.5).

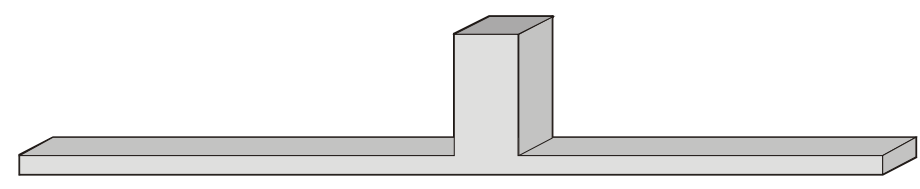

FIGURA 1.5 Viga T

Para o caso que considera seis graus de liberdade o instrumento utilizado é uma viga chamada viga-C, esquematizada na Figura (1.6). 


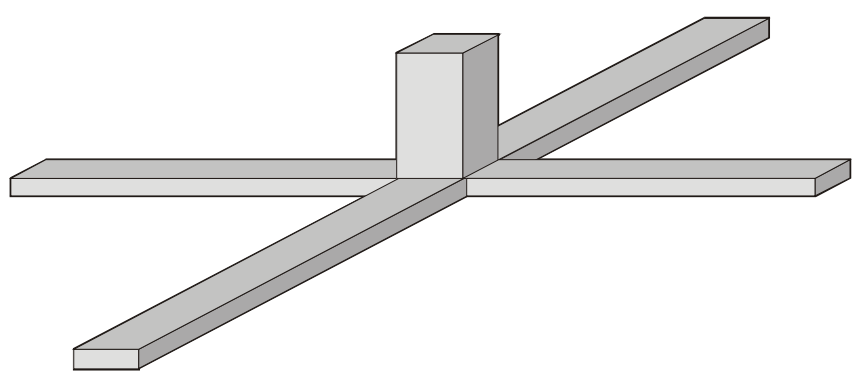

FIGURA 1.6 Viga C

Esses instrumentos podem medir um conjunto completo de acelerações lineares e angulares. Com o instrumento cluster colocado em cima da estrutura sob teste, uma série de testes específicos foi tomada para adquirir um conjunto de FRFs experimentais da estrutura combinada (item de teste + instrumento). Com as FRFs analíticas tomadas a partir do método dos elementos finitos, podem-se obter as matrizes de acelerância multidirecional na interface e a matrizes acelerância multidirecional de transferência. Um software especial que contém o pacote de elementos finitos dos instrumentos cluster e algumas rotinas de processamento de sinais digitais foi elaborado para a extração completa de forma automática.

LIU e EWINS (2000) investigaram as conseqüências da omissão dos GDLR em técnicas de acoplamento utilizando-se FRFs. A importância dos GDLR esta descrita por uma função erro para sistemas fracamente acoplados. Esta função erro revela a composição de erros causados pela ausência dos GDLR. Dois casos são estudados para demonstrar a eficiência do método. O primeiro caso é refere-se a duas vigas idênticas acoplada para formar uma viga maior, Figura (1.7 a). O segundo caso estudado consiste em acoplar as 
mesmas vigas, utilizando uma junta, de forma que uma viga fique em cima da outra conectada por uma junta, Figura (1.7 b).

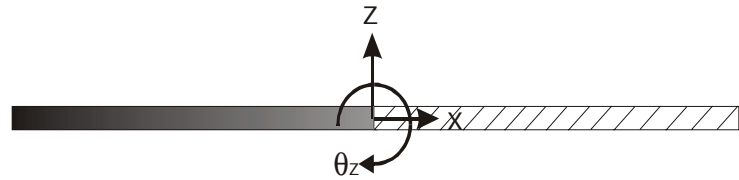

(a)
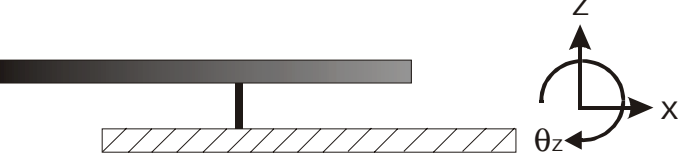

(b)

FIGURA 1.7 Vigas acopladas (a) formar viga maior, (b) utilização de juntas, LIU e EWINS (2000)

Para facilitar a análise os autores consideram como uma estrutura sendo uma viga e a junta e a outra estrutura fica sendo só a outra viga. A análise de acoplamento é realizada com os seguintes procedimentos: primeiro supõe que todas as FRFs são disponíveis para ambas as estruturas. Estas FRFs são utilizadas para se obter a FRF do sistema acoplado. Depois são consideradas somente as FRFs envolvendo graus de liberdade de translação sem mudar a estrutura. Usa estas FRFs com GDLT são utiizadas para obter as FRFs estimadas do sistema acoplado. Os dois resultados são comparados. Pode se concluir que a análise de acoplamento sem considerar as FRFs envolvendo os GDLR subestima os picos de frequiências naturais.

\subsection{Objetivos}

Esta dissertação tem, então, como objetivo principal o estudo de técnicas de medidas de Funções de Resposta em Freqüência (FRFs) cuja relação saída/entrada são 
respectivamente as grandezas angulares e lineares. Para o cumprimento deste objetivo principal definiram-se os seguintes objetivos secundários:

- Realizar um estudo analítico de técnicas de medidas de movimentos angulares.

- Aplicar técnicas experimentais de obtenção de graus de liberdade de rotação previamente estudadas em uma estrutura simples do tipo viga para que se possa avaliar em detalhes a qualidade dos resultados sem que uma maior complexidade da estrutura possa interferir nas análises.

- Confrontar os resultados das técnicas experimentais com os modelos teóricos desenvolvidos;

- Avaliar o desempenho de tais técnicas de medidas de FRFs angulares/lineares através de medidas diretas de acelerações angulares através de um acelerômetro piezelétrico angular comercialmente disponível.

A escolha das técnicas para validação neste trabalho se deu analisando as seguintes características: custo, precisão, facilidade na aplicação e a implementação. As técnicas escolhidas para o estudo foram às técnicas do bloco $\mathrm{T}$ e das diferenças finitas pela facilidade de implementação e pelo baixo custo, pois utilizam somente acelerômetros de medidas de translação que são convencionais em análise modal experimental e a técnica que usa transdutores de resposta angular apesar de ser relativamente cara se escolheu essa técnica pois é a única que permite medir diretamente as acelerações angulares. 


\subsection{Organização da Dissertação}

Esse trabalho é composto por sete capítulos, onde se tem o desenvolvimento dos objetivos secundários bem distribuídos para a obtenção do objetivo principal.

O capítulo 1 corresponde a capítulo de introdução, onde são apresentados os objetivos desta dissertação assim como a revisão de literatura que da base para a realização do trabalho.

O capítulo 2 apresenta o desenvolvimento da teoria escolhida para a confrontação dos resultados experimentais. A teoria corresponde a uma análise do sistema contínuo para a estrutura estudada.

A técnicas de estimativa de acelerações angulares escolhidas para a realização desse trabalho estão apresentadas no capítulo 3.

O capítulo 4 apresenta uma simulação numérica da estrutura estudada. Essa simulação foi desenvolvida para verificação do modelo teórico assim como complementação do estudo.

Os resultados experimentais das técnicas em questão estão dispostos no capítulo 5.

A conclusão desse trabalho é apresentada no capítulo 6 assim como sugestões para a continuação deste que poderão ser desenvolvidas no futuro.

No capítulo 7 encontram-se as referências bibliográficas discorridas no decorrer deste trabalho assim como as bibliográficas usadas para o desenvolvimento deste.

No anexo está apresentado o cálculo para se obter as matrizes de transformação da técnica de diferenças finitas que será apresentada no capítulo 3, além disso algumas técnicas de medidas de grandezas angulares aplicadas aqui precisaram de cálculos 
matemáticos, esses estão apresentados em outro anexo. Esses cálculos foram desenvolvidos com a ajuda de um software matemático, Matlab ${ }^{\circledR}$.

O próximo capítulo aborda aspectos teóricos e conceituais sobre análise modal em sistemas contínuos. Conforme será visto adiante a estrutura utilizada nos ensaios experimentais desta dissertação é uma viga metálica em suspensão livre-livre. Então é de grande importância o desenvolvimento de um modelo analítico onde se possa obter em detalhes dados do comportamento físico da estrutura sob estudo. 


\section{CAPÍTULO 2}

\section{Modelo Contínuo PaRa Viga de EULER -}

\section{BERNOULLI}

Este capítulo discute aspectos teóricos da vibração livre e forçada harmônica de sistemas contínuos com especial atenção para estruturas do tipo viga. A vibração transversal destas estruturas será discutida em detalhes desde a obtenção do modelo analítico dado pela equação diferencial parcial de quarta ordem com o estabelecimento de algumas hipóteses simplificadoras, até a obtenção do modelo de resposta de uma viga livre-livre dado pelas FRFs para vários pontos ao longo do seu comprimento. 


\subsection{Modelo Contínuo da Viga para Euler - Bernoulli}

Considere o diagrama de corpo livre de um elemento de viga como mostrado na Figura (2.1), onde $m_{\theta}(x, t)$ é o momento fletor, $v(x, t)$ é a força cortante e a $f(x, t)$ é a força externa por unidade de comprimento da viga e $w(x, t)$ é deslocamento. Desta forma a força de inércia atuando na viga pode ser escrita como

$$
F_{I}=\rho A(x) d x \frac{\partial^{2} w}{\partial t^{2}}(x, t)
$$

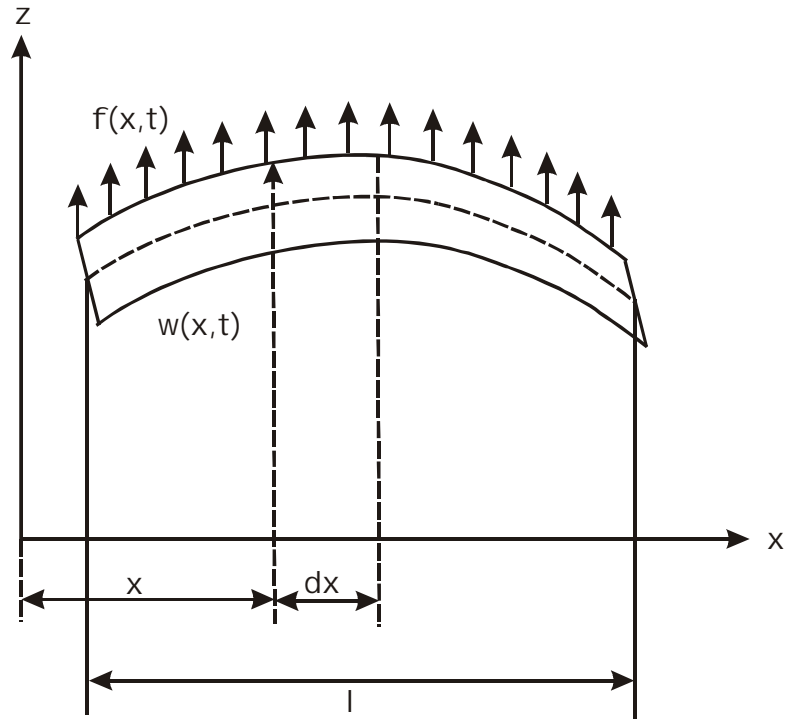

(a) 


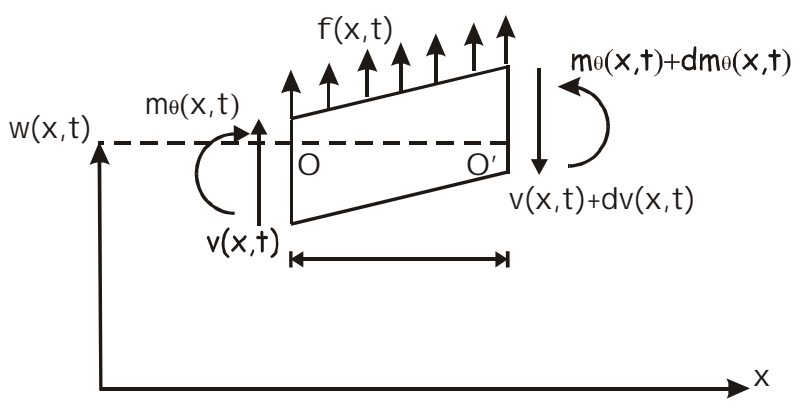

(b)

FIGURA 2.1 Viga sobre movimento transversal (a). Diagrama de corpo livre (b). RAO

Através de um balanço de forças no elemento mostrado na Figura (2.1a) utilizando a segunda lei do movimento de Newton obtém-se a equação de movimento para este elemento na direção z, que é dada por

$$
-(v+d v)+f(x, t) d x+v=\rho A(x) d x \frac{\partial^{2} w}{\partial t^{2}}(x, t)
$$

onde $\rho$ é a densidade e $A(x)$ é a área da seção transversal da viga. A equação para o movimento angular do elemento infinitesimal é obtida de forma análoga, desta vez utilizando-se a versão angular da segunda lei de Newton, através do balanço de momentos em torno do eixo y passando pelo ponto $\mathrm{O}$.

$$
\left(m_{\theta}+d m_{\theta}\right)-(v+d v) d x+f(x, t) d x \frac{d x}{2}-m_{\theta}=0
$$




$$
d v=\frac{\partial v}{\partial x} d x
$$

e

$$
d m_{\theta}=\frac{\partial m_{\theta}}{\partial x} d x
$$

Desprezando-se os termos $d x$ de segunda ordem e substituindo as Equações (2.4) e (2.5) nas Equações (2.2) e (2.3), obtém se as seguintes expressões, RAO (1995):

$$
\begin{aligned}
& -\frac{\partial v}{\partial x}(x, t)+f(x, t)=\rho A(x) \frac{\partial^{2} w}{\partial t^{2}}(x, t) \\
& \frac{\partial m_{\theta}}{\partial x}(x, t)-v(x, t)=0
\end{aligned}
$$

Usando a relação

$$
v(x, t)=\frac{\partial m_{\theta}}{\partial x}
$$

A partir da Equação (2.7), a Equação (2.6) se torna:

$$
-\frac{\partial^{2} m_{\theta}}{\partial x^{2}}+f(x, t)=\rho A(x) \frac{\partial^{2} w}{\partial t^{2}}(x, t)
$$


Considerando a teoria elementar da viga de Euler - Bernoulli (ou teoria da viga esbelta), as seguintes hipóteses devem ser consideradas:

a) A existência de linha neutra (eixo $\mathrm{x}$ ), onde a viga não sofre tração nem compressão;

b) Seções planas e perpendiculares à linha neutra permanecem planas e perpendiculares após a deformação, ou seja, as deformações devidas ao cisalhamento são desprezadas;

c) Material elástico linear e homogêneo;

d) As tensões normais desenvolvidas na direção $y$ e $z, \sigma_{y}$ e $\sigma_{z}$, são desprezíveis comparadas à tensão axial $\sigma_{\mathrm{x}},(\mathrm{CRAIG}, 1984)$

e) As dimensões da seção transversal da viga são pequenas se comparadas com seu comprimento. Isto permite que o efeito de inércia de rotação da seção transversal e deformação pela força cortante sejam desprezados. (TIMOSHENKO, 1990)

A relação entre momento e deflexão pode ser expressa por, RAO (1995)

$m_{\theta}(x, t)=E I(x) \frac{\partial^{2} w}{\partial t^{2}}(x, t)$

onde $E$ é o modulo de Young e $I(x)$ é o momento de Inércia polar. Inserindo a Equação (2.10) na Equação (2.9), tem-se a equação da viga não uniforme para vibração transversal

$\frac{\partial^{2}}{\partial x^{2}}\left[E I(x)\left(\frac{\partial^{2} w}{\partial x^{2}}(x, t)\right)\right]+\rho A(x) \frac{\partial^{2} w}{\partial t^{2}}(x, t)=f(x, t)$ 
para uma viga uniforme tem-se que o momento de Inércia polar e a área da seção cruzada são constantes ao longo de todo comprimento $x$, bem como as propriedades do material ( $\rho$ e E), logo a Equação (2.11) se reduz à

$$
E I \frac{\partial^{4} w}{\partial x^{4}}(x, t)+\rho A \frac{\partial^{2} w}{\partial t^{2}}(x, t)=f(x, t)
$$

Esta última equação representa uma equação diferencial parcial de quarta ordem a coeficientes constantes que descreve a vibração transversal não amortecida de uma viga de seção transversal constante, sendo desprezados os efeitos de deformação transversal por efeitos da força cortante e inércia de rotação, de acordo com o modelo de Euler-Bernoulli.

Para a vibração livre e não amortecida, faz-se $f(x, t)=0$, e assim a equação de movimento se transforma, RAO (1995)

$E I \frac{\partial^{4} w}{\partial x^{4}}(x, t)+\rho A \frac{\partial^{2} w}{\partial t^{2}}(x, t)=0$

que é a equação homogênea associada à Equação geral (2.12)

\subsection{Analise para uma Viga Livre Livre}

A solução da Equação (2.13) pode ser obtida assumindo uma solução do tipo

$w(x, t)=W(x) \cos (\omega t-\varphi)$ 
Para resolver a Equação (2.13) usa-se separações de variáveis

$w(x, t)=X(x) T(t)$

onde $X(x)$ é o deslocamento transversal como função da variável espacial $x$, ou seja, o modo de vibrar também conhecido em vibração do modelo contínuo como autofunção, CRAIG (1994), enquanto que $T(t)$ é o deslocamento transversal como função do tempo. Aplicando essa transformação na Equação (2.13) tem

$T(t) E I \frac{\partial^{4} X}{\partial x^{4}}(x)+X(x) \rho A \frac{\partial^{2} T}{\partial t^{2}}(t)=0$

ou ainda

$\frac{E I}{\rho A X(x)} \frac{\partial^{4} X}{\partial x^{4}}(x)=-\frac{\frac{\partial^{2} T}{\partial t^{2}}(t)}{T(t)}$

Assumindo que $T(t)$ possa ser expresso como

$T(t)=\cos (\omega t-\varphi)$

a relação 
$\frac{\frac{\partial^{2} T}{\partial t^{2}}(t)}{T(t)}=-\omega^{2}$

assim substitui-se a Equação (2.19) em (2.17) como resultado fica

$\frac{\partial^{4} X}{\partial x^{4}}(x)=\frac{\omega^{2} \rho A}{E I} X(x)$

A Expressão (2.20) é uma equação diferencial de quarta ordem, que representa a vibração transversal da estrutura estudada e que fornece os modos de vibrar para cada freqüência natural.

Agora definindo

$$
\lambda^{4}=\frac{\rho A \omega^{2}}{E I}
$$

Onde $\lambda$ é o autovalor do problema da vibração livre não amortecido e esta diretamente relacionado com a freqüência natural do sistema. Aplicando a Equação (2.21), pode-se escrever a Equação (2.20) da seguinte forma

$$
\frac{\partial^{4} X}{\partial x^{4}}(x)=\lambda^{4} X(x)
$$


A função $X(x)$ representa uma auto função que esta associada ao autovalor $\lambda$ e que representa os modos de vibrar da estrutura.

A solução geral para e Equação (2.22) é, CRAIG (1984)

$X(x)=A \sinh (\lambda x)+B \cosh (\lambda x)+C \sin (\lambda x)+D \cos (\lambda x)$

Há cinco incógnitas na Expressão (2.23). Quatro delas sendo constantes de amplitude e uma sendo o autovalor $\lambda$. A determinação destas constantes depende das condições de contorno do problema físico em estudo CRAIG (1981). No presente estudo pretende-se estudar o comportamento vibratório de uma viga livre-livre, e desta forma as condições de contorno podem ser definidas como segue.

Para uma viga livre livre o momento fletor nas extremidades é nulo assim a Equação (2.10) torna-se

$\frac{\partial^{2} X}{\partial x^{2}}=0$

A Equação (2.24) é a primeira condição de contorno para as extremidades da estrutura estudada. A segunda condição de contorno diz respeito à força cortante, ou seja, para uma viga livre-livre a força cortante nas extremidades é nula, assim

$$
v(x, t)=\frac{\partial m_{\theta}}{\partial x}
$$


Substituindo a Equação (2.10) para o momento fletor na Equação (2.25) para a força cortante e considerando que a força cortante deve ser zero nas extremidades da viga, tem-se a segunda condição de contorno na Equação (2.26)

$\frac{\partial^{3} X}{\partial x^{3}}=0$

Derivando-se a Equação (2.23) para os pontos extremos da viga, ou seja ponto $x=0$ e $x=l$, e aplicando as condições de contorno acima definidas pelas Equações (2.24) e (2.26), tem

$\frac{\partial^{2} X}{\partial x^{2}}(x)=\lambda^{2} A \sinh (\lambda x)+\lambda^{2} B \cosh (\lambda x)-\lambda^{2} C \sin (\lambda x)-\lambda^{2} D \cos (\lambda x)=0$

$\frac{\partial^{3} X}{\partial x^{3}}(x)=\lambda^{3} A \cosh (\lambda x)+\lambda^{3} B \sinh (\lambda x)-\lambda^{3} C \cos (\lambda x)+\lambda^{3} D \sin (\lambda x)=0$

Para $x=0$

$\frac{\partial^{2} X}{\partial x^{2}}(0)=\lambda^{2} B-\lambda^{2} D=0$

assim obtemos

$B=D$ 


\section{E para}

$$
\frac{\partial^{3} X}{\partial x^{3}}(0)=\lambda^{3} A-\lambda^{3} C=0
$$

obtemos

$$
A=C
$$

Para $x=l$

$$
\begin{aligned}
& \frac{\partial^{2} X}{\partial x^{2}}(l)=\lambda^{2} A \sinh (\lambda l)+\lambda^{2} B \cosh (\lambda l)-\lambda^{2} C \sin (\lambda l)-\lambda^{2} D \cos (\lambda l)=0 \\
& \frac{\partial^{3} X}{\partial x^{3}}(l)=\lambda^{3} A \cosh (\lambda l)+\lambda^{3} B \sinh (\lambda l)-\lambda^{3} C \cos (\lambda l)+\lambda^{3} D \sin (\lambda l)=0
\end{aligned}
$$

Escrevendo-se estas últimas relações, ou seja, Equações (2.31) e (2.32) na forma matricial tem-se

$$
\left[\begin{array}{cccc}
0 & \lambda^{2} & 0 & -\lambda^{2} \\
\lambda^{3} & 0 & -\lambda^{3} & 0 \\
\lambda^{2} \sinh (\lambda l) & \lambda^{2} \cosh (\lambda l) & -\lambda^{2} \sin (\lambda l) & -\lambda^{2} \cos (\lambda l) \\
\lambda^{3} \cosh (\lambda l) & \lambda^{3} \sinh (\lambda l) & -\lambda^{3} \cos (\lambda l) & \lambda^{3} \sin (\lambda l)
\end{array}\right]\left\{\begin{array}{l}
A \\
B \\
C \\
D
\end{array}\right\}=\left\{\begin{array}{l}
0 \\
0 \\
0 \\
0
\end{array}\right\}
$$


Para esse conjunto de equações homogêneas apresentar solução não trivial, o determinante dos coeficientes deve ser nulo. Calculando este determinante, obtém a equação característica para o problema da vibração livre não amortecida da viga livre-livre CRAIG (1981)

$1-\cosh (\lambda l) \cos (\lambda l)=0$

A Equação (2.34) representa uma equação transcendental e possui infinitas raízes. A Tabela (2.1) apresenta algumas destas raízes.

TABELA 2.1 Autovalores da Equação Transcendental

\begin{tabular}{cc}
\hline \hline$\lambda_{0} l$ & 0 \\
\hline$\lambda_{1} l$ & 4,673 \\
\hline$\lambda_{2} l$ & 7,853 \\
\hline$\lambda_{3} l$ & 10,996 \\
\hline$\lambda_{4} l$ & 14,137 \\
\hline$\lambda_{5} l$ & 17,279 \\
\hline \hline
\end{tabular}

As freqüências naturais da viga livre-livre podem ser obtidas a partir dos resultados mostrados na Tabela (2.1) acima, através da Equação (2.21) e das propriedades físicas e geométricas da viga em estudo. A viga usada neste trabalho é uma viga de alumínio e suas propriedades estão listadas na TABELA (2.2): 
TABELA 2.2 Propriedades da viga estudada

\begin{tabular}{cc}
\hline \hline Comprimento $(l)$ & $0,9 \mathrm{~m}$ \\
\hline Massa $(m)$ & $369,30 \mathrm{~g}$ \\
\hline Volume $(V)$ & $1,4010^{-4} \mathrm{~m}^{3}$ \\
\hline Densidade $(\rho)$ & $2,7010^{3} \mathrm{~kg} / \mathrm{m}^{3}$ \\
\hline Área $(A)$ & $1,5610^{-4} \mathrm{~m}^{2}$ \\
\hline Momento de Inércia $(I)$ & $5,0010^{-10} \mathrm{~kg} \mathrm{~m}{ }^{2}$ \\
\hline Modulo de Young $(E)$ & $69 \mathrm{GPa}$ \\
\hline \hline
\end{tabular}

Para a determinação das freqüências naturais da viga livre-livre de alumínio, a Equação (2.21) pode ser rescrita da seguinte forma

$$
\omega_{n}=\sqrt{\frac{E I}{\rho A}} \lambda_{n}^{2}
$$

onde $n$ denota a n-ésima freqüência natural da viga. Os resultados estão mostrados na Tabela (2.3), onde a raiz 0 é uma raíz de multiplicidade dois.

TABELA 2.3 Freqüências Naturais (Hz)

\begin{tabular}{cc}
\hline \hline$\omega_{0}$ & 0 \\
\hline$\omega_{1}$ & 39,83 \\
\hline$\omega_{2}$ & 109,79 \\
\hline$\omega_{3}$ & 215,23 \\
\hline$\omega_{4}$ & 355,78 \\
\hline$\omega_{5}$ & 537,49 \\
\hline \hline
\end{tabular}


Para determinar os modos de vibrar é necessário obter-se as constantes $A, B, C$ e $D$ de acordo com a Equação (2.23). Então, substituindo-se as Equações (2.29) e (2.30) na Equação (2.31) tem-se

$$
B=A \frac{(\sin (\lambda l)-\sinh (\lambda l))}{(\cosh (\lambda l)-\cos (\lambda l))}
$$

Substituindo na Equação (2.23), temos a expressão para os modos normais de vibrar de translação da viga livre-livre

$$
X(x)=A\left((\sin (\lambda x)+\sinh (\lambda x))+\left(\frac{\sin (\lambda l)-\sinh (\lambda l)}{\cosh (\lambda l)-\cos (\lambda l)}\right)(\cosh (\lambda x)+\cos (\lambda x))\right)
$$

A Expressão para os modos de vibrar angulares é obtida através da derivada parcial de $X(x)$ em relação a $x$ na Equação (2.37)

$$
\Theta(x)=A \lambda\left((\cos (\lambda x)+\cosh (\lambda x))+\left(\frac{\sin (\lambda l)-\sinh (\lambda l)}{\cosh (\lambda l)-\cos (\lambda l)}\right)(\sinh (\lambda x)-\sin (\lambda x))\right)
$$

Esses modos angulares fornecem a inclinação da estrutura, ou seja, o movimento angular para cada freqüência natural. Para a viga estudada, os modos de vibrar de corpo rígido são apresentados na Figura (2.2). Estes modos de vibrar estão associados às freqüências naturais nulas obtidas acima 

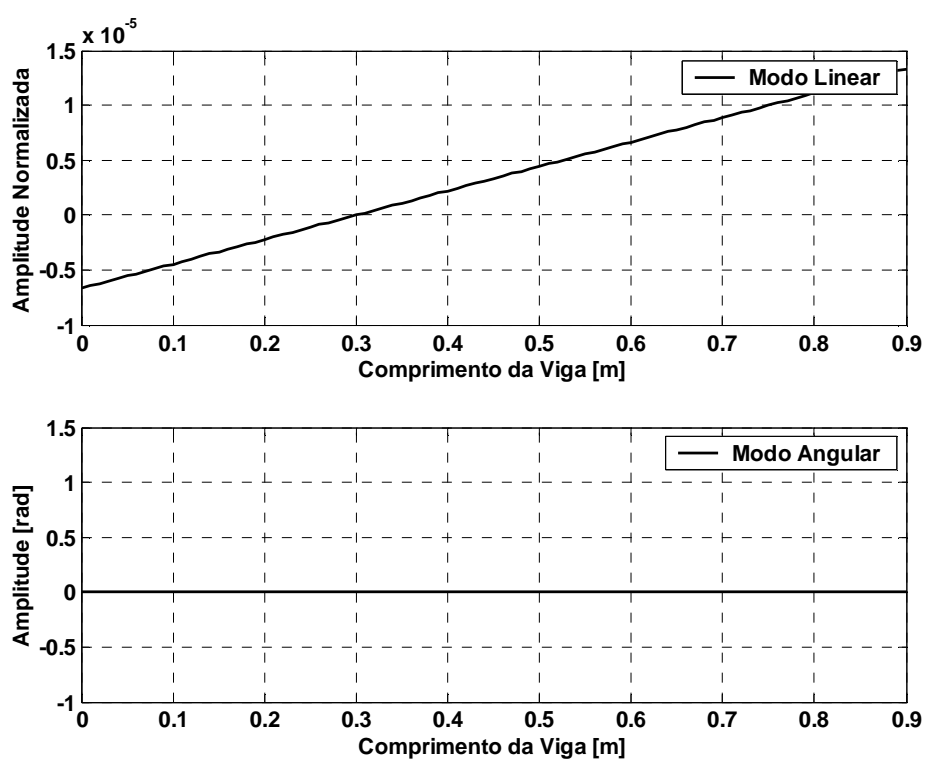

FIGURA 2.2 Modo de vibrar de corpo rígido

A Figura (2.3) apresenta o primeiro modo de vibrar linear e o primeiro modo de vibrar angular. A amplitude do modo de vibrar linear foi normalizada pelo comprimento da viga. $\mathrm{O}$ modo de vibrar angular possui amplitude em radianos.
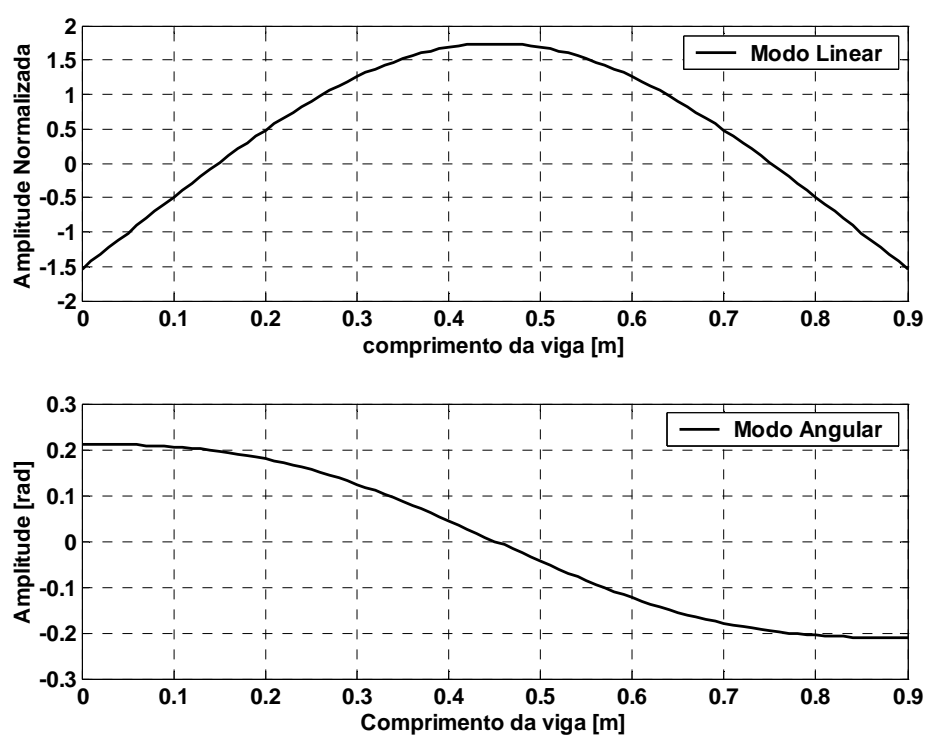

FIGURA 2.3 Primeiro Modo de Vibrar 
O segundo modo de vibrar linear de angular esta mostrada na Figura (2.4). Para as amplitudes desses modos a normalização pelo comprimento da viga foi tomada para o modo linear e para o modo angular a amplitude aparece em radianos.
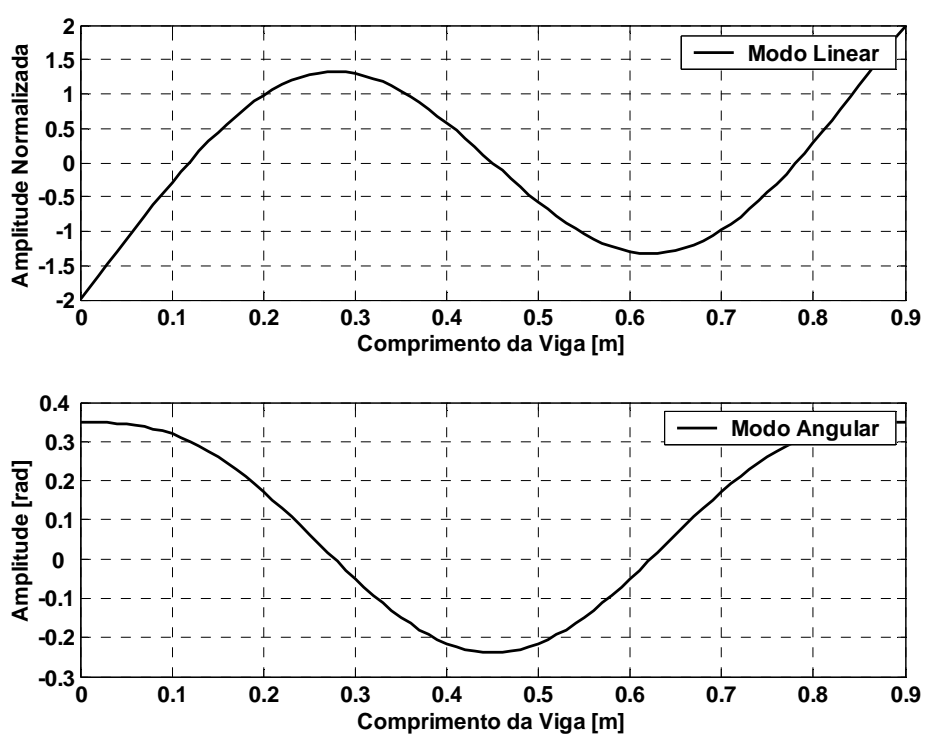

FIGURA 2.4 Segundo Modo de Vibrar

A Figura (2.5) apresenta a terceiro modo de vibrar linear e angular. A normalização desses modos foram feitas de maneira análoga aos modos de vibrar anteriormente apresentados. 

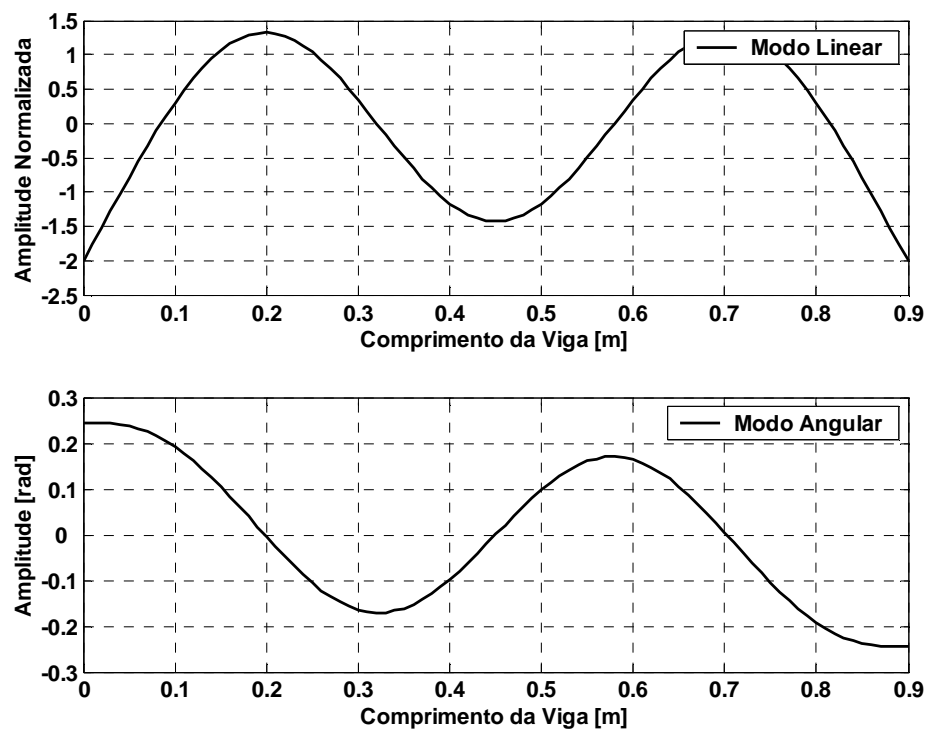

FIGURA 2.5 Terceiro Modo de Vibrar

O quarto modo de vibrar da viga de alumínio em estudo é mostrado na Figura (2.6).
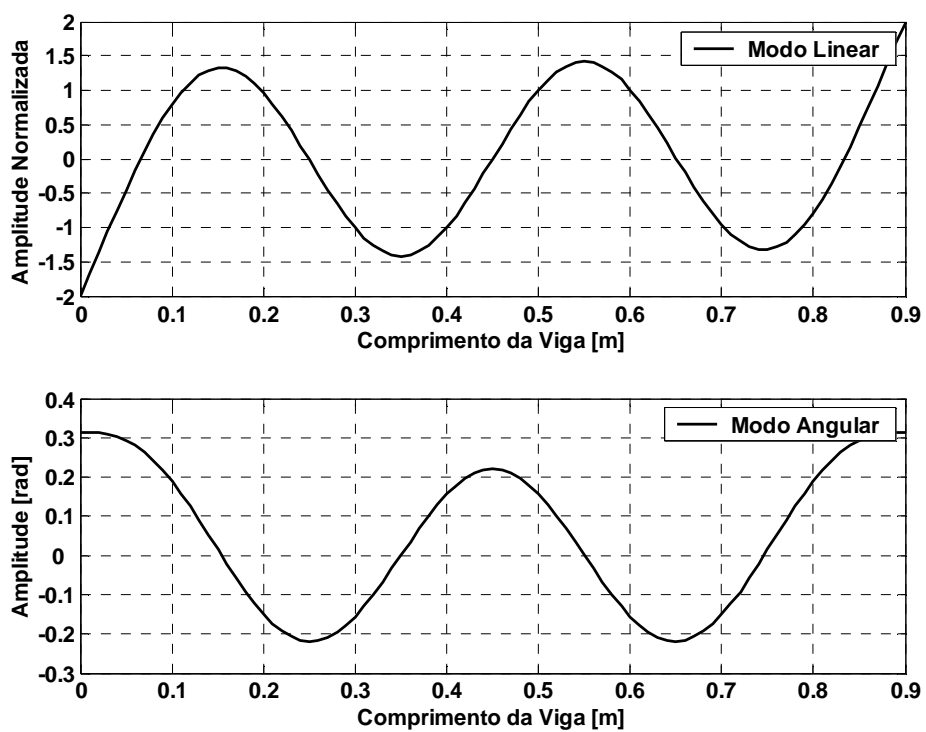

FIGURA 2.6 Quarto modo de vibrar 
O quinto modo de vibrar esta representada na Figura (2.7). As amplitudes seguem o padrão dos modos anteriores.
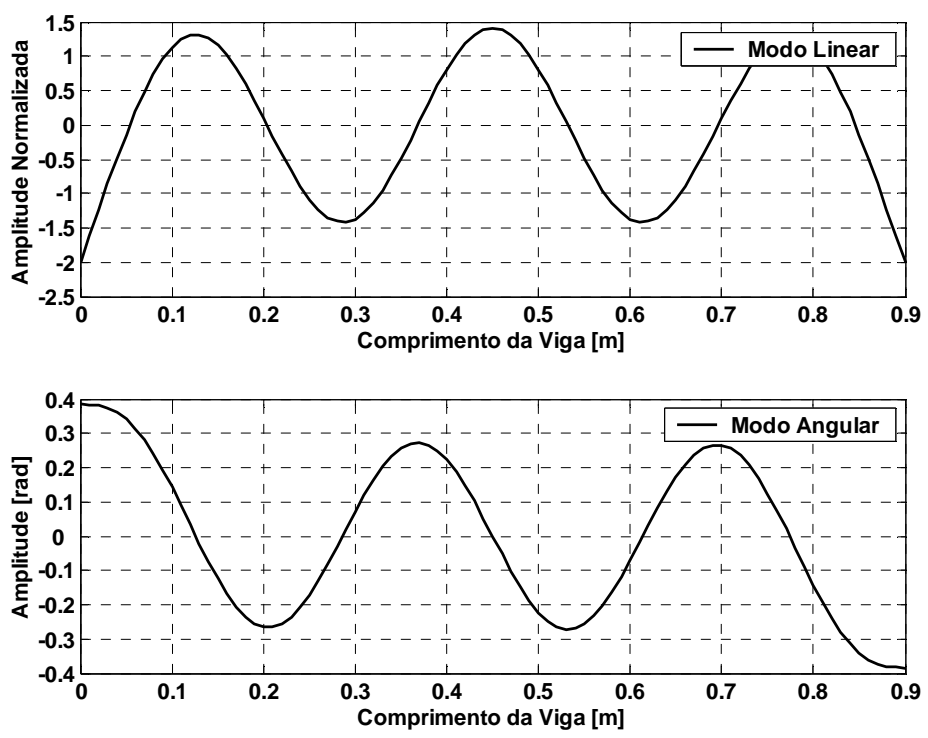

FIGURA 2.7 Quinto Modo de Vibrar

Os modos de vibrar naturais possuem uma propriedade de ortogonalidade que permite calcular a massa e a rigidez modal para o sistema contínuo, McCONNELL (1995). Estas propriedades de ortogonalidade esta contida no teorema de Sturm - Liouville, McCONNELL (1995). A condição de ortogonalidade par a massa requer integração para todo comprimento $l$ da viga. Essa integral é dada por

$$
\int m(x) X_{p} X_{r} d x=\left\{\begin{array}{c}
0 \text { para } r \neq p \\
m_{p} \text { para } r=p
\end{array}\right.
$$

onde $m_{p}$ é a massa modal do $p$-ésimo modo. Similarmente, a condição de ortogonalidade para a rigidez requer integração para todo o comprimento $l$ da viga, assim: 


$$
\int \frac{d^{2}}{d x^{2}}\left[E I \frac{d^{2} X_{p}(x)}{d x^{2}}\right] X_{r}(x) d x=\left\{\begin{array}{c}
0 \text { para } r \neq p \\
k_{p} \text { para } r=p
\end{array}\right.
$$

onde $k_{p}$ é a rigidez modal para o $p$-ésimo modo de vibrar.

As condições de ortogonalidade foram calculadas pois serão necessárias para obter a massa modal, $m_{p}$, e a rigidez modal, $k_{p}$, para posteriormente se calcular as FRFs do sistema contínuo.

\subsection{Modelo Modal para Vibração Forçada}

A equação diferencial do movimento para o sistema em questão pode ser escrita como a Equação (2.41), McCONNELL (1995).

$m \frac{\partial^{2} w}{\partial t^{2}}+C \frac{\partial w}{\partial t}-\frac{\partial}{\partial x}\left[K \frac{\partial w}{\partial x}\right]=f(x, t)$

onde $C$ é o amortecimento proporcional ao comprimento $l$, e $f(x, t)$ é a força de excitação por unidade de comprimento. Inicialmente será assumido que a excitação pode ser escrita da seguinte forma

$f(x, t)=P(x) f(t)$ 
onde $P(x)$ é a distribuição espacial de carregamento e $f(t)$ é a força de entrada no domínio do tempo. Em seguida será assumido que o movimento transversal pode ser escrito como a superposição dos vários modos de vibrar do sistema contínuo, McCONNELL (1995).

$w(x, t)=\sum_{p=1}^{n} X_{p}(x) q_{p(t)}$

onde $q_{p}(t)$ é a $q$-ésima coordenada generalizada no espaço modal que será determinada. Substituindo-se as Equações (2.42) e (2.43) na Equação (2.41), tem-se

$$
\sum_{p=1}^{n}\left\{m X_{p} \ddot{q}_{p}+C X_{p} \dot{q}_{p}-\frac{\partial}{\partial x}\left[K \frac{\partial X_{p}}{\partial x}\right] q_{p}\right\}=P(x) f(t)
$$

A complexidade da Equação (2.44) é reduzida se for multiplicada por $X_{n} d x$, e em seguida integrada em todo comprimento $l$, e aplicar as condições de ortogonalidade obtidas nas Equações (2.39) e (2.40). Assumindo que o amortecimento é proporcional à massa e rigidez, ou seja

$$
[C]=\tau[M]+\beta[K]
$$

as constantes de proporcionalidade de massa e rigidez foram adotadas aproximadamente iguais as do alumínio que é o material da estrutura analisada, onde $\beta$ é da ordem de $10^{-5} \mathrm{e}$ $\tau$ é 0 . Tem-se como resultado 
$m_{p} \ddot{q}_{p}+C_{p} \dot{q}_{p}-k_{p} q_{p}=Q_{p} f(t)$

Onde $m_{p}$ é a p-ésima massa modal, $C_{p}$ é a p-ésima amortecimento modal, $k_{p}$ é a pésima rigidez modal, $Q_{p}$ é a p-ésima força de excitação generalizada. A força de excitação generalizada $Q_{p}$ é dada por

$Q_{p}=\int P(x) X_{p}(x) d x$

A Equação (2.47) é extremamente importante para testes de vibração, pois ela diz como um dado modo será excitado por uma dada distribuição espacial da força excitadora $P(x)$.

Quando a excitação no domínio do tempo é dada por

$f(t)=f_{0} e^{j \omega t}$

a solução da Equação (2.46) se torna

$w(x, t)=\sum_{p=1}^{n} \frac{X_{p}(x) Q_{p}}{D_{p}} e^{j \omega t}=\sum_{p=1}^{n} X_{p}(x) H_{p} Q_{p} e^{j \omega t}$

onde a FRF $H_{p}$ é definida como

$$
H_{p}=\frac{1}{D_{p}}
$$


onde $D_{p}$ é dado por:

$D_{p}=k_{p}-m_{p} \omega^{2}+j C_{p} \omega$

\subsection{FRF do modelo contínuo}

Há dois tipos principais de FRF que são geradas com o sistema contínuo McCONNELL (1995). O primeiro tipo corresponde à excitação com força distribuída, enquanto que o segundo corresponde à excitação com força concentrada. O enfoque desse trabalho é para o segundo tipo de FRF.

Para um carregamento concentrado, temos a força em $x=a$ como mostra a Figura (2.8)

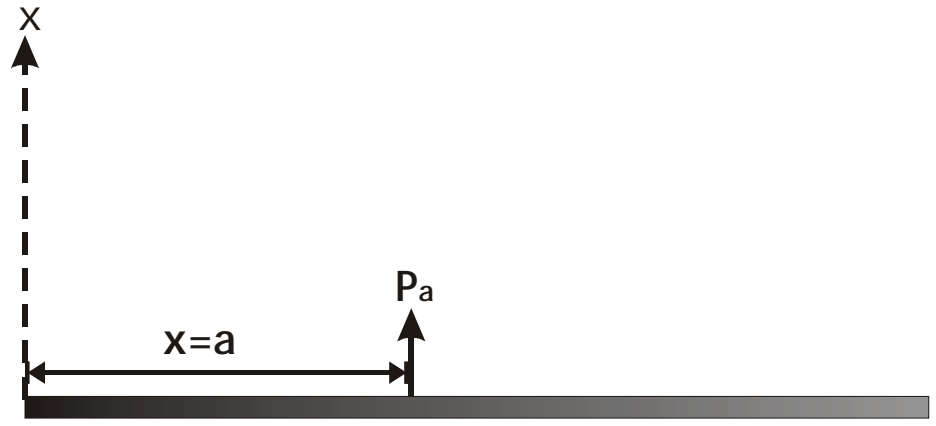

FIGURA 2.8 Excitação de Força Concentrada, McCONNELL (1995)

A força é descrita como

$P(x)=P_{a} \delta(x-a)$ 
onde $\delta(x-a)$ é a função delta de Dirac. Substituindo a Equação (2.42) na Equação (2.41), tem-se

$Q_{p}=P_{a} X_{p}(a)$

Substituindo a Equação (2.53) na Equação (2.49) obtém-se a resposta na posição $b$ devido a uma força concentrada aplicada na posição $a$

$w(b, t)=\sum_{p=1}^{n} X_{p}(b) H_{p} X_{p}(a) P_{a} e^{j \omega t}=H_{b a} P_{a} e^{j \omega t}$

onde a FRF $H_{b a}$ é dada por

$H_{b a}=\sum_{p=1}^{n} X_{p}(b) H_{p} X_{p}(a)$

Nota-se que a FRF é composta pelo produto de dois modos de vibrar e a função FRF $H_{p}$, McCONNEL (1985).

Para se obter a FRF onde uma saída esta relacionada a grandezas angulares, um dos modos a serem considerados na Equação (2.55) é o modo de vibrar angular, dado pela Equação (2.38), assim fica, McCONNELL (2000)

$H_{b a}=\sum_{p=1}^{n} \Theta_{p}(b) H_{p} X_{p}(a)$ 
Aplicando a teoria descrita para o modelo de viga em questão obtemos a FRF do sistema contínuo para uma entrada e uma saída linear e para uma entrada linear e uma saída angular.

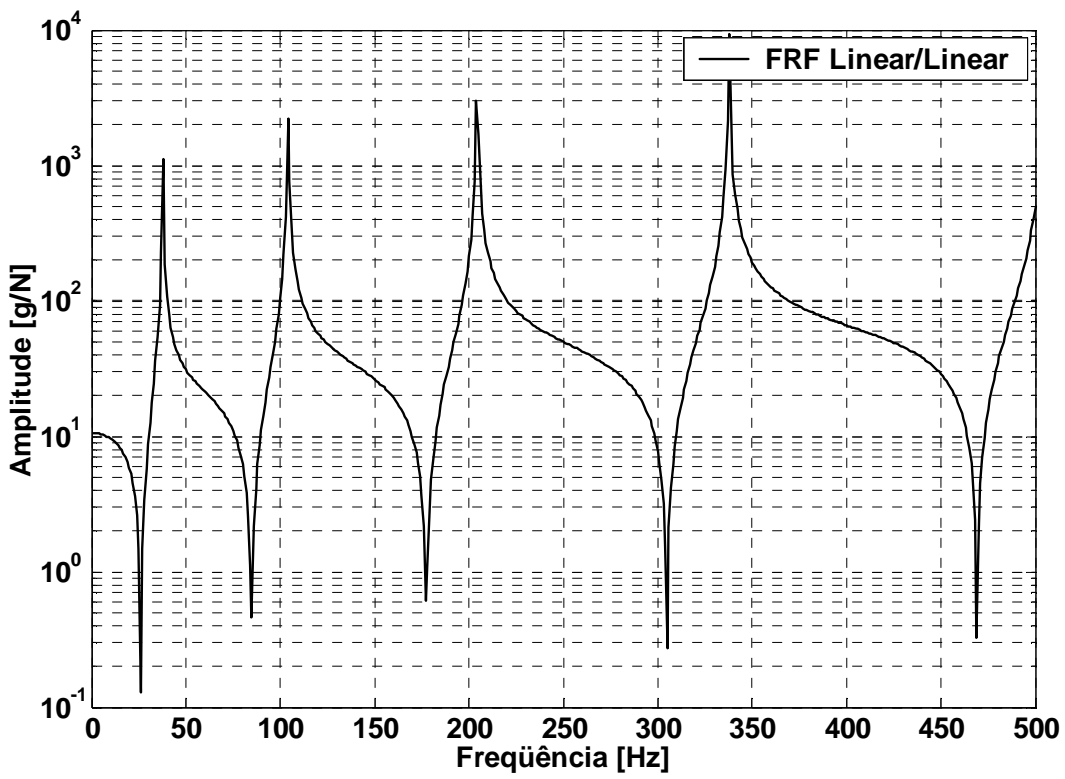

FGURA 2.9 FRF Linear/Linear

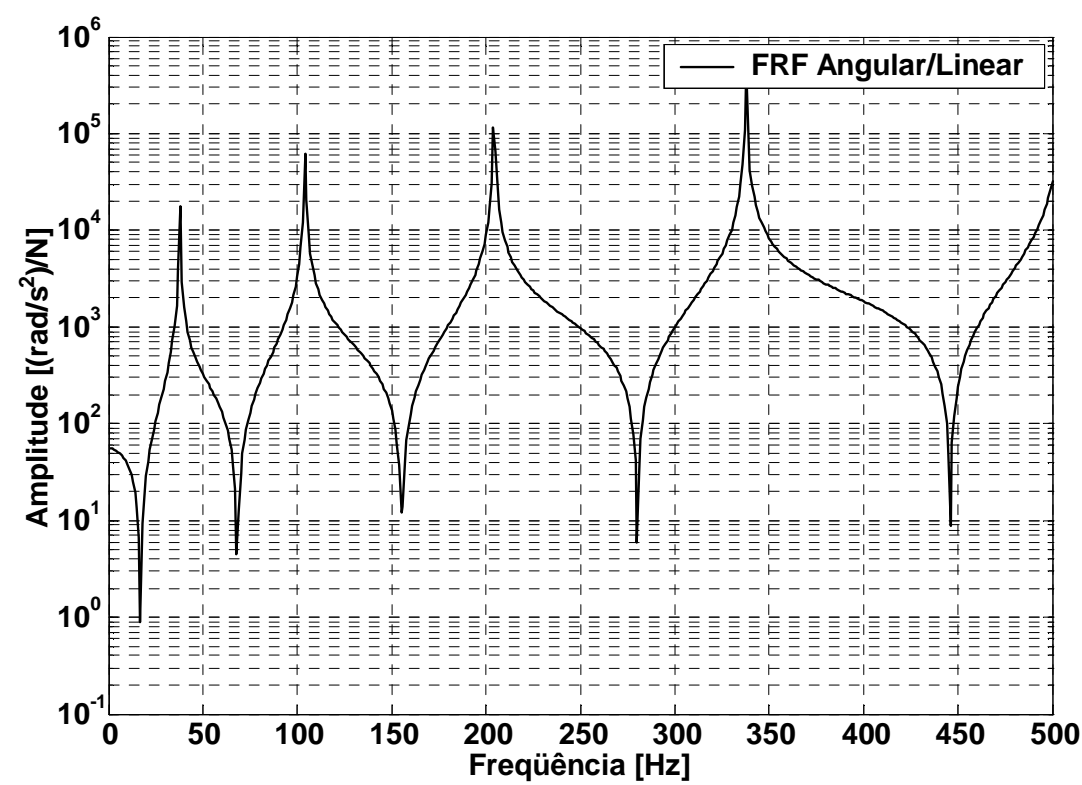

FIGURA 2.10 FRF Angular/Linear 
Para obter as FRFs linear/ linear e angular/ linear para vários pontos ao longo do comprimento da viga estudada, foram analisados os aspectos teóricos e analíticos da vibração livre e forçada harmônica de sistemas contínuos com especial atenção para estruturas do tipo viga. A expressão para vibração transversal dessa estrutura foi obtida com o auxílio de algumas hipóteses simplificadoras para a teoria da viga de Euler-Bernoulli chegando assim em uma equação diferencial de quarta ordem que descreve essa vibração. A partir de condições de contorno adequada chega-se à solução para vibração livre e forçada.

O próximo capítulo apresenta uma análise do desenvolvimento de algumas técnicas de medidas de grandezas angulares que foram as técnicas escolhidas para o desenvolvimento deste trabalho. 


\section{CAPÍtulo 3}

\section{TÉCNICAS DE ESTIMAÇÃO DE ACELERAÇÕES ANGULARES A PARTIR DE DADOS EXPERIMENTAIS}

O principal objetivo deste capítulo é o de apresentar e discutir algumas técnicas para a estimativa de acelerações angulares a partir de dados experimentais. Serão discutidas duas técnicas indiretas de determinação de acelerações angulares, sendo que a primeira delas utiliza um dispositivo conhecido como Bloco $\mathrm{T}$ e, a segunda sendo baseada num procedimento de diferenças finitas. Também será discutido o princípio de funcionamento de um sensor piezelétrico para medidas diretas de acelerações angulares. Este sensor será usado na parte experimental deste trabalho para obterem-se dados para fins de comparação com os resultados obtidos a partir das técnicas usadas. 


\subsection{Definições Básicas de Entrada e Saída}

O propósito dessa seção é apresentar em linhas gerais as relações básicas de entradas e saídas para uma estrutura como mostrada na Figura (3.1). A notação usada aqui corresponde ao domínio da freqüência notação comumente empregada em análise modal, descrevendo a relação entrada saída como função da freqüência $\omega$ que é chamado de função de resposta em freqüência, ou simplesmente FRF, McCONNELL (1995).
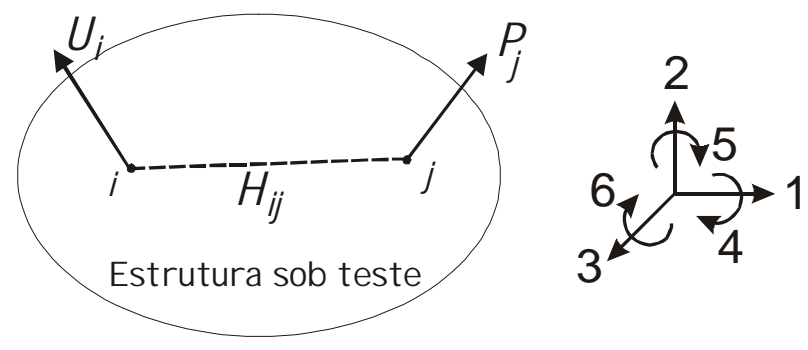

FIGURA 3.1 Posição de entradas e saídas para medidas experimentais de FRF da estrutura em termos das coordenadas globais.

O vetor de excitação $\{P\}_{j}=\{\mathrm{P}(\omega)\}_{j}$ aplicado no ponto de coordenada $j$ na Figura (3.1) é composto de seis componentes, sendo três delas forças lineares orientadas de acordo com o sistema de coordenadas auxiliar mostrado na Figura (3.1), e três momentos, também definidos em relação ao mesmo sistema de coordenadas. Desta forma, existem um total de seis esforços atuando em um único ponto da estrutura sob estudo.

Similarmente, o movimento de saída da estrutura na posição $i$ (podendo este ser tanto deslocamento quanto velocidade ou aceleração) pode ser descrito pelo vetor $\{U\}_{i}$ que por sua vez é composto de seis elementos, sendo três movimentos lineares ao longo dos eixos 
coordenados e três movimentos angulares em torno dos mesmos eixos. Então, como existem seis esforços de entrada e seis movimentos de saída, conclui-se que existem somente entre os pontos de coordenadas $i$ e $j$ trinta e seis potenciais relações de entrada $e$ saída entre as diversas variáveis, McCONNELL (1995). Estas relações de entrada e saída podem ser escritas na forma matricial de acordo com a seguinte equação

$\{U\}_{i}=[H]_{i j}\{P\}_{j}$

Reescrevendo agora a Equação (3.1) em termos dos vetores de força e momento como entrada e os vetores de aceleração linear e aceleração angular como saída, obtém-se

$$
\left\{\begin{array}{l}
\{X\} \\
\{\Theta\}
\end{array}\right\}_{i}=\left[\begin{array}{ll}
{\left[H_{x x}\right]} & {\left[H_{x \theta}\right]} \\
{\left[H_{\theta x}\right]} & {\left[H_{\theta \theta}\right]}
\end{array}\right]_{i j}\left\{\begin{array}{c}
\{F\} \\
\{M\}
\end{array}\right\}_{j}
$$

$\mathrm{Na}$ Equação (3.2) os vetores $\{X\}=\{X(\omega)\}$ e $\{\Theta\}=\{\Theta(\omega)\}$ representam os movimentos lineares e angulares associados ao $i$-ésimo grau de liberdade da estrutura, respectivamente. Da mesma forma, $\{F\}=\{F(\omega)\}$ e $\{M\}=\{M(\omega)\}$ representam as entradas lineares e angulares aplicadas ao $j$-ésimo grau de liberdade da estrutura, respectivamente. A matriz de FRF do sistema agora a aparece na Equação (3.2) escrita de forma particionada em quatro sub matrizes. A sub matriz $\left[H_{x x}\right]=\left[H_{x x}(\omega)\right]$ contém as FRF que relacionam as saídas lineares com as respectivas entradas lineares aplicadas à estrutura. A sub-matriz $\left[H_{\mathrm{x} \theta}\right]=\left[H_{\theta \mathrm{x}}\right]$ contém as FRFs que relacionam as saídas lineares com as respectivas entradas angulares aplicadas à estrutura. Pela lei de reciprocidade diz-se que a sub matriz que 
relacionam as entradas angulares com as respectivas saídas lineares é igual à sub matriz que relacionam as saídas lineares com as respectivas entradas angulares. E por último, a sub matriz $\left[H_{\theta \theta}\right]$ contém as FRFs que relacionam as saídas angulares com suas respectivas entradas angulares aplicadas à estrutura.

Tomando-se como base a Equação (3.2), os movimentos lineares podem ser extraídos desta de forma a serem escritos como

$$
\left\{X_{i}\right\}=\left[H_{x x}\right]_{i j}\{F\}_{j}+\left[H_{\theta x}\right]_{i j}\{M\}_{j}
$$

A Equação (3.3) mostra claramente que os movimentos lineares resultantes são devido a duas contribuições. A primeira deve-se aos esforços lineares e as FRFs contidas em $\left[H_{x x}\right]$. A segunda contribuição vem dos esforços angulares e das FRF contidas na matriz $\left[H_{\theta \mathrm{x}}\right]$. Entretanto, em ensaios experimentais convencionais que utilizam acelerômetros lineares, somente os movimentos lineares são medidos. Então, fica claro pela Equação (3.3) que o efeito dos movimentos angulares (causados pelos $\{M\}$ ) podem afetar significativamente os dados experimentais. Então, torna-se de grande importância à correta estimativa dos movimentos angulares e respectivas FRF para que se possa refinar os dados colhidos nos ensaios experimentais.

Um elemento da matriz $\left[H_{x \theta}\right]$ é definido pela razão no domínio da freqüência do movimento linear pelo momento, ou seja

$$
H_{x \theta}(\omega)=\frac{X}{M}(\omega)
$$


De forma análoga, um elemento em posição simétrica na matriz de FRF dada pela Equação (3.2) é dado por

$$
H_{\theta x}(\omega)=\frac{\theta}{F}(\omega)
$$

Embora, na teoria exista uma relação de reciprocidade entre essas duas FRF, experimentalmente uma medida direta da primeira, Equação (3.5) oferece grande dificuldade, visto que ela requer a medida do momento aplicado à estrutura. Esta medida requer instrumentação que ainda não está disponível no mercado, para largas faixas de frequiências. Desta forma, as técnicas de medidas de FRF angulares descritas neste trabalho serão baseadas no modelo dado pela Equação (3.6), visto que existem técnicas diretas e indiretas para a medida dos movimentos angulares e posterior estimativa da FRF angular/linear. Portanto, este trabalho estará focado na determinação de FRF angular dada pela Equação (3.6).

\subsection{Medidas de Aceleração Angular Utilizando o Bloco T}

A técnica de medição de aceleração angular descrita nesta secção faz uso de dois acelerômetros lineares montados em corpo rígido em forma de $T$ com eixos de sensibilidades paralelos separados por uma distância $2 s$ como na Figura (3.2), McCONNELL (1995). Para se obter uma estimativa da a aceleração angular no ponto $P$, o bloco $\mathrm{T}$ deve inicialmente ser rigidamente conectado à estrutura neste ponto, McCONNELL, (1995). 


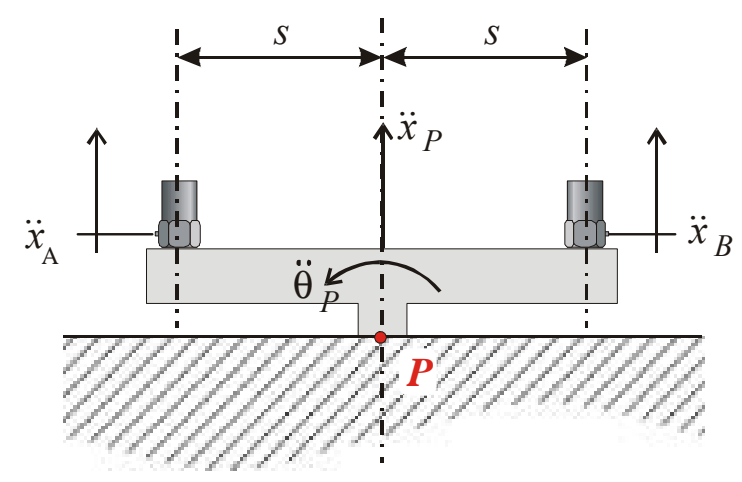

FIGURA 3.2 Esquema do bloco montado na estrutura de teste

O sinal da aceleração gerado pelo acoplamento dos acelerômetros pode ser convertido em uma aceleração translacional e rotacional no ponto $P$ como mostra as Equações (3.7) e (3.8) abaixo

$\ddot{x}_{P}=\frac{\ddot{x}_{A}+\ddot{x}_{B}}{2}$

$\ddot{\theta}_{P}=\frac{\ddot{x}_{A}-\ddot{x}_{B}}{2 s}$

Uma desvantagem dessa técnica deve-se ao fato do sinal de aceleração angular apresentar contaminação por ruído. Isto acontece pelo fato dos acelerômetros estarem muito próximos, de acordo com a Figura (3.2), e o sinal de aceleração resultante ser uma diferença entre os sinais de acelerações medidos pelos dois acelerômetros. Desta forma, quando a Equação (3.8) é usada o sinal resultante pode estar seriamente contaminado por ruído. Outro problema com esta técnica é a possível utilização de acelerômetros diferentes 
quanto à massa e ou sensibilidade à tensão, pois a diferença entre as massa dos acelerômetros pode introduzir um momento de inércia adicional no bloco $\mathrm{T}$ fazendo com que a medida seja afetada; já a diferença de sensibilidade à tensão pode resultar em sinais com níveis incorretos de amplitudes. Apesar dessa dificuldade, esta técnica tem sido aplicada com razoável sucesso em várias situações de teste.

Cabe salientar que a medida da aceleração angular com esta técnica resolve uma parte da medida da FRF angular pura do sistema, ou seja, aquela correspondente à saída do sistema. Embora uma técnica confiável de aplicação de momento puro em uma estrutura seja ainda um problema não resolvido em sua plenitude à técnica do bloco T apresenta uma possível aproximação para a aplicação do momento puro desejado na estrutura sob teste. A Figura (3.3) mostra a distribuição de forças paralelas que são aplicadas separadamente em cada braço do bloco $\mathrm{T}$ gerando momento na estrutura.

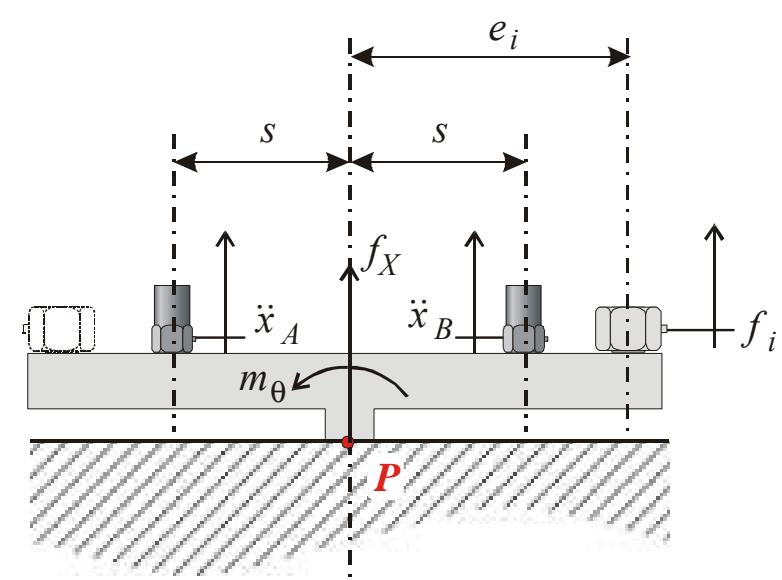

FIGURA 3.3 Montagem do bloco com entrada de força e momento, MAIA, et. al. (1997) 
Basicamente, deseja-se relacionar a força $f_{x}$ e o momento $m_{\theta}$ com as respostas $\ddot{x}_{P}$ e $\ddot{\theta}_{P}$. Portanto, executando um primeiro teste com a força $f_{l}$ aplicada no lado direito do bloco, pode-se escrever as seguintes relações, MAIA (1997)

$f_{x}=f_{1}-m\left(\ddot{x}_{P}\right)_{1}$

$m_{\theta}=e_{1} f_{1}-I_{P}\left(\ddot{\theta}_{P}\right)_{1}$

onde $m$ é a massa do conjunto, ou seja, a massa do bloco e dos acelerômetros e $I_{P}$ é o momento de inércia em relação a $P$. Os valores de aceleração $\left(\ddot{x}_{P}\right)_{1}$ e $\left(\ddot{\theta}_{P}\right)_{1}$ no ponto $P$ podem ser relacionados aos valores medidos através das Equações (3.7) e (3.8). A equação de receptância relacionando essas quantidades é

$\left\{\begin{array}{l}\left(x_{P}\right)_{1} \\ \left(\theta_{P}\right)_{1}\end{array}\right\}=\left[\begin{array}{ll}\alpha_{x x} & \alpha_{x \theta} \\ \alpha_{\theta x} & \alpha_{\theta \theta}\end{array}\right]\left\{\begin{array}{l}f_{x} \\ m_{\theta}\end{array}\right\}=[\alpha(\omega)]\left\{\begin{array}{c}f_{1}+\omega^{2} m\left(x_{P}\right)_{1} \\ e_{1} f_{1}+\omega^{2} I_{P}\left(\theta_{P}\right)_{1}\end{array}\right\}$

dividindo por $f_{1}$

$\left\{\begin{array}{c}\frac{\left(x_{P}\right)_{1}}{f_{1}} \\ \frac{\left(\theta_{P}\right)_{1}}{f_{1}}\end{array}\right\}=[\alpha(\omega)]\left\{\begin{array}{l}1+\omega^{2} m \frac{\left(x_{P}\right)_{1}}{f_{1}} \\ e_{1}+\omega^{2} I_{P} \frac{\left(\theta_{P}\right)_{1}}{f_{1}}\end{array}\right\}$ 
Executando-se o segundo teste (dentro da mesma faixa de freqüências) com a força de excitação $f_{2}$ aplicada do outro lado do bloco, obtém-se de maneira análogo.

$$
\left\{\begin{array}{c}
\frac{\left(x_{P}\right)_{2}}{f_{2}} \\
\frac{\left(\theta_{P}\right)_{2}}{f_{2}}
\end{array}\right\}=[\alpha(\omega)]\left\{\begin{array}{c}
1+\omega^{2} m \frac{\left(x_{P}\right)_{2}}{f_{2}} \\
-e_{2}+\omega^{2} I_{P} \frac{\left(\theta_{P}\right)_{2}}{f_{2}}
\end{array}\right\}
$$

Escrevendo as Equações (3.12) e (3.13) numa única matriz tem-se

$$
\left[\begin{array}{cc}
\frac{\left(x_{p}\right)_{1}}{f_{1}} & \frac{\left(x_{p}\right)_{2}}{f_{2}} \\
\frac{\left(\theta_{p}\right)_{1}}{f_{1}} & \frac{\left(\theta_{p}\right)_{2}}{f_{2}}
\end{array}\right]=[\alpha(\omega)]\left[\begin{array}{cc}
1+\omega^{2} m \frac{\left(x_{P}\right)_{1}}{f_{1}} & 1+\omega^{2} m \frac{\left(x_{P}\right)_{2}}{f_{2}} \\
e_{1}+\omega^{2} I_{P} \frac{\left(\theta_{P}\right)_{1}}{f_{1}} & -e_{2}+\omega^{2} I_{P} \frac{\left(\theta_{P}\right)_{2}}{f_{2}}
\end{array}\right]
$$

Usando as igualdades

$$
\begin{aligned}
& \left(x_{p}\right)_{1}=-\frac{1}{\omega^{2}}\left(\ddot{x}_{p}\right)_{1} \\
& \mathrm{e} \\
& \left(x_{p}\right)_{2}=-\frac{1}{\omega^{2}}\left(\ddot{x}_{p}\right)_{2}
\end{aligned}
$$

e ainda

$$
\left(\theta_{p}\right)_{1}=-\frac{1}{\omega^{2}}\left(\ddot{\theta}_{p}\right)_{1}
$$


$\left(\theta_{p}\right)_{2}=-\frac{1}{\omega^{2}}\left(\ddot{\theta}_{p}\right)_{2}$

juntamente com as Equações (3.7) e (3.8) para $\left(\ddot{x}_{P}\right)_{1}$ e $\left(\ddot{\theta}_{P}\right)_{1}$ e equivalente para $\left(\ddot{x}_{P}\right)_{2}$ e $\left(\ddot{\theta}_{P}\right)_{2}$, tem-se

$$
\begin{aligned}
& \left(x_{p}\right)_{1}=-\frac{1}{\omega^{2}} \frac{\left(\ddot{x}_{A}+\ddot{x}_{B}\right)_{1}}{2} \\
& \left(x_{p}\right)_{2}=-\frac{1}{\omega^{2}} \frac{\left(\ddot{x}_{A}+\ddot{x}_{B}\right)_{2}}{2}
\end{aligned}
$$

$\mathrm{e}$

$$
\begin{aligned}
& \left(\theta_{p}\right)_{1}=-\frac{1}{\omega^{2}} \frac{\left(\ddot{x}_{A}+\ddot{x}_{B}\right)_{1}}{2 s} \\
& \left(\theta_{p}\right)_{2}=-\frac{1}{\omega^{2}} \frac{\left(\ddot{x}_{A}+\ddot{x}_{B}\right)_{2}}{2 s}
\end{aligned}
$$

Para melhor entendimento dos termos da Equação (3.14), vai-se analisar de forma separada os lados direto e esquerdo desta equação. Substituindo, primeiramente, as Equações (3.19), (3.20) e (3.21), (3.22) no lado esquerdo da Equação (3.14), obtém-se

$$
-\frac{1}{\omega^{2}}\left[\begin{array}{cc}
\frac{\left(\ddot{x}_{A}+\ddot{x}_{B}\right)_{1}}{2 f_{1}} & \frac{\left(\ddot{x}_{A}+\ddot{x}_{B}\right)_{2}}{2 f_{2}} \\
\frac{\left(\ddot{x}_{A}-\ddot{x}_{B}\right)_{1}}{2 s f_{1}} & \frac{\left(\ddot{x}_{A}-\ddot{x}_{B}\right)_{2}}{2 s f_{2}}
\end{array}\right]=[\alpha(\omega)]\left[\begin{array}{cc}
1+\omega^{2} m \frac{\left(x_{P}\right)_{1}}{f_{1}} & 1+\omega^{2} m \frac{\left(x_{P}\right)_{2}}{f_{2}} \\
e_{1}+\omega^{2} I_{P} \frac{\left(\theta_{P}\right)_{1}}{f_{1}} & -e_{2}+\omega^{2} I_{P} \frac{\left(\theta_{P}\right)_{2}}{f_{2}}
\end{array}\right]
$$


Abrindo a matriz da Equação (3.23), e reescrevendo-a como produto de outras matrizes, tem

$-\frac{1}{\omega^{2}}\left[\begin{array}{cc}0,5 & 0,5 \\ (2 s)^{-1} & -(2 s)^{-1}\end{array}\right]\left[\begin{array}{cc}\frac{\left(\ddot{x}_{A}\right)_{1}}{f_{1}} & \frac{\left(\ddot{x}_{A}\right)_{2}}{f_{2}} \\ \frac{\left(\ddot{x}_{B}\right)_{1}}{f_{1}} & \frac{\left(\ddot{x}_{B}\right)_{2}}{f_{2}}\end{array}\right]=[\alpha(\omega)]\left[\begin{array}{cc}1+\omega^{2} m \frac{\left(x_{P}\right)_{1}}{f_{1}} & 1+\omega^{2} m \frac{\left(x_{P}\right)_{2}}{f_{2}} \\ e_{1}+\omega^{2} I_{P} \frac{\left(\theta_{P}\right)_{1}}{f_{1}} & -e_{2}+\omega^{2} I_{P} \frac{\left(\theta_{P}\right)_{2}}{f_{2}}\end{array}\right]$

chamando agora

$[T]=\left[\begin{array}{cc}0,5 & 0,5 \\ (2 s)^{-1} & -(2 s)^{-1}\end{array}\right]$

e

$$
[G]=\left[\begin{array}{ll}
\left(\frac{\ddot{x}_{A}}{f}\right)_{1} & \left(\frac{\ddot{x}_{A}}{f}\right)_{2} \\
\left(\frac{\ddot{x}_{B}}{f}\right)_{1} & \left(\frac{\ddot{x}_{B}}{f}\right)_{2}
\end{array}\right]
$$

com as matrizes (3.25) e (3.26) chega-se de forma clara aos temos do lado esquerdo da Equação (3.8), como queríamos analisar. 


$$
-\frac{1}{\omega^{2}}[T][G]=[\alpha(\omega)]\left[\begin{array}{cc}
1+\omega^{2} m \frac{\left(x_{P}\right)_{1}}{f_{1}} & 1+\omega^{2} m \frac{\left(x_{P}\right)_{2}}{f_{2}} \\
e_{1}+\omega^{2} I_{P} \frac{\left(\theta_{P}\right)_{1}}{f_{1}} & -e_{2}+\omega^{2} I_{P} \frac{\left(\theta_{P}\right)_{2}}{f_{2}}
\end{array}\right]
$$

Para analisar o lado direito da Equação (3.14), faz-se de forma análoga os procedimentos decorridos para a analise do lado esquerdo da Equação (3.14), ou seja, substitui as Equações (3.19), (3.20), (3.21) e (3.22) no lado direito da Equação (3.14) e obtém

$$
-\frac{1}{\omega^{2}}[T][G]=[\alpha(\omega)]\left[\begin{array}{cc}
1+\omega m\left(-\frac{1}{\omega^{2}}\right) \frac{\left(\ddot{x}_{A}+\ddot{x}_{B}\right)_{1}}{f_{1}} & 1+\omega m\left(-\frac{1}{\omega^{2}}\right) \frac{\left(\ddot{x}_{A}+\ddot{x}_{B}\right)_{2}}{f_{2}} \\
e_{1}+\omega^{2} I_{p}\left(-\frac{1}{\omega^{2}}\right) \frac{\left(\ddot{x}_{A}-\ddot{x}_{B}\right)_{1}}{2 s f_{1}} & -e_{2}+\omega^{2} I_{p}\left(-\frac{1}{\omega^{2}}\right) \frac{\left(\ddot{x}_{A}-\ddot{x}_{B}\right)_{2}}{2 s f_{2}}
\end{array}\right]
$$

Abrindo a matriz (3.28) e reescrevendo-a como produto de outras matrizes, fica se

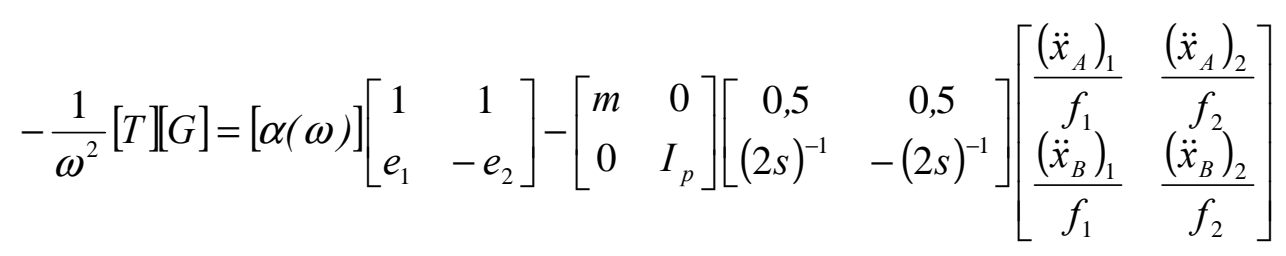

chamando agora

$$
[\Pi]=\left[\begin{array}{cc}
1 & 1 \\
e_{1} & -e_{2}
\end{array}\right]
$$




$$
[M]=\left[\begin{array}{cc}
m & 0 \\
0 & I_{P}
\end{array}\right]
$$

tem-se

$$
-\frac{1}{\omega^{2}}[T][G]=[\alpha(\omega)][\Pi]-[M][T][G]
$$

Reescrevendo a Equação (3.32) isolando [ $\alpha(\omega)]$, encontra-se

$$
[\alpha(\omega)]=-\frac{1}{\omega^{2}}[T][G][[\Pi]-[M][T][G]]^{-1}
$$

Dessa forma, os elementos relevantes de $[\alpha(\omega)]$ podem ser calculados a partir da geometria do bloco de excitação, pois as matrizes $[T],[\Pi]$ e $[M]$ possuem apenas informação sobre os espaçamentos entre os acelerômetros usados nesta técnica e propriedades como massa e momento de inércia que são inerentes da geometria do bloco $T$, e após a medida dos elementos de $[G]$, que é composta por forças e acelerações que são obtidos diretamente do equipamento de medição.

Quando as propriedades de inércia do bloco são muito pequenas comparadas com a estrutura de teste, elas podem ser desprezadas e Equação (3.33) torna-se

$$
[\alpha(\omega)]=-\frac{1}{\omega^{2}}[T][G][\Pi]^{-1}
$$

onde 


$$
[\Pi]^{-1}=\left[\begin{array}{cc}
\frac{e_{2}}{e_{1}+e_{2}} & \frac{1}{e_{1}+e_{2}} \\
\frac{e_{1}}{e_{1}+e_{2}} & -\frac{1}{e_{1}+e_{2}}
\end{array}\right]
$$

As equações previamente desenvolvidas são relativas a medidas das FRF de ponto, ou seja, a excitação e a medida se dão no mesmo ponto. De maneira similar se obtém as expressões para medidas de FRF de transferência, cujo ponto de excitação é diferente do ponto de medida. Observe que, neste caso, as propriedades de inércia do bloco não podem ser levadas em conta, MAIA (1997).

\subsection{Medidas de Aceleração Angular Através da Técnica de Diferenças Finitas}

A Técnica de Diferenças finitas se baseia em adquirir matrizes de medidas de resposta linear e a partir delas as medidas de resposta angular são derivadas usando a formulação de primeira ou segunda ordem conforme o número de acelerômetros que estão sendo usados. O ponto de medida pode ser escolhido como sendo qualquer um da distribuição dos acelerômetros e para tanto as formulações para os pontos à frente, atrás e no meio do ponto escolhido para a medida são necessárias. O espaçamento entre os acelerômetros tem que ser constante e conhecido. Será apresentada a formulação da técnica das Diferenças Finitas, DUARTE (1996). 
Como representado esquematicamente na Figura (3.4), três ou dois acelerômetros, conforme a fórmula de diferenças finitas empregada, são colocados próximos um do outro com um espaçamento constante e igual a $s$. Então, medidas de translação são tomadas e a técnica de diferenças finitas é então usada para derivar as acelerações angulares necessárias. Um dos acelerômetros é colocado no ponto que se deseja medir a aceleração angular (representado na figura pelo ponto $P$ ), e a posição dos outros acelerômetros depende da formulação de diferenças finitas empregada na direção do eixo global, DUARTE (1996).

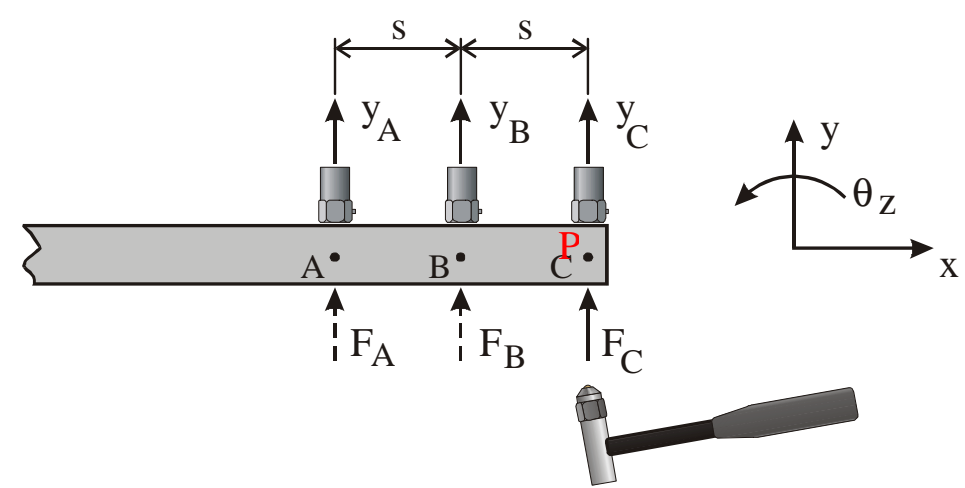

FIGURA 3.4 Método das diferenças Finitas para medidas de GDLR

A seguir são introduzidas as matrizes de transformação da técnica de diferenças finitas de primeira e segunda ordem necessárias para estimar parâmetros angulares, que são necessárias para a obtenção das funções de resposta em frequiência angulares. 


\subsubsection{Matrizes de Transformações da Técnica de Diferenças Finitas.}

\subsubsection{Aproximação de Primeira Ordem}

Para esta aproximação somente os pontos $B$ e $C$ da Figura (3.4) serão usados. As deduções dessas matrizes de transformação para aproximação de primeira ordem estão dispostas no Anexo 1. As transformações matriciais para ponto à frente do ponto de medida e para o ponto atrás do pondo de medida, são respectivamente, DUARTE (1996):

$$
\begin{aligned}
& {\left[T_{1 f}\right]=\left[\begin{array}{cc}
0 & 1 \\
\frac{1}{s} & -\frac{1}{s}
\end{array}\right]} \\
& {\left[T_{1 b}\right]=\left[\begin{array}{cc}
0 & 1 \\
-\frac{1}{s} & \frac{1}{s}
\end{array}\right]}
\end{aligned}
$$

Pode-se perceber que os elementos da última linha dessas matrizes possuem sinais opostos. A Equação (3.36) pode ser usada se o ponto $P$ (onde se quer medir aceleração angular) coincide com o ponto de medida $B$, isto é $P=B$ e o sistema de coordenadas é o assumido na Figura (3.4), ou se $P=C$ e o sistema de coordenadas tem a direção oposta aquele da figura. Por outro lado, a Equação (3.37) pode ser usada para a configuração representada na Figura (3.4) ou se $P=C$ e o sistema de coordenadas é o oposto ao representado aqui. Ambas as matrizes de transformação são precisamente equivalentes. 


\subsubsection{Aproximação de Segunda Ordem}

Neste caso, três localizações são necessárias, como na Figura (3.4). Três possíveis fórmulas podem ser empregadas, dependendo dos acelerômetros e da posição do sistema de coordenadas utilizado. As deduções dessas matrizes de transformação para aproximação de segunda ordem estão dispostas no Anexo 2. Para a aproximação de segunda ordem, as matrizes de transformação do ponto à frente, do ponto central e do ponto atrás do ponto de medida são respectivamente:

$$
\begin{aligned}
& {\left[T_{2 f}\right]=\frac{1}{2 s}\left[\begin{array}{ccc}
0 & 0 & 2 s \\
-1 & 4 & -3
\end{array}\right]} \\
& {\left[T_{2 c}\right]=\frac{1}{2 s}\left[\begin{array}{ccc}
0 & 2 s & 0 \\
-1 & 0 & 1
\end{array}\right]} \\
& {\left[T_{2 b}\right]=\frac{1}{2 s}\left[\begin{array}{ccc}
0 & 0 & 2 s \\
1 & -4 & 3
\end{array}\right]}
\end{aligned}
$$

Como para a aproximação de primeira ordem, as matrizes de transformação para os pontos à frente e atrás do ponto de medidas diferem uma da outra apenas pelo sinal da ultima linha da matriz. A Equação (3.38) pode ser usada se o ponto $P=A$, e o sistema de coordenadas ser o mesmo que o da Figura (3.4), ou se $P=C$ e o sistema de coordenadas ter direção oposta ao da Figura (3.4). Por outro lado, a Equação (3.40) pode ser usada para a configuração representada na figura ou para $P=A$ e o sistema de coordenadas ter direção oposta ao da Figura (3.4). A Equação (3.39) pode ser usada se $P=B$, e neste caso o sistema 
de coordenadas pode ser tanto o representado na Figura (3.4), como um sistema equivalente com eixos possuindo sentidos opostos ao da Figura (3.4). Além disso, todas as três matrizes de transformação são precisamente equivalentes, DUARTE, (1996).

\subsubsection{Aproximação Baseada no Modelo de Resposta}

A aplicação original da aproximação das diferenças finitas para derivar quantidades angulares foi relacionada para cálculos de FRFs. As FRFs de translação são medidas e, usando as matrizes de transformação introduzidas na seção anterior, as correspondentes FRFs totais do sistema (coordenadas de translação e de rotação) são obtidas para um ponto específico, ASHORY (1999). Para se conseguir isto, basta resolver as seguintes equações:

$$
[H(\omega)]_{e s t}=\left[\begin{array}{ll}
{\left[H_{y y}(\omega)\right]} & {\left[H_{\theta y}^{T}(\omega)\right]} \\
{\left[H_{\theta y}(\omega)\right]} & {\left[H_{\theta \theta}(\omega)\right]}
\end{array}\right]=\left[T_{*}\right][H(\omega)]_{\text {med }}\left[T_{*}\right]^{T}
$$

o subscrito * pode ser qualquer uma das matrizes de transformação descrita na seção anterior. A matriz $[H]_{\text {med }}$ para aproximação de primeira ordem fica da forma:

$$
[H(\omega)]_{\text {med }}=\left[\begin{array}{ll}
\frac{\ddot{y}_{B}}{F_{B}} & \frac{\ddot{y}_{B}}{F_{C}} \\
\frac{\ddot{y}_{C}}{F_{B}} & \frac{\ddot{y}_{C}}{F_{C}}
\end{array}\right]=\left[\begin{array}{ll}
{\left[H_{B B}(\omega)\right]} & {\left[H_{B C}(\omega)\right]} \\
{\left[H_{C B}(\omega)\right]} & {\left[H_{C C}(\omega)\right]}
\end{array}\right]
$$


Desenvolvendo a Equação (3.41) para aproximação de primeira ordem para pontos à frente e atrás do ponto de medida respectivamente e considerando a simetria, tem-se:

$$
\begin{gathered}
{\left[H_{e s t}(\omega)\right]_{1 f}=\left[\begin{array}{cc}
{\left[H_{C C}\right]} & -\frac{1}{s}\left(\left[H_{C C}\right]-\left[H_{C B}\right]\right) \\
s y m & \frac{1}{s^{2}}\left(\left[H_{C C}\right]-2\left[H_{C B}\right]+\left[H_{B B}\right]\right)
\end{array}\right]} \\
{\left[H_{e s t}(\omega)\right]_{1 b}=\left[\begin{array}{cc}
{\left[H_{C C}\right]} & \frac{1}{s}\left(\left[H_{C C}\right]-\left[H_{C B}\right]\right) \\
s y m & \frac{1}{s^{2}}\left(\left[H_{C C}\right]-2\left[H_{C B}\right]+\left[H_{B B}\right]\right)
\end{array}\right]}
\end{gathered}
$$

Como visto acima, a única diferença entre as matrizes dos pontos à frente e atrás do ponto de medida é que os sinais das diagonais secundárias são invertidos. Um resultado similar ocorre para as aproximações de segunda ordem, nos mesmos pontos, como expressos nas Equações (3.46), (3.47) e (3.48),

$$
[H]_{\text {med }}=\left[\begin{array}{lll}
\frac{\ddot{y}_{A}}{F_{A}} & \frac{\ddot{y}_{A}}{F_{B}} & \frac{\ddot{y}_{A}}{F_{C}} \\
\frac{\ddot{y}_{B}}{F_{A}} & \frac{\ddot{y}_{B}}{F_{B}} & \frac{\ddot{y}_{B}}{F_{C}} \\
\frac{\ddot{y}_{C}}{F_{A}} & \frac{\ddot{y}_{B}}{F_{B}} & \frac{\ddot{y}_{C}}{F_{C}}
\end{array}\right]=\left[\begin{array}{lll}
{\left[H_{A A}\right]} & {\left[H_{A B}\right]} & {\left[H_{A C}\right]} \\
{\left[H_{B A}\right]} & {\left[H_{B B}\right]} & {\left[H_{B C}\right]} \\
{\left[H_{C A}\right]} & {\left[H_{C B}\right]} & {\left[H_{C C}\right]}
\end{array}\right]
$$


$\left[H_{e s t}(\omega)\right]_{2 f}=\left[\begin{array}{cc}{\left[H_{C C}\right]} & -\frac{1}{2 s}\left(\left[H_{C A}\right]-4\left[H_{C B}\right]+3\left[H_{C C}\right]\right) \\ s y m & \frac{1}{4 s^{2}}\left(\left[H_{A A}\right]-8\left[H_{B A}\right]+6\left[H_{C A}\right]+16\left[H_{B B}\right]-24\left[H_{C B}\right]+9\left[H_{C C}\right]\right)\end{array}\right]$

$\left[H_{e s t}(\omega)\right]_{2 b}=\left[\begin{array}{cc}{\left[H_{C C}\right]} & \frac{1}{2 s}\left(\left[H_{C A}\right]-4\left[H_{C B}\right]+3\left[H_{C C}\right]\right) \\ s y m & \frac{1}{4 s^{2}}\left(\left[H_{A A}\right]-8\left[H_{B A}\right]+6\left[H_{C A}\right]+16\left[H_{B B}\right]-24\left[H_{C B}\right]+9\left[H_{C C}\right]\right)\end{array}\right]$

$\left[H_{e s t}(\omega)\right]_{2 C}=\left[\begin{array}{cc}{\left[H_{B B}\right]} & \frac{1}{S}\left(\left[H_{C B}\right]-\left[H_{B A}\right]\right) \\ \operatorname{sym} & \frac{1}{4 s^{2}}\left(\left[H_{A A}\right]-2\left[H_{C A}\right]+\left[H_{C C}\right]\right)\end{array}\right]$

Então como descrito nas Equações (3.46), (3.47) e (3.48), tem-se uma estimativa das acelerações angulares para os pontos à frente, atrás e no meio do ponto de medida.

A principal vantagem da técnica de diferenças finitas baseadas em curvas de FRFs é que, como o próprio nome sugere, curvas de FRF são obtidas. Nenhum aparato especial é requerido, transdutores convencionais são usados e os ensaios modais são realizados de maneira normal, (DUARTE, 1996). 


\subsection{Medidas de Aceleração Angular obtida via Acelerômetro} Angular Piezelétrico

Para se projetar um sensor de uso na análise modal experimental, algumas características e condições importantes têm que ser satisfeitas tais como: faixa de freqüência útil larga o suficiente em relação à máxima freqüência desejada da estrutura sob teste; insensibilidade a entradas transversais; massa pequena, dentre outras.

Estas condições são satisfeitas por um elemento piezelétrico na forma de duas chapas piezelétricas com polarização inversa, colocadas uma sobre a outra e cortadas em fatias para formar um retângulo montado em um suporte central, mostrado na Figura (3.5), INSALACO (2002).

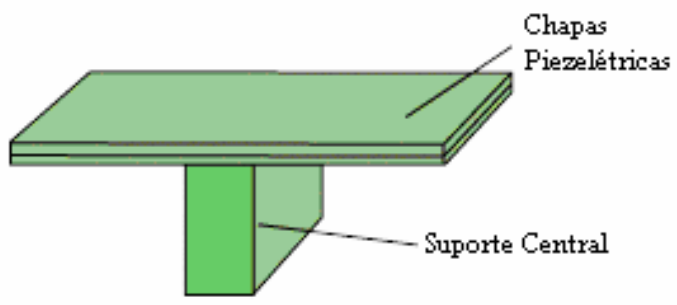

FIGURA 3.5. Acelerômetro formado de chapas piezelétricas, INSALACO (2002)

Este elemento também serve como uma massa sísmica desde que permita a flexão da viga quando exposta a acelerações. Quando configurada como uma viga cantilever, a forma retangular resulta em um sistema sísmico de extremidades flexíveis em um eixo de sensibilidade comparado com duas direções ortogonais definindo o plano transversal. Esta 
disposição é simétrica sobre um sustentáculo central, ou seja o movimento observado de um lado do sustentáculo será o mesmo movimento observado do outro lado, podendo ser na mesma direção ou em direção oposta, INSALACO (2002).

Algumas rotações sobre este ponto central geram igual magnitude porém cargas inversas em cada metade da viga simétrica. Acelerações lineares criam curvas similares em cada lado da viga e as cargas são então somadas, resultando em uma saída proporcional à aceleração linear imposta, como vista na Figura (3.6), INSALACO, (2002).

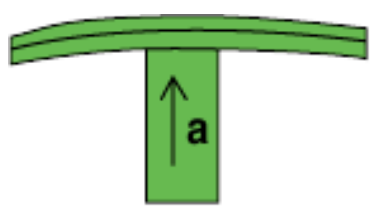

(A)

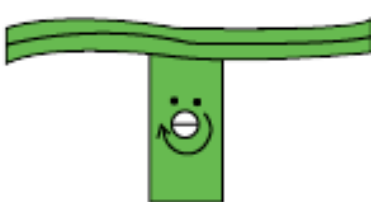

(B)

FIGURA 3.6 Deformações das vigas piezoelétricas quando expostas às acelerações lineares (A) e angulares (B), INSALACO (2002)

Pode-se notar na Figura (3.6) que se a entrada dos dois lados da estrutura piezelétrica puder ser medida de maneira independente, as acelerações angulares e lineares pode ser determinadas. Estas vigas separadas atuam como um sistema sísmico independente com seu centróide exatamente na mesma posição para cada uma das chapas separadas. Este tipo de configuração para a viga retangular é inerentemente insensível para acelerações transversais, como mostra a Figura (3.7), INSALACO,(2002). 


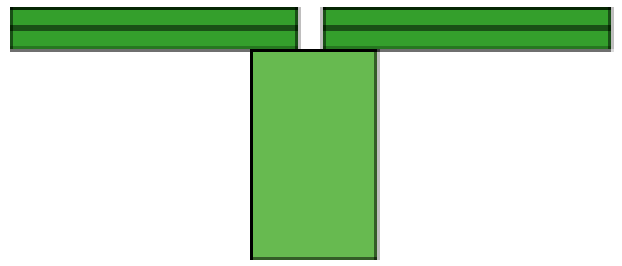

FIGURA 3.7. Elementos de viga separados no centróide, INSALACO (2002).

Com o advento da microeletrônica, foi possível amplificar as cargas geradas por cada uma das vigas piezelétricas separadamente com a inserção uma eletrônica interna a uma casca projetada para ter pouco peso. As cargas geradas por cada uma das vigas piezoelétricas podem ser vista na Figura (3.8)

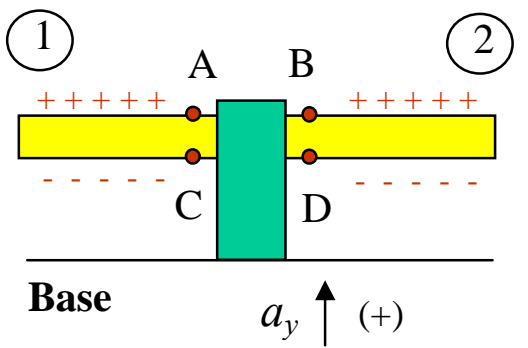

(a)

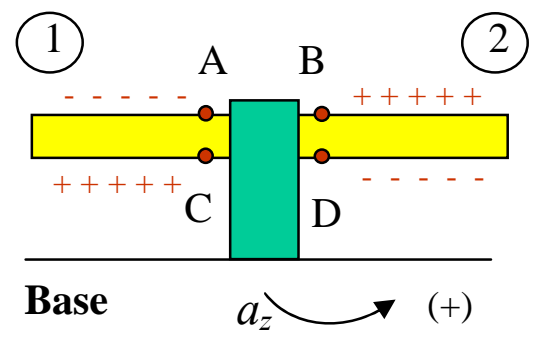

(b)

FIGURA 3.8 Distribuição de cargas para Aceleração linear (a) e angular (b).

Os sinais de saída de cada lado da configuração de vigas separadas de material piezoelétrico são conectados a um condicionador de sinal capaz de fornecer energia à eletrônica interna do sensor e processar o sinal em canais independentes. Potenciômetros podem ser usados para ajustar cada sensibilidade dos canais com exatidão. Circuitos elétricos processam as somas e diferenças e fornecem ambas as saídas, aceleração linear e aceleração angular. Na Figura (3.9) pode-se ver a configuração do circuito elétrico. 


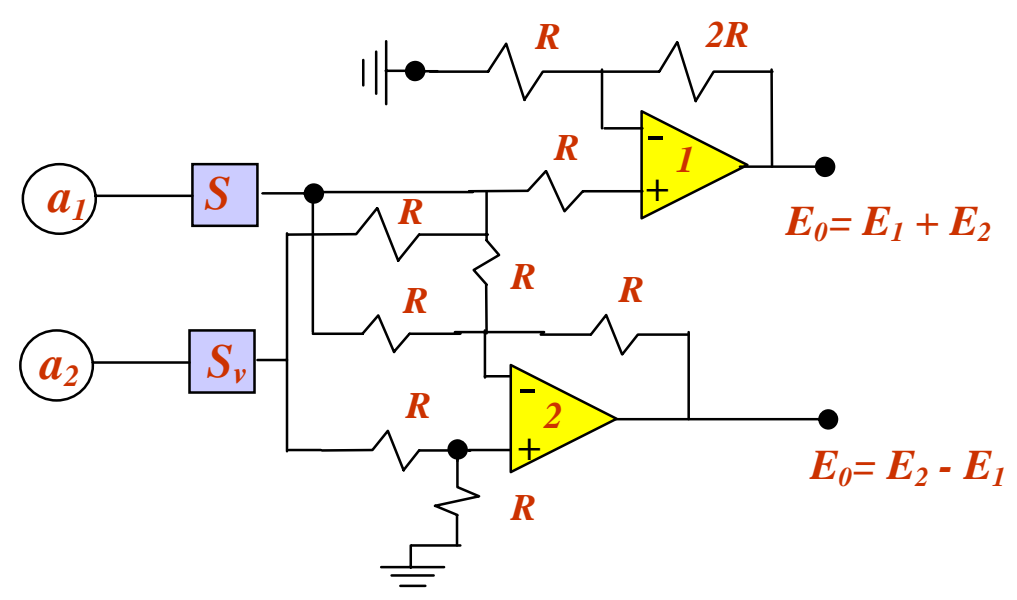

FIGURA 3.9 Circuito elétrico de Soma e Diferença

A tensão de saída para cada lado da viga piezoelétrica é dada por, McCONNELL (1995):

$E_{1} \cong S_{v 1} a_{1}$

$E_{2} \cong S_{v 2} a_{2}$

onde $S_{v i}$ é a sensibilidade de tensão do $i$-ésimo sensor. Quando as Equações (3.49) e (3.50) são substituídas nas Equações (3.7) e (3.8), obtém-se

$\ddot{x}=\frac{S_{a_{2}} E_{2}+S_{a_{1}} E_{1}}{2}=\frac{S_{a}}{2}\left(E_{2}+E_{1}\right)$

$\ddot{\theta}=\frac{S_{a_{2}} E_{2}-S_{a_{1}} E_{1}}{2}=\frac{S_{a}}{2 L}\left(E_{2}-E_{1}\right)$ 
onde $S_{a i}$ é a sensibilidade unitária do $i$-ésimo sensor. A sensibilidade unitária em termos da sensibilidade de tensão é dada por

$S_{a}=\frac{1}{S_{v}}$

as Equações (3.51) e (3.52) tem que ter mesma sensibilidade para cada canal de medida, McCONNELL (1995)

O circuito de soma e diferença mostrado na Figura (3.9) é assumido que tenha a mesma sensibilidade de tensão, $S_{v}$, para cada canal de aceleração. Assim, o operador 1 do circuito é um amplificador de soma onde a saída esta ajustada para ser a soma das tensões $E_{1}$ e $E_{2} . \mathrm{O}$ operador 2 é dado pela diferenças das tensões $E_{1} E_{2}$. A aceleração linear é dada em $g$ por volt e a aceleração angular é dada por $\mathrm{rad} / \mathrm{s}^{2}$ por volt (McCONNELL, 1995).

Para o sensor com a microeletrônica é desenvolvido para ter pouca massa, ele pode ser observado na Figura (3.10), INSALACO (2002).

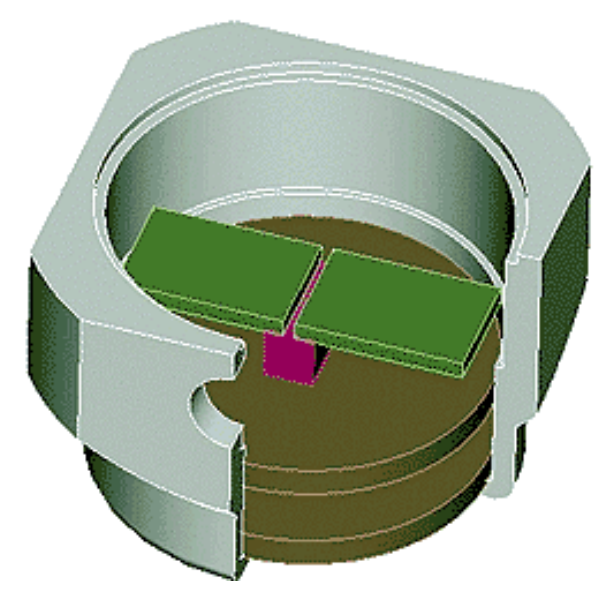

FIGURA 3.10 Miniatura eletrônica contendo um pequeno sensor com pouca massa, INSALACO (2002). 
O acelerômetro angular usado neste trabalho, Figura (3.11), possui como base o piezoelétrico quartzo.

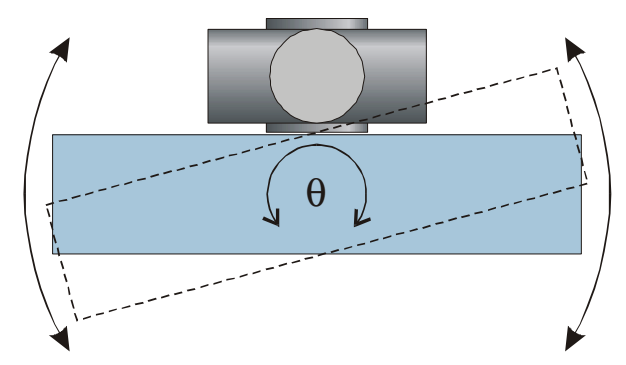

FIGURA 3.11 Acelerômetro angular com quartzo

Configuração desse acelerômetro consiste em dois cristais de quartzo separado por uma distância constante, ver Figura (3.12).

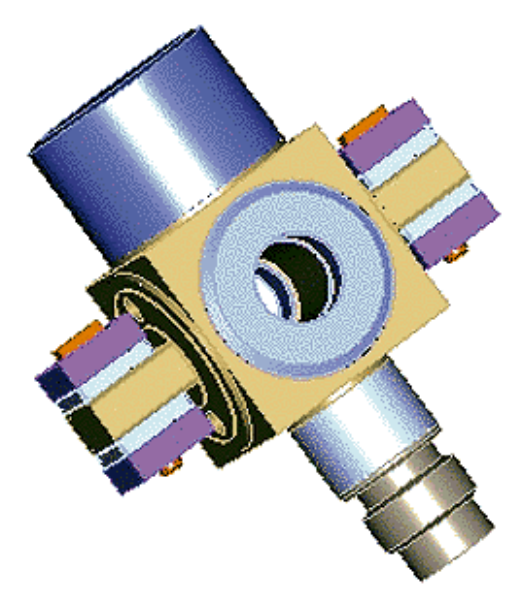

FIGURA 3.12 Acelerômetro Angular feito com cristais de quartzo, INSALACO (2002).

As propriedades naturais desse material estão absolutamente baseadas na sua estrutura molecular. Essas características são estáveis. O quartzo pode ser cortado em varias 
configurações diferentes onde as características são dependentes de uma orientação resultante da rede cristalina com respeito à geometria física. Uma orientação comum, referida como corte de cisalhamento, é bem aceita pois se consegue uma sensibilidade transversal baixa e o efeito da deformação da base é desprezado. Comparado com a construção da viga piezelétrica engastada-livre descrita acima, eles são equivalentes em peso e tamanho, contudo, consegue-se uma sensibilidade baixa para o caso do acelerômetro com quartzo.

Neste capítulo as técnicas do Bloco T das Diferenças Finitas de Primeira e Segunda Ordem e o Acelerômetro Angular Piezoelétrico foram apresentas e discutidas com o objetivo de obter acelerações angulares a partir de dados experimentais e então calcular as FRF angulares/lineares. As duas primeiras técnicas em questão são técnicas indiretas de obtenção de aceleração angular, já o acelerômetro angular é uma técnica direta e tem como objetivo a confrontação com os resultados obtidos mediante as técnicas indiretas.

O próximo capítulo apresenta a teoria dos Elementos Finitos para a estrutura em questão, viga livre livre. 


\section{Capítulo 4}

\section{SIMULAÇÃO NUMÉRICA ATRAVÉS DO MÉTODO DOS ELEMENTOS FINITOS PARA VIGA DE EULER - BERNOULLI.}

Neste capítulo será realizada uma análise da estrutura sob teste pelo método dos

Elementos Finitos. Para esta análise algumas hipóteses simplificadoras foram estabelecidas, tais como, na análise da vibração transversal de uma viga sua seção transversal é constante, se despreza efeitos de inércia de rotação e deformação pelo efeito da força cortante (GRAIG 1984). Além disto, assumi-se constantes as propriedades como Módulo de Young, Coeficiente de Poisson, densidade, etc. Para isso serão desenvolvidas as matrizes elementares de massa e rigidez e assim calcularam-se os modos de vibrar e as frequiências naturais para a viga. Também será feita uma análise de elementos finitos usando um software comercial, Ansys ${ }^{\circledR}$, para se obter os modos de vibrar e as frequiências naturais que serviram para confrontação dos resultados. 


\subsection{Introdução}

O método dos elementos finitos é um método numérico que pode ser usado para uma solução precisa de problemas de vibração estrutural. Neste método, a estrutura sob estudo é discretizada em elementos, os quais são interconectados em pontos, chamados de pontos nodais, ou simplesmete nós. A utilização desta técnica requer que algumas hipóteses simplificadoras sejam estabelecidas. Por exemplo, na análise da vibração transversal de vigas com seção transversal constante, geralmente é utilizado o modelo de Euler-Bernoulli, o qual despreza efeitos de inercia de rotação e deformação pelo efeito da força cortante (GRAIG 1984). Além disto, também são feitas simplificações a cerca do comportamento dos materiais usados, assumindo-se constantes propriedades como Módulo de Young, Coeficiente de Poisson, densidade, etc. Durante o processo de solução, o equilíbrio de forças nos nós e a compatibilidade dos deslocamentos entre o elemento são satisfeitos tal que a estrutura inteira (a montagem de elementos) comporte-se como um corpo único, RAO (1995).

A formulação do método para a viga de Euler - Bernoulli, as transformações de coordenadas e as soluções obtidas com esse método para a estrutura estudada, serão apresentados neste capítulo 


\subsection{Equação de movimento transversal}

Considerando a viga uniforme como mostrada na Figura (4.10), com dois graus de liberdade por nó, o campo de deslocamento para o método dos elementos finitos pode ser definido como:

$w(x, t)=\psi_{1}(x) w_{1}(t)+\psi_{2}(x) \theta_{1}(t)+\psi_{3}(x) w_{2}(t)+\psi_{4}(x) \theta_{2}(t)$

onde $\psi_{1}(x), \psi_{2}(x), \psi_{3}(x)$ e $\psi_{4}(x)$ são as funções de forma ou interpolação, $w_{1}$ e $w_{2}$ são os deslocamentos nodais e $\theta_{1}$ e $\theta_{2}$ são as rotações nodais.

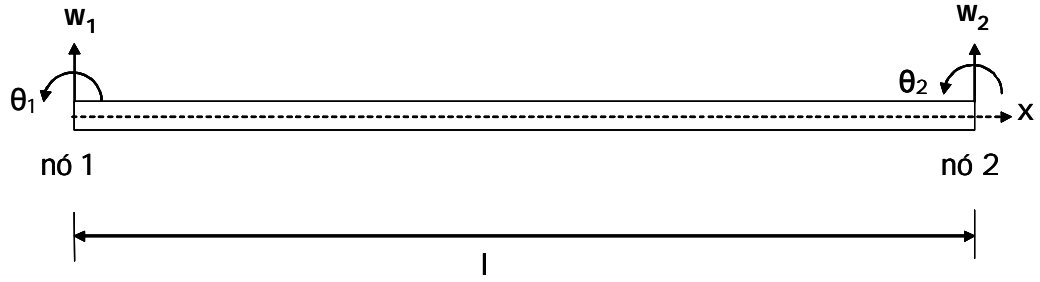

FIGURA 4.1 Elemento de Viga de Euler - Bernoulli

As funções de forma da viga devem satisfazer as seguintes condições de contorno:

$$
\begin{aligned}
& \psi_{1}(0)=1, \psi_{1}^{\prime}(0)=\psi_{1}(l)=\psi_{1}^{\prime}(l)=0 \\
& \psi_{2}^{\prime}(0)=1, \psi_{2}(0)=\psi_{2}(l)=\psi_{2}^{\prime}(l)=0 \\
& \psi_{3}(l)=1, \psi_{3}(0)=\psi_{3}^{\prime}(0)=\psi_{3}^{\prime}(l)=0 \\
& \psi_{4}^{\prime}(l)=1, \psi_{4}(0)=\psi_{4}^{\prime}(0)=\psi_{4}(l)=0
\end{aligned}
$$


Adotando-se uma função interpolação cúbica, o campo de deslocamentos da viga pode ser escrito como CRAIG (1981)

$$
w(x)=a_{1}+a_{2}\left(\frac{x}{l}\right)+a_{3}\left(\frac{x}{l}\right)^{2}+a_{4}\left(\frac{x}{l}\right)^{3}
$$

onde $a_{1}, a_{2}, a_{3}$ e $a_{4}$ são constantes.

Substituindo a quatro condições de contorno descritas pelas Equações (4.2), (4.3), (4.4)e (4.5) na Equação (4.6), tem-se:

$$
\begin{aligned}
& \psi_{1}=1-3\left(\frac{x}{l}\right)^{2}+2\left(\frac{x}{l}\right)^{3} \\
& \psi_{2}=x-2 l\left(\frac{x}{l}\right)^{2}+l\left(\frac{x}{l}\right)^{3} \\
& \psi_{3}=3\left(\frac{x}{l}\right)^{2}-2\left(\frac{x}{l}\right)^{3} \\
& \psi_{4}=-l\left(\frac{x}{l}\right)^{2}+l\left(\frac{x}{l}\right)^{3}
\end{aligned}
$$

As equações (4.7), (4.8), (4.9) e (4.10) são denominadas equações de forma e suas curvas estão apresentadas na Figura (4.2) 


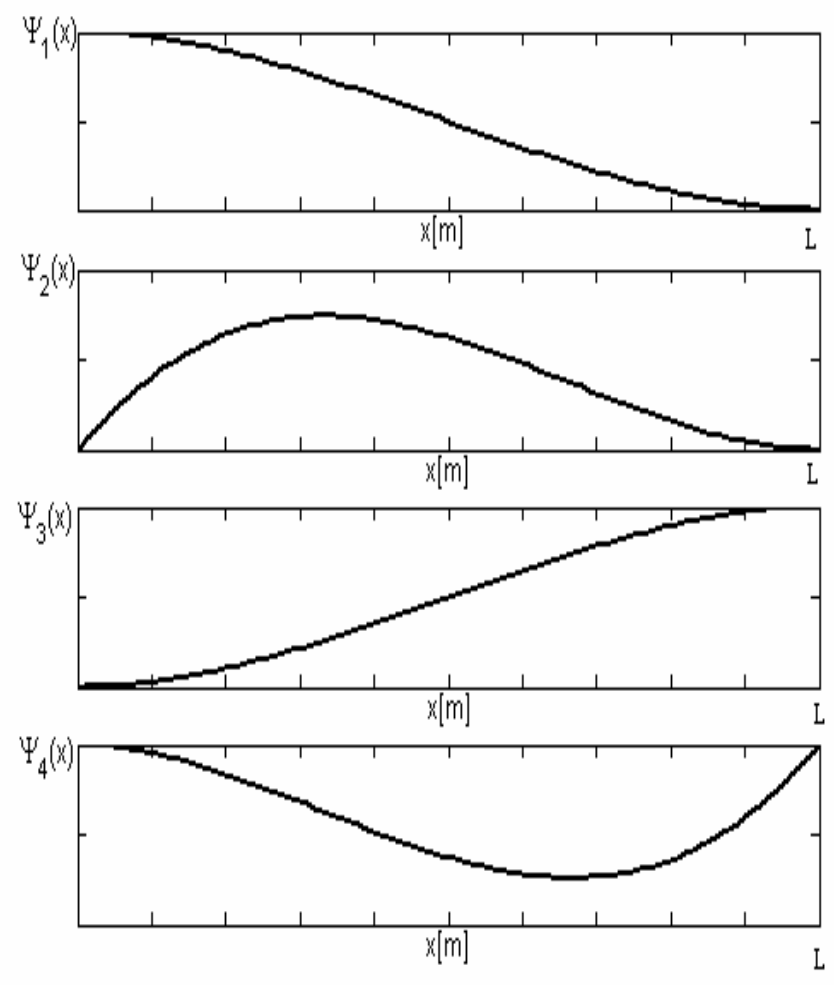

FIGURA 4.2 Função de Forma do Método dos Elementos Finitos para Elemento de Viga

As expressões para massa do elemento e rigidez do elemento, são (CRAIG 1984)

$k_{i j}=\int_{0}^{l} E I \psi_{i}^{\prime \prime} \psi_{j}^{\prime \prime} d x$

$$
m_{i j}=\int_{0}^{l} \rho A \psi_{i} \psi_{j} d x
$$

as matrizes de massa e rigidez são obtidas a partir de uma análise da energia potencial, para o caso da rigidez, e da energia cinética para o caso da massa. 


\section{A força externa}

$f_{i}=\int_{0}^{l} f(x, t) \psi_{i} d x$

Substituindo as Equações (4.7), (4.8), (4.9)e (4.10) nas Equações (4.11) e (4.12), temse

$$
\left[k_{e}\right]=\frac{E I}{l^{3}}\left[\begin{array}{cccc}
12 & 6 l & -12 & 6 l \\
6 l & 4 l^{2} & -6 l & 2 l^{2} \\
-12 & -6 l & 12 & -6 l \\
6 l & 2 l^{2} & -6 l & 4 l^{2}
\end{array}\right]
$$

$$
\left[m_{e}\right]=\frac{\rho A l}{420}\left[\begin{array}{cccc}
156 & 22 l & 54 & -12 l \\
22 l & 4 l^{2} & 13 l & -3 l^{2} \\
54 & 13 l & 156 & -22 l \\
-13 l & -3 l^{2} & -22 l & 4 l^{2}
\end{array}\right]
$$

As equações (4.14) e (4.15) representam as matrizes elementares de massa e rigidez para a modelagem da vibração transversal da viga, segundo o modelo de Euler-Bernoulli. Estas matrizes elementares são usadas na montagem das matrizes de rigidez e massa globais da estrutura sob estudo, de acordo com regras para a montagem de tais matrizes (CRAIG, 1982). Conforme mostradas acima as matrizes elementares são simétricas e são cheias. Entretanto, quando usadas na montagem das matrizes globais o resultado, geralmente são matrizes de banda, tanto para a rigidez quanto para a massa. Cabe salientar 
que a formulação acima recebe o nome de formulação consisitente de rigidez e massa, e, para o caso da matriz de massa existe ainda a possibilidade de obter-se uma matriz diagonal, quando se utiliza a conhecida formulação por parâmetros concentrados (lumped)

\subsection{Transformação de Coordenadas}

As matrizes de massa e rigidez elementares desenvolvidas para o elemento da viga de Euler - Bernoulli baseiam-se no sistema de coordenadas local, conforme a Figura (4.3). Para que essas matrizes possam ser aplicadas a estruturas formadas por diversos elementos é necessária à transformação desta do sistema de coordenada local para o sistema de coordenadas global.

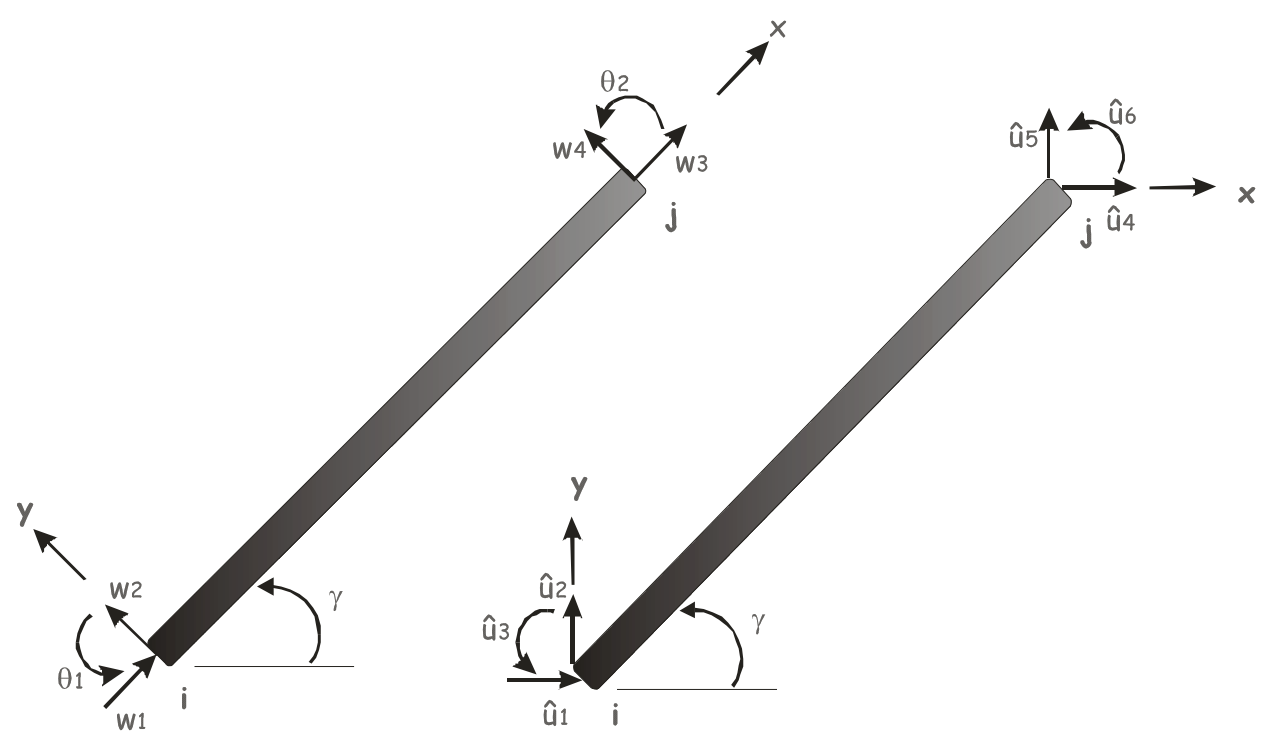

FIGURA 4.3 Transformação de Coordenadas para a Viga

Observando a Figura (4.3), verifica-se que a relação entre os graus de liberdade do sistema local e os graus de liberdade do sistema global é 


$$
\left\{\begin{array}{l}
v_{1} \\
v_{2} \\
\theta_{1} \\
v_{3} \\
v_{4} \\
\theta_{2}
\end{array}\right\}=\left[\begin{array}{cccccc}
\cos \gamma & \sin \gamma & 0 & 0 & 0 & 0 \\
-\sin \gamma & \cos \gamma & 0 & 0 & 0 & 0 \\
0 & 0 & 1 & 0 & 0 & 0 \\
0 & 0 & 0 & \cos \gamma & \sin \gamma & 0 \\
0 & 0 & 0 & -\sin \gamma & \cos \gamma & 0 \\
0 & 0 & 0 & 0 & 0 & 1
\end{array}\right]\left\{\begin{array}{l}
\hat{u}_{1} \\
\hat{u}_{2} \\
\hat{u}_{3} \\
\hat{u}_{4} \\
\hat{u}_{5} \\
\hat{u}_{6}
\end{array}\right\}
$$

sendo

$$
\cos \gamma=\frac{x_{j}-x_{i}}{l}
$$

$\operatorname{sen} \gamma=\frac{y_{j}-y_{i}}{l}$

$l=\sqrt{\left(x_{j}-x_{i}\right)^{2}+\left(y_{j}-y_{i}\right)^{2}}$

onde $\left(x_{i}, y_{i}\right)$ são as coordenadas do nó i e $\left(x_{j}, y_{j}\right)$ são as coordenadas do nó $j$ do elemento no sistema de coordenadas global.

Note que as rotações são as mesmas em ambas as coordenadas, que é $\theta_{1}=\hat{u}_{3}$ e $\theta_{2}=\hat{u}_{6}$. A expressão para $v_{l}$ é obtida pelo diagrama mostrado abaixo retirado da Figura (4.3) 


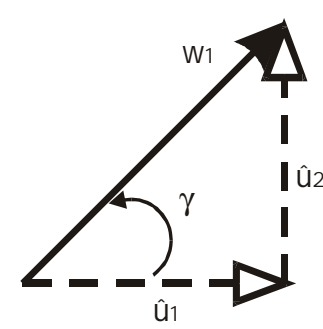

FIGURA 4.4 Diagrama para os deslocamentos

de onde obtém-se

$$
\begin{aligned}
& w_{1}=\widehat{u}_{1} \cos \gamma \\
& w_{1}=\widehat{u}_{2} \sin \gamma
\end{aligned}
$$

se ambos os deslocamentos estão presentes, então

$$
w_{1}=\widehat{u}_{1} \cos \gamma+\widehat{u}_{2} \sin \gamma
$$

Similarmente para o nó j, tem-se

$$
w_{2}=\widehat{u}_{3} \cos \gamma+\widehat{u}_{4} \sin \gamma
$$

e assim para todos os deslocamentos, obtendo a matriz da Equação (4.16), CRAIG (1985). 


\subsection{Solução Numérica}

Para a aplicação do método são realizadas três etapas: Pré-processamento, solução e o pós-processamento. Estas etapas são oferecidas ao usuário quando da utilização de um programa comercial de Elementos Finitos. Será feita a seguir uma breve descrição destas etapas, salientando-se que estas etapas serão seguidas quando da realização de simulações com o programa Ansys ${ }^{\circledR}$ (ANSYS User's Manual) adiante neste capítulo.

\section{Pré-Processamento:}

É a etapa de preparação do problema para posteriormente solucioná-la. É nesta fase, que se faz a modelagem do fenômeno, assumindo hipóteses, condições iniciais, condições de contorno e carregamentos, assim como a escolha do elemento, das propriedades dos materiais e da geometria que representará a forma do componente a ser analisado. A seguir são descritas duas subetapas importantes para o pré-processamento, HUEBNER (1994):

$>\quad$ Discretização do contínuo - O contínuo é o corpo físico, estrutura que esta sendo analisada. A discretização pode ser simplesmente descrita como o processo no qual o domínio é subdividido em um sistema equivalente de elementos finitos, os quais podem, ser por exemplo triângulos ou quadriláteros para o problema de duas dimensões ou tetraedros e hexaedros em três dimensões. Esses elementos possuem os chamados nós que podem ser internos ou externos, ou seja, pertencem ao interior dos elementos ou estão localizados na aresta do mesmo, HUEBNER (1994);

$>\quad$ Seleção das funções de interpolação - as funções de interpolação ou deslocamentos assumidas representam apenas aproximadamente a distribuição exata ou real dos deslocamentos. Geralmente, a forma adotada para as funções de interpolação é a 
polinomial, pela simplicidade de manipulação matemática. Existem três fatores interrelacionados que influenciam a seleção da função de interpolação: escolha do tipo e do grau da função (como normalmente o tipo adotado é o polinômio, apenas o grau deve ser escolhido), o tipo das variáveis de campo que descrevem o modelo (normalmente o deslocamento nos nós ou suas derivadas) e finalmente, o modelo deve satisfazer certos requisitos que garantam que o resultado numérico se aproxime da solução correta, HUEBNER (1994);

\section{Solução}

A solução do problema tem como ponto de partida o modelo configurado na etapa anterior. A solução é baseada em um algoritmo numérico que visa solucionar de maneira mais rápida e acurada, uma equação diferencial com condições de contorno e/ou condições iniciais impostas pelo modelo. A seguir são descritas algumas subetapas para solucionar um problema:

$>$ Encontrar as propriedades dos elementos: depois de realizadas a etapa anterior, ou seja, o elemento e a função interpolação terem sido selecionada, é necessário determinar as equações matriciais expressando as propriedades dos elementos individuais. Para essa tarefa pode usar uma da quatro aproximações mencionadas: aproximação direta, aproximação variacional, aproximação residual sobrecarregada ou aproximação por balanço de energia. A aproximação variacional é freqüentemente mais conveniente, porém para algumas aplicações depende inteiramente da natureza do problema HUEBNER (1994);

Reunir as propriedades dos elementos para obter a equação do sistema: para encontrar as propriedades de todo o sistema modelado por uma rede de elementos, é necessário reunir todas as propriedades dos elementos, em outras palavras, tem que combinar as equações matriciais expressando o comportamento dos elementos e formar a 
equação matricial que expressa o comportamento da solução do sistema inteiro. Em geral, a base para um método de montagem é a exigência das interconexões nodais. Os deslocamentos em um nó devem ser os mesmos para todos os elementos adjacentes HUEBNER (1994).

Resolver a equação do sistema: as equações montadas no passo anterior são resolvidas para deslocamentos desconhecidos. Em problemas lineares, esta é uma aplicação relativamente direta das técnicas de álgebra matricial. Entretanto, para problemas não lineares, as soluções desejadas são obtidas por umas seqüências de passos, cada qual envolvendo a modificação das matrizes, HUEBNER (1994).

\section{Pós-processamento}

Esta é a ultima etapa. Ela depende apenas da necessidade de quem esta modelando o problema, ou seja, é o conjunto solução da equação diferencial que descreve o fenômeno em estudo, podendo ser:

- deslocamentos nodais;

- deformação da geometria

- gradiente de tensão, conforme o critério escolhido

- gradiente de temperatura;

- deslocamentos nodais ao longo do tempo;

- freqüências naturais e modos de vibrar da estrutura.

Um aspecto importante é que esses algoritmos numéricos podem ser implementados computacionalmente para agilizar o calculo. Atualmente existem vários pacotes comercias de software de elementos finitos. 
Um algoritmo numérico foi implementado em ambiente Matlab ${ }^{\circledR}$,(Matlab User’s Manual, 2002), para gerar a solução da estrutura estudada pelo método dos elementos finitos. Por questões de simplicidade, somente foi implementada a etapa de solução do modelo, de acordo com o exposto acima. Utilizou-se para o pós-processamento os recursos gráficos disponíveis no Matlab $^{\circledR}$. Para esta função a estrutura foi discretizada em 30 elementos. Obtiveram-se as freqüências naturais e os modos de vibrar da estrutura em questão.

Na TABELA (4.1) encontram-se as propriedades da estrutura analisada.

TABELA 4.1 Propriedades da viga

\begin{tabular}{cc}
\hline \hline Comprimento $(l)$ & $0,9 \mathrm{~m}$ \\
\hline Massa $(m)$ & $0,369 \mathrm{~kg}$ \\
\hline Volume $(V)$ & $1,4110^{-4} \mathrm{~m}^{3}$ \\
\hline Densidade $(\rho)$ & $2,6910^{3} \mathrm{~kg} / \mathrm{m}^{3}$ \\
\hline Área $(A)$ & $1,5610^{-4} \mathrm{~m}^{2}$ \\
\hline Momento de Inércia $(I)$ & $5,0010^{-10} \mathrm{~kg} \mathrm{~m}{ }^{2}$ \\
\hline Modulo de Young $(E)$ & $69 \mathrm{GPa}$ \\
\hline Coeficiente de Poisson & 0,33 \\
\hline \hline
\end{tabular}

A faixa de freqüência de interesse corresponde à faixa que vai de 0 a $400 \mathrm{~Hz}$, portanto serão obtidos somente os modos que correspondem a esta faixa de freqüência. As Figuras de (4.5) a (4.9), representa os modos de vibrar da viga em estudo, considerando o modo de vibrar linear, onde os deslocamentos em cada ponto são considerados e os modos de vibrar angulares onde as rotações nesses pontos são consideradas. Optou-se pela normalização dos autovetores tomando-se como referência o maior elemento de cada autovetor para a normalização do respectivo modo de vibrar. 


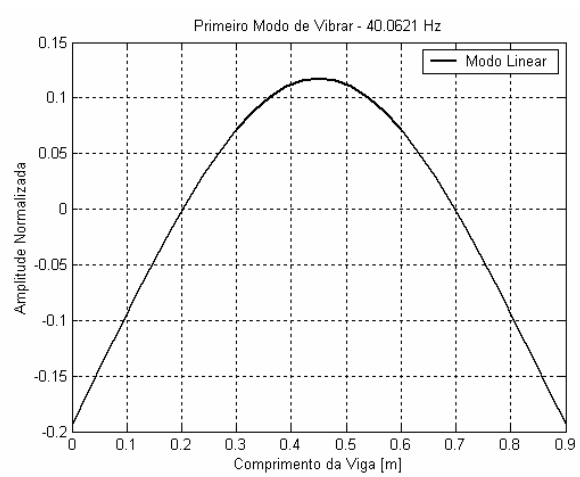

(a)

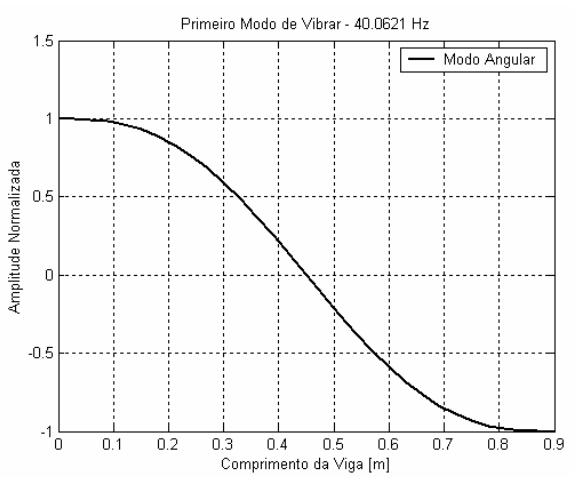

(b)

FIGURA 4.5 Primeiro Modo de Vibrar a 40,6021 Hz (a) Linear, (b) Angular

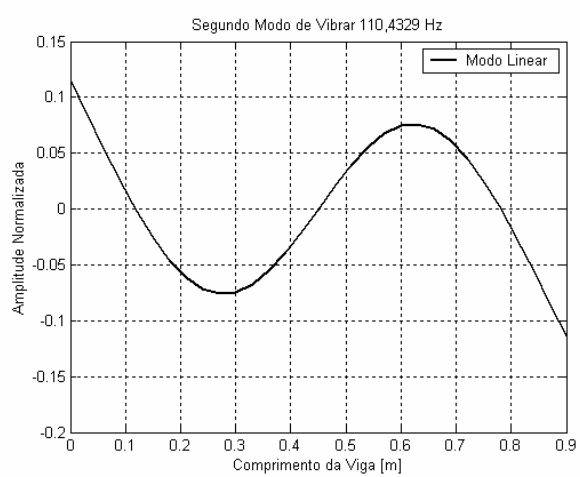

(a)

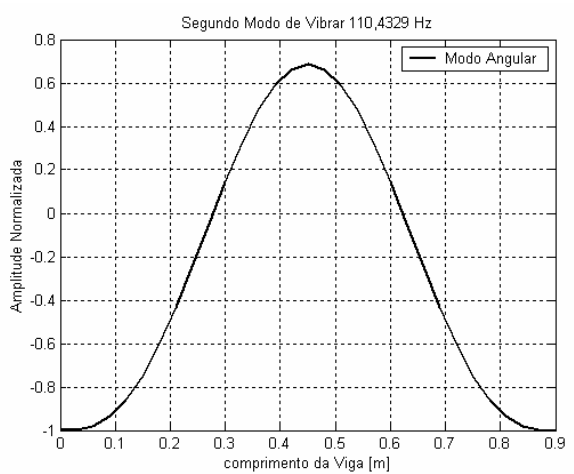

(b)

FIGURA 4.6 Segundo Modo de Vibrar a 110,4344 Hz (a) Linear, (b) Angular

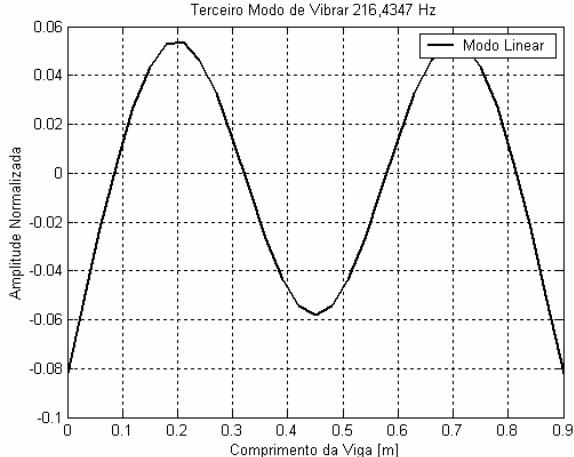

(a)

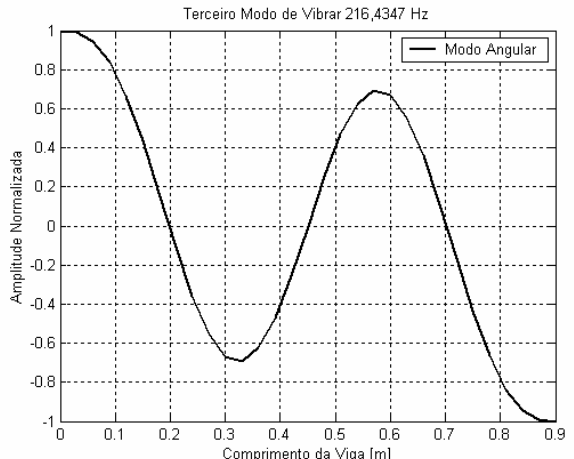

(b)

FIGURA 4.7 Terceiro Modo de Vibrar a 216,5054 Hz (a) Linear, (b) Angular 


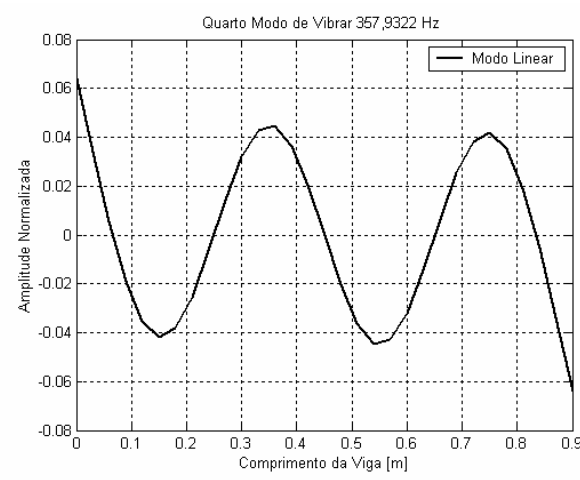

(a)

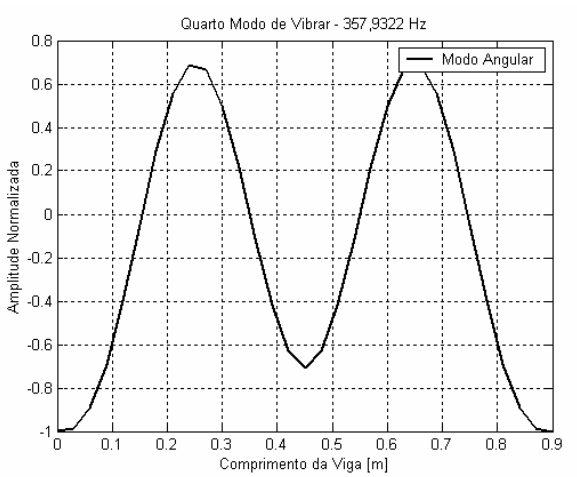

(b)

FIGURA 4.8 Quarto Modo de Vibrar a 357,9322 Hz (a) Linear, (b) Angular

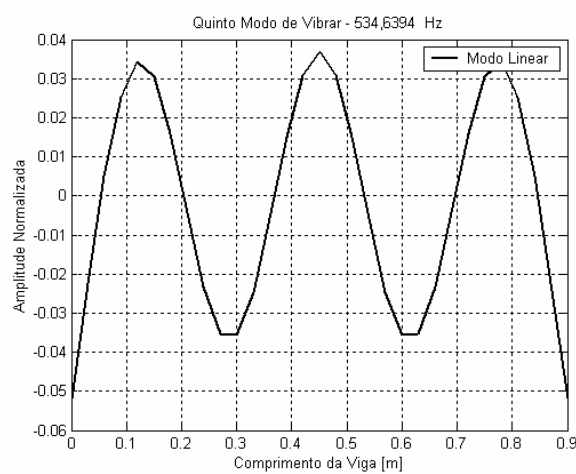

(a)

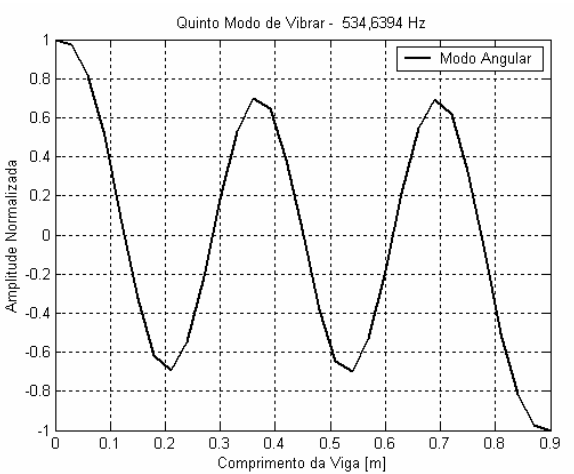

(b)

FIGURA 4.9 Quinto Modo de Vibrar a 534,6394 Hz (a) Linear, (b) Angular

Pode-se notar nas curvas mostradas acima que alguns modos apresentam uma leve estilização em regiões de amplitude máxima ou mínima. Este fenômeno é observado principalmente para aqueles modos de vibrar que apresentam as freqüências naturais mais altas, confome as Figuras (4.8) e (4.9). Isto se deve ao fato de que, à medida que se aumenta à faixa de freqüências analisadas, torna-se necessário um refinamento maior do 
modelo, no sentido deste conter um número maior de elementos, reduzindo assim este problema de discretização.

Também foi feita uma analise em Elementos Finitos utilizando um software comercial, Ansys ${ }^{\circledR}$. Para tanto se obteve os modos de vibrar e as freqüências naturas da mesma estrutura aqui discutida. Obtiveram-se os seguintes resultados:

FREQ $=40,119$

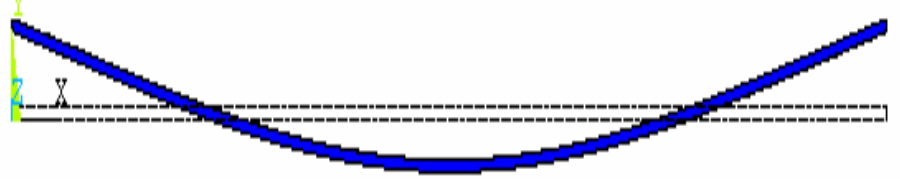

FIGURA 4.10 Primeiro modo de vibrar de flexão no plano XY

$\operatorname{FRE} 0=110.592$

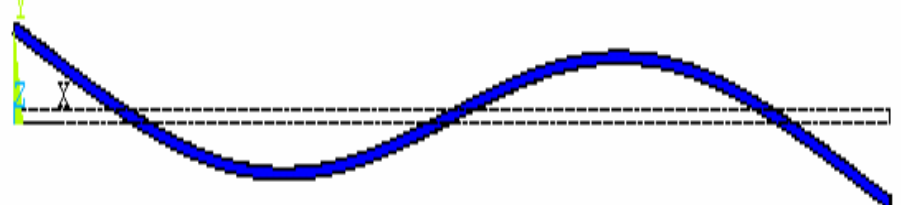

FIGURA 4.11 Segundo modo de vibrar de flexão no plano XY 
FREQ $=162.626$

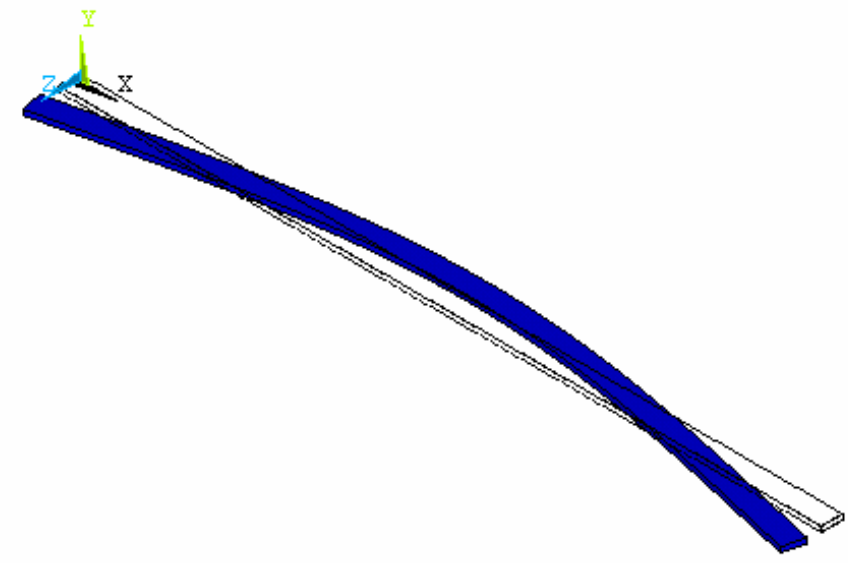

FIGURA 4.12 Primeiro modo de vibrar de flexão no plano XZ

$\mathbb{R E R}=216.815$

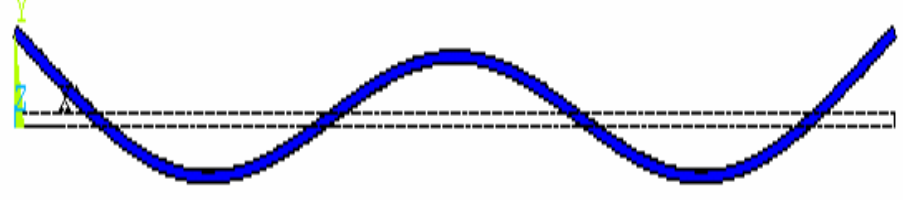

FIGURA 4.13 Terceiro modo de vibrar de flexão no plano XY 
IRE $0=358.434$

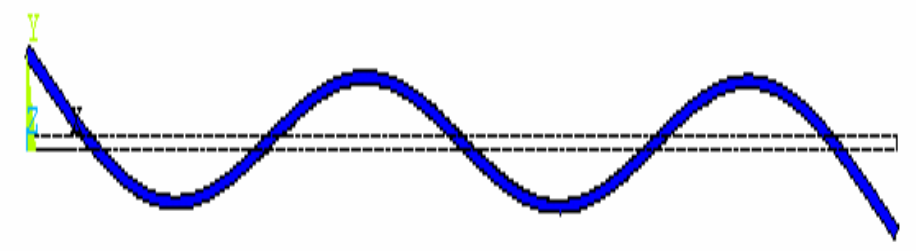

FIGURA 4.14 Quarto modo de vibrar de flexão no plano XY

FREQ $=446.039$

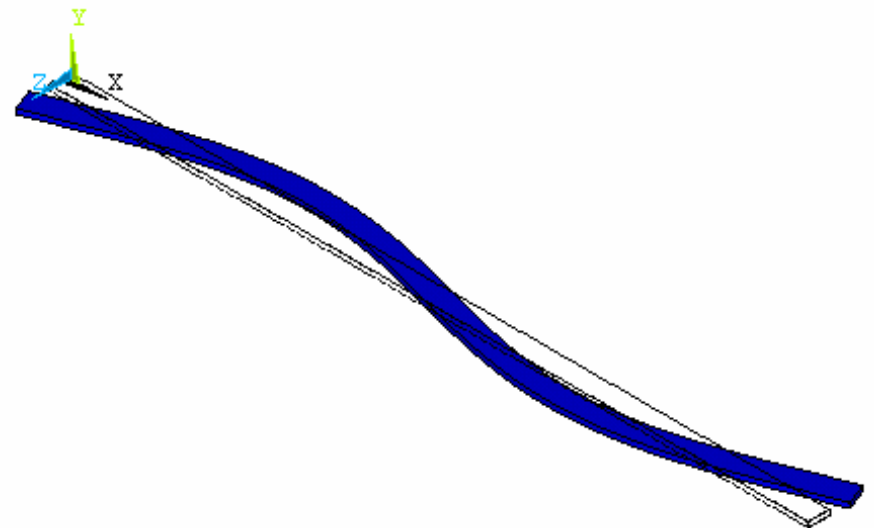

FIGURA 4.15 Segundo modo de vibrar de flexão no plano XZ

Pode se notar que para a análise feita com o pacote comercial não houve separação dos modos lineares e angulares. Isto deve se ao fato desses modos ser uma composição dos deslocamentos e dos ângulos para cada ponto discretizado, apresentado por um modo apenas.

Também foi realizada uma simulação em elementos finitos utilizando o programa comercial para o bloco T. A simulação foi feita apenas para um bloco que foi escolhido por 
ensaio experimental discorrido no capítulo 5 - Resultados Experimentais. O Bloco T é constituído do mesmo material da viga, alumínio, assim pode-se utilizar as mesmas propriedades já especificadas para a viga. Para se obter bom resultado com a técnica do bloco $\mathrm{T}$ é obrigatório que este se comporte como corpo rígido na faixa de freqüência em que as analises estão sendo feitas. Fez então uma simulação de análise modal estrutural do bloco $\mathrm{T}$ isolado, onde sua base foi considerada como tendo deslocamentos nulos em todas as direções. Os dois primeiros modos de vibrar do Bloco T em duas vistas são mostrados nas Figuras (4.16) e (4.17). O primeiro modo de vibrar corresponde a uma freqüência de $6348 \mathrm{~Hz}$, e o segundo modo de vibrar corresponde a 9395 Hz.Os resultados mostram que não aparecem freqüências naturais na faixa de freqüência de 0 a $5000 \mathrm{~Hz}$, o que caracteriza comportamento de corpo rígido nesta faixa de freqüência.
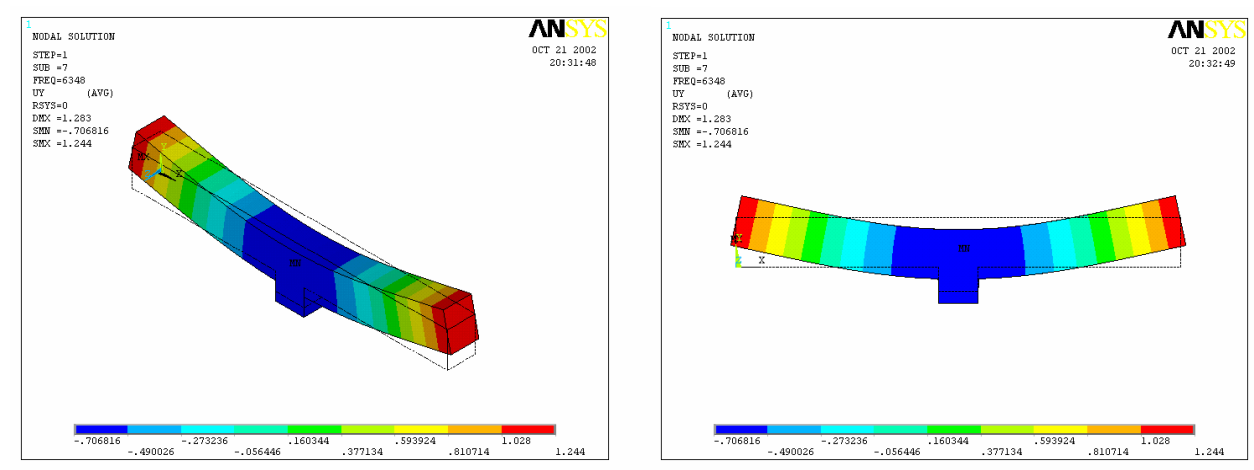

FIGURA 4.16 Primeiro modo de vibrar do Bloco T $-6348 \mathrm{~Hz}$
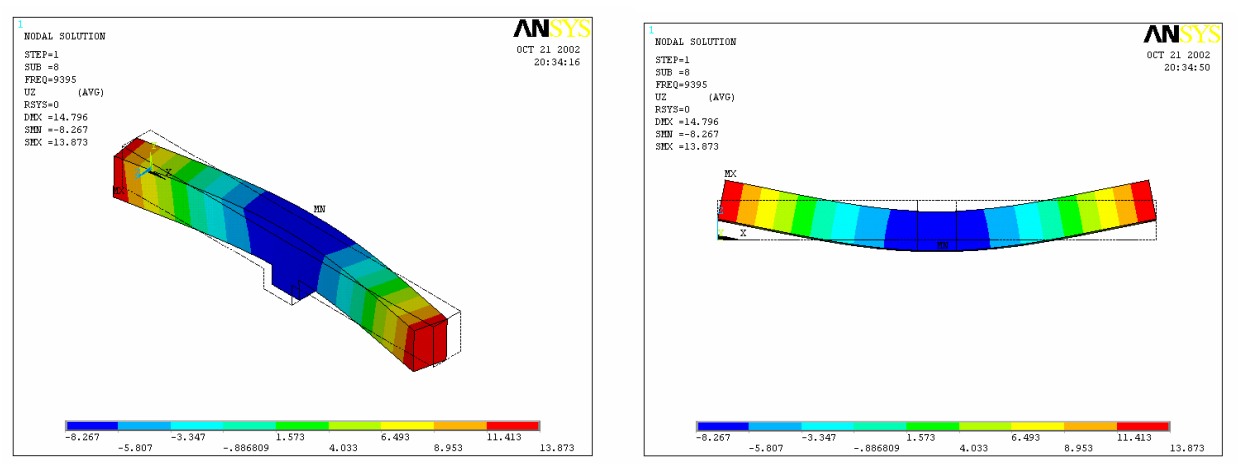

FIGURA 4.17 Segundo modo de vibrar do Bloco T $-9395 \mathrm{~Hz}$ 
Neste capítulo foi feita uma análise da estrutura sob teste pelo método dos elementos finitos. Foram desenvolvidas as matrizes elementares de massa e rigidez e assim calcularam-se os modos de vibrara e as freqüências naturais para a viga. Também foi feita uma análise de elementos finitos usando um software comercial, Ansys ${ }^{\circledR}$, e obtiveram-se os modos de vibrar e as freqüências naturais que serviram para confrontação dos resultados.

No Capítulo 5 serão dispostos os resultados experimentais obtidos com as técnicas apresentadas nesta dissertação. 


\section{Capítulo 5}

\section{RESULTADOS EXPERIMENTAIS}

O principal objetivo deste capítulo é apresentar e discutir os resultados experimentais obtidos com as técnicas discorridas anteriormente nesta dissertação. Serão analisados os resultados das duas técnicas indiretas de determinação de acelerações angulares, sendo a primeira delas a técnica do Bloco T e, a segunda sendo baseada num procedimento de diferenças finitas de primeira e segunda ordem. Também serão analisados os resultados obtidos com o sensor piezelétrico para medidas diretas de acelerações angulares. Os resultados de todas as técnicas serão confrontados entre si e com os resultados teórico discorrido no capítulo 2. Algumas considerações importantes serão feitas em termos da escolha da geometria do Bloco $\mathrm{T}$ utilizada bem como a importância de uma correta fixação do Bloco T na estrutura sob teste. 


\subsection{Considerações Práticas para realização de Ensaios Experimentais}

\section{com Bloco T}

Esta seção faz algumas considerações importantes a respeito da correta fixação do Bloco T. Conforme estabelecido na secção 3.2 do Capítulo 3 uma das hipóteses básicas para o correto uso deste dispositivo é que ele não apresente freqüências naturais na faixa útil de freqüências coberta pelo ensaio. Os resultados obtidos com a simulação numérica, descrita no capítulo anterior, mostraram que o bloco $\mathrm{T}$ se comporta como corpo rígido para frequiências até $5000 \mathrm{~Hz}$. Entretanto, uma fixação inadequada do bloco T na estrutura sob teste pode introduzir erros nas medidas. Então, é importante certificar-se de que a presença do bloco não interfere na resposta da estrutura, o que poderia introduzir erros na medida.

Esta avaliação foi feita por um teste simples, que consiste em fixar o bloco $\mathrm{T}$ diretamente sobre o excitador eletrodinâmico, e excitá-lo no próprio ponto de fixação. A Figura (5.1) ilustra o experimento.

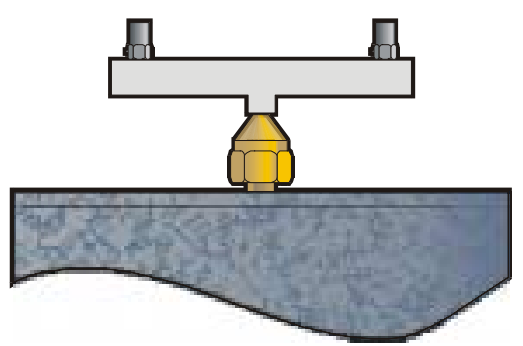

FIGURA 5.1 Bloco T 
O bloco T em questão possui uma massa de $20,14 \mathrm{~g}$ e está montado sob um excitador eletrodinâmico MB Dynamics. Os acelerômetros usados são da B\&K tipo 4375 com 3,11 $\mathrm{pC} / \mathrm{g}$ de sensibilidade à carga e $2,4 \mathrm{~g}$ de massa cada um.

O teste foi realizado para duas situações de fixação do bloco, cera de abelha e parafusos com contra-porca. Em ambas situações, as acelerações nas extremidades do bloco foram medidas simultaneamente. Os resultados obtidos em ambos os casos para a faixa de interesse de 0 a $500 \mathrm{~Hz}$ (pois nesta faixa já se observa o comportamento dinâmico da estrutura com as primeiras freqüências naturais) podem ser vistos nas Figuras (5.2) e (5.3).

As Figuras (5.2) e (5.3) apresentam o sinal de aceleração dos dois acelerômetros e o ângulo de fase entre esses sinais para os dois casos estudados, cera de abelha e parafuso. Pode-se observar na Figura (5.2) que para uma freqüência de $287 \mathrm{~Hz}$ o bloco apresenta uma ressonância, o que não representa comportamento de corpo flexível do bloco em si, mas uma fixação inadequada do bloco T sobre o excitador. Isto pode ser observado, visto que há inversão do ângulo de fase nos sinais dos acelerômetros, o que contradiz a flexão simples esperada para o primeiro modo de uma estrutura tipo viga como esta. 

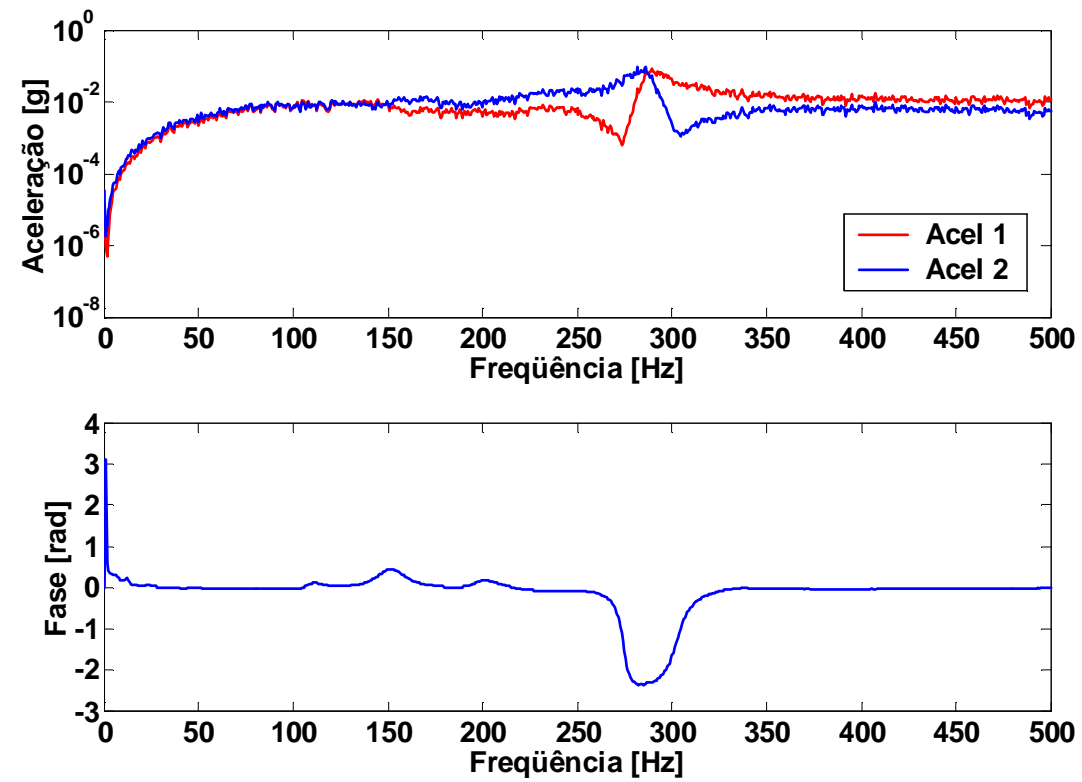

FIGURA 5.2 Aceleração e Ângulo de Fase dos Acelerômetros no Bloco T preso com parafuso e contra porca
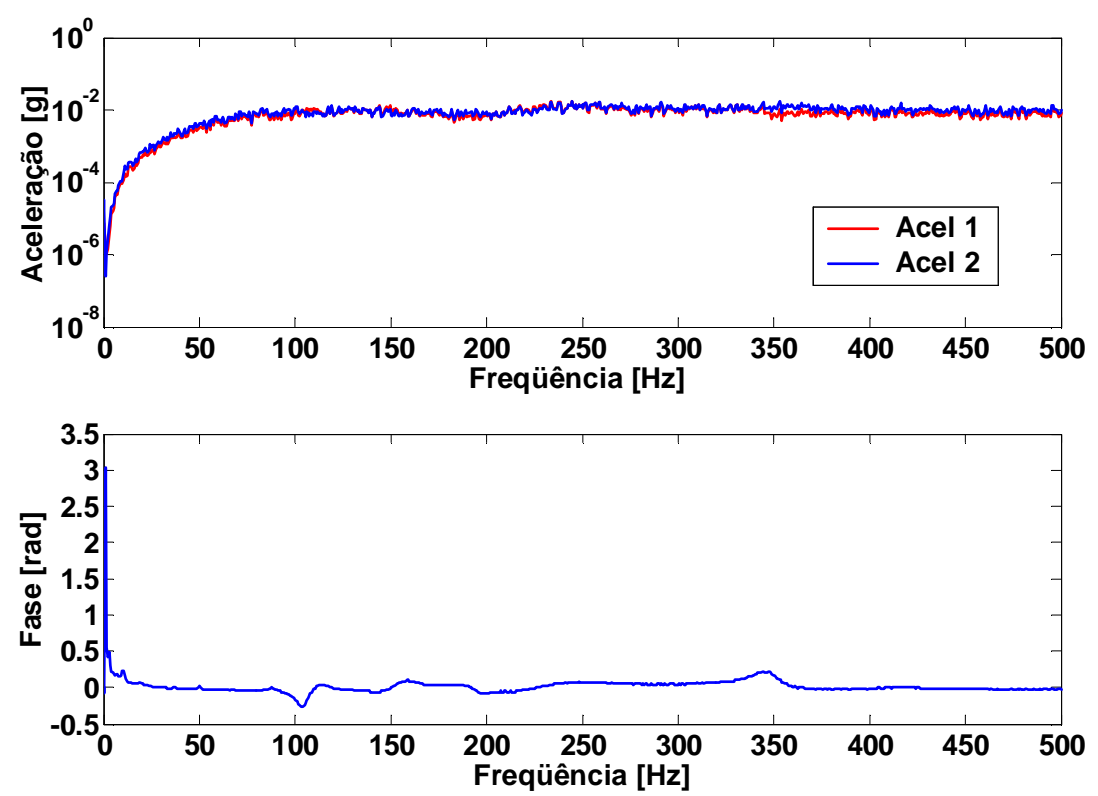

FIGURA 5.3 Aceleração e Ângulo de Fase dos Acelerômetros no Bloco T preso com cera 
O comportamento do bloco fixado com cera ao excitador, exibido pela Figura (5.3), mostra-se satisfatório na faixa de interesse. Neste caso, o bloco comporta-se como um corpo rígido, o que permite aplicar duas das hipóteses básica do equacionamento da teoria do Bloco T. A primeira o qual diz que ele tem que ter comportamento como corpo rígido dentro da faixa de freqüência de interesse. $\mathrm{E}$ a segunda o qual diz que o bloco $\mathrm{T}$ não pode influenciar na dinâmica da estrutura introduzindo freqüências naturais que não são próprias da estrutura sob teste.

\subsection{Utilização de Várias Configurações de Blocos T}

Para que fosse possível realizar medidas com o máximo de precisão, e também realizar uma análise da influência da geometria do bloco $\mathrm{T}$ nas medidas, foram testadas varias configurações de blocos T. A Figura (5.4) apresenta estas configurações onde suas medidas estão expressas em milímetros. 

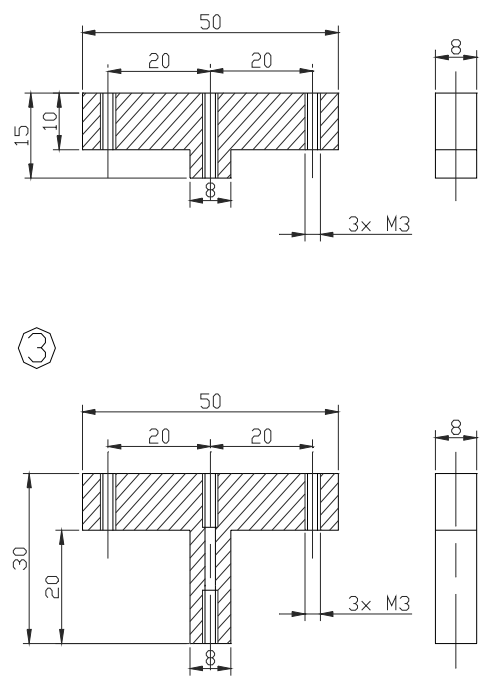

FIGURA 5.4 Diferentes configurações de Bloco T

As propriedades de cada uma das configurações dos blocos $\mathrm{T}$ estão mostradas na TABELA (5.1)

TABELA 5.1 Descrição das propriedades dos diferentes blocos T

\begin{tabular}{cccc}
\hline \hline Blocos $\mathbf{T}$ & $\begin{array}{c}\text { Número de } \\
\text { Chamada }\end{array}$ & Material & Massa (g) \\
\hline & $\mathbf{1}$ & Alumínio & 10,81 \\
\hline & $\mathbf{2}$ & Alumínio & 20,14 \\
\hline
\end{tabular}


Os testes foram realizados na estrutura sob estudo, ou seja, uma viga de alumínio cujas dimensões são: 900x25,2x6,2 mm e massa de 369,30 g que estava suspensa por fios muito finos para simular a condição de livre livre, conforme mostrado na Figura 5.5. Foram usados dois acelerômetros idênticos da B\&K 4375, sensibilidade de 3,11 pC/g (ou 24,9 $\mathrm{mV} / \mathrm{g}$ ) e massa de 2,4g cada. Esses acelerômetros foram fixados no bloco $\mathrm{T}$ com cera de abelha e este fixado na estrutura da mesma maneira. Os ensaios experimentais consistiram em anexar os blocos em duas posições diferentes da viga, sendo a primeira posição no ponto de excitação da estrutura e a segunda posição no extremo oposto ao de excitação. A estrutura foi excitada por um excitador eletrodinâmico da MB Dynamics. Um sinal aleatório foi usado como força de excitação, foi usada uma janela retangular, o motivo deste procedimento foi o interesse na influência da resposta dos blocos na dinâmica da estrutura. Como mostrado na Figura (5.5), a estrutura foi excitada em uma das suas extremidades e obtiveram-se as FRFs no ponto de excitação, $H_{11}$, e de transferência, $H_{12}$ para todas as configurações de bloco $\mathrm{T}$.

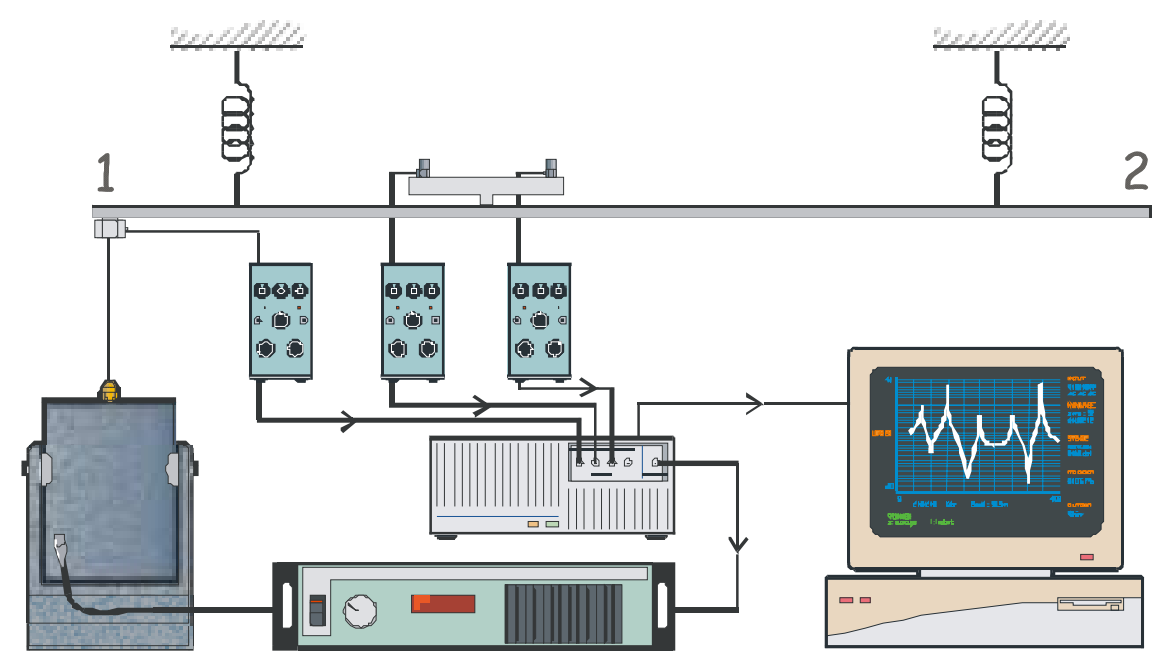

FIGURA 5.5 Aparato experimental para ensaios dos blocos T 
Embora não de disponha de um critério rigoroso para escolher o bloco $\mathrm{T}$ mais adequado para os demais experimentos (por exemplo baseado em níveis de ruído, sensibilidade do bloco $\mathrm{T}$, etc) procurou-se escolher o bloco cujo resultado fosse o mais limpo em termos de prováveis distorções em termos de amplitudes. O ruído presente nas FRF é resultado da maneira de como essas curvas são obtidas, ou seja, da subtração de sinais de aceleração separados apenas pela distância dos acelerômetros que estão posicionados nas extremidades dos braços do bloco $\mathrm{T}$.

A Figura (5.6) apresenta as FRFs no ponto de excitação para as quatro configurações diferentes do bloco T. Pelas curvas apresentadas na Figura (5.6) pode-se observar que a configuração do bloco T (2) (na TABELA (5.1) o bloco T de número de chamada 2), onde os braços são mais compridos e a haste é menor apresenta um resultado melhor, pois todas as freqüências naturais são evidenciadas e a curva de FRF é limpa da presença de ruídos. A curva para a configuração de bloco T (1) não apresenta a frequiência natural próxima dos $100 \mathrm{~Hz}$ que é visível em todas as outras curvas. Para a curva de configuração de bloco T (3), a freqüência natural de $40 \mathrm{~Hz}$ não aparece e ao invés disso a curva apresenta bastante ruído para essa faixa de frequiência que vai até $50 \mathrm{~Hz}$. Outro problema para esta curva é que para a faixa de freqüência de 300 a $400 \mathrm{~Hz}$ a estrutura possui uma freqüência natural em torno de $350 \mathrm{~Hz}$ o qual não aparece na curva para a configuração em questão. Para a curva de FRF que foi obtida usando a configuração de bloco T (4) pode-se observar que apresenta ruídos marcantes na faixa de freqüência de 400 a $500 \mathrm{~Hz}$. 


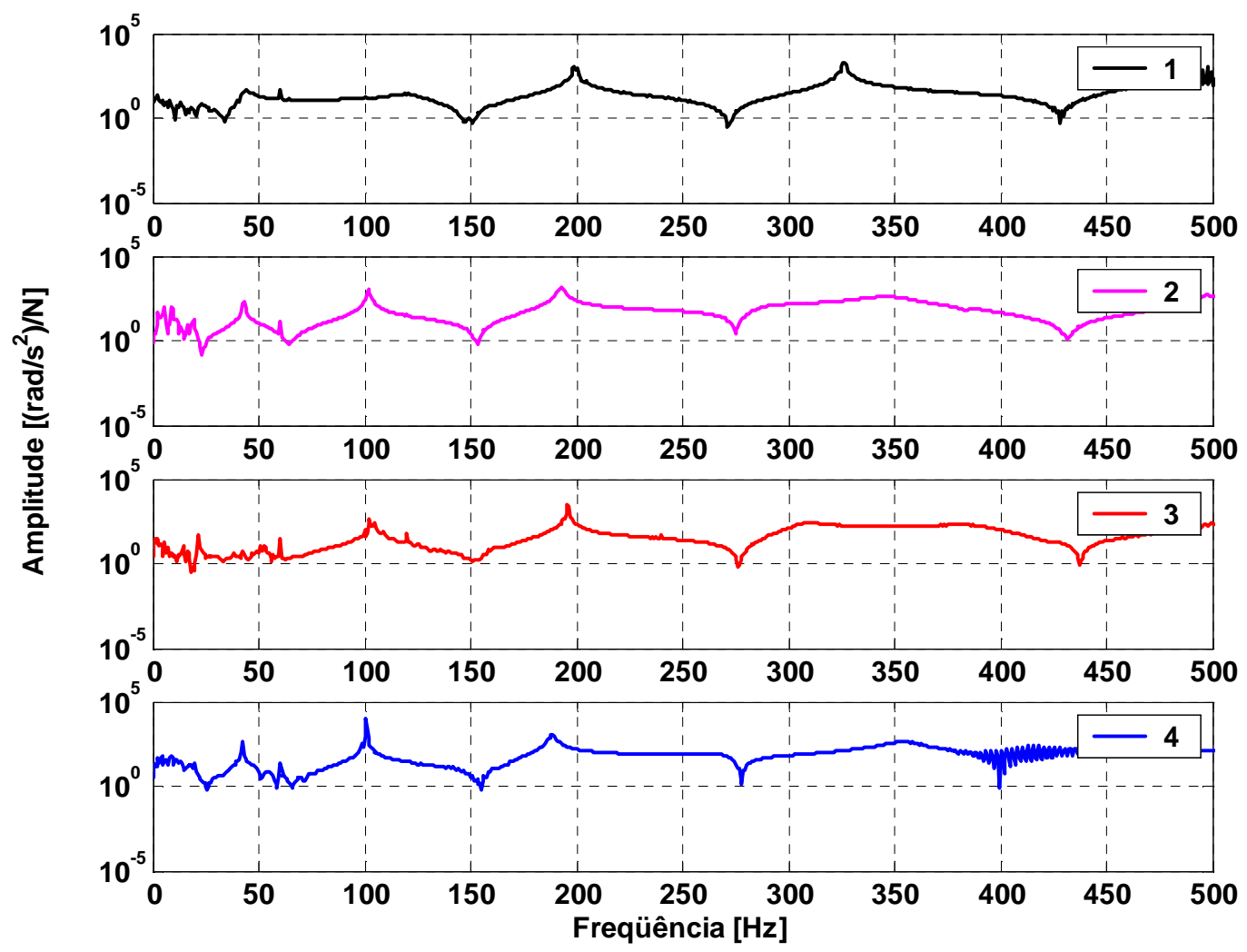

FIGURA 5.6 FRF Angular/Linear no ponto de excitação com diferentes configurações Blocos T

A Figura (5.7) apresenta as FRFs onde a resposta foi obtida no ponto extremo oposta da excitação para todas as configurações de blocos $\mathrm{T}$ onde as medidas foram feitas no ponto extremo ao de excitação. Pelas curvas apresentadas na FIGURA (5.7) pode perceber que as FRFs tomadas com as configurações de bloco T, (3) e (4), onde os braços são menores apresentaram resultado relativamente melhor que as FRFs tomadas com as configurações de blocos T (1) e (2), cujos braços são maiores. 


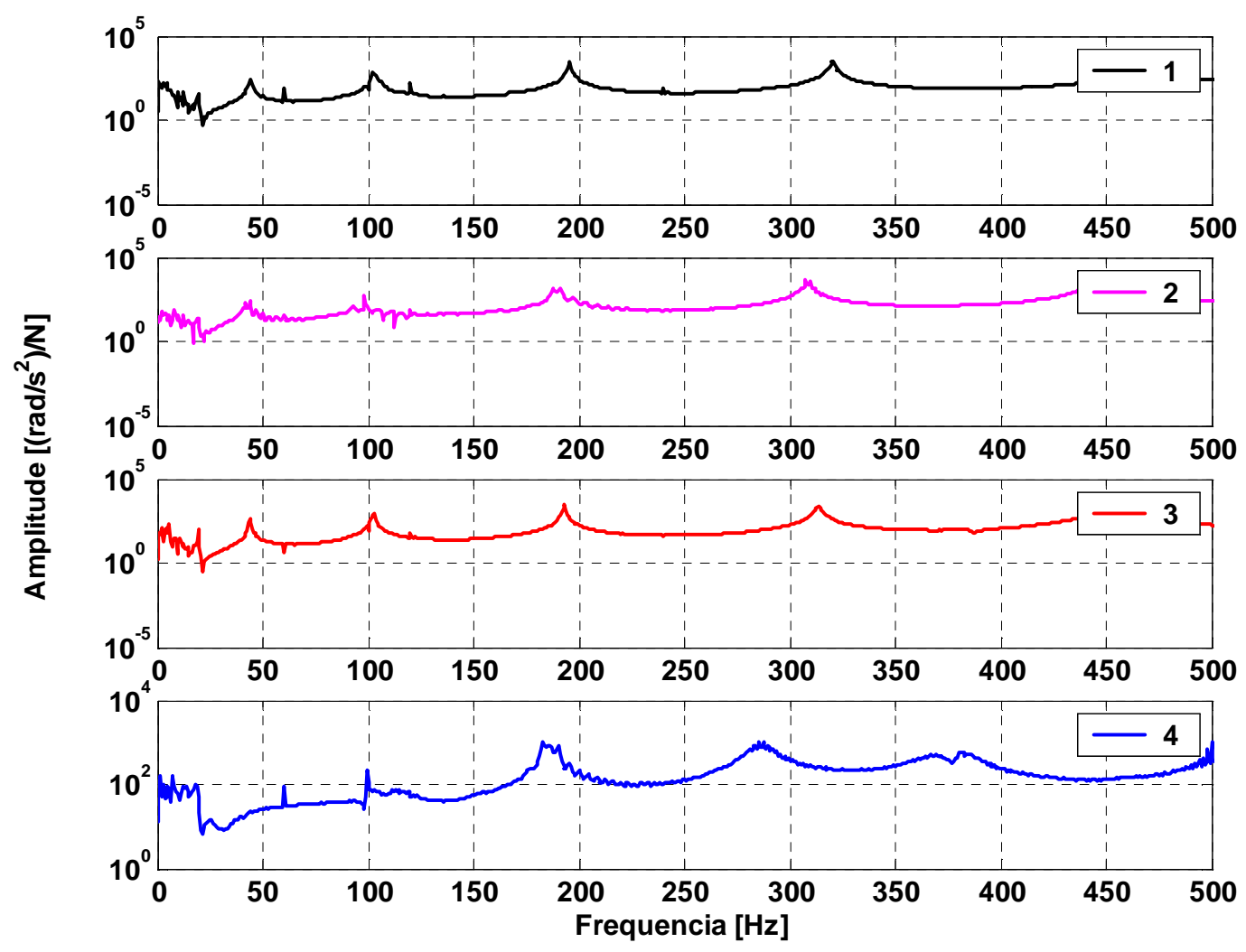

FIGURA 5.7 FRF Angular/Linear de transferência com diferentes configurações de Blocos $\mathrm{T}$

Neste trabalho, o enfoque são medidas feitas no ponto de excitação para testar as diversas técnicas de obtenção de FRFs angulares/lineares. Portanto, a configuração de bloco escolhida para realização dos testes foi o bloco $\mathrm{T}$ que apresenta maior comprimento de braço e menor comprimento de haste, número (2) na TABELA (5.1), pelo fato de apresentar um resultado mais satisfatório nas curvas das FRFs em questão. A sensibilidade do bloco T é dependente do comprimento do seu braço, pois este determina a quantidade de rotação que o bloco esta sentindo a partir dos sinais medidos pelos acelerômetros lineares. 
Entretanto, quando se aumenta o comprimento do braço do bloco T, aumenta-se também sua massa, possibilitando a introdução de outros problemas na medida.

\subsection{Resultados Experimentais Obtidos com o Bloco T}

Esta seção detalha os resultados obtidos com a utilização do Bloco T escolhido na seção anterior. A Figura. (5.8) esquematiza o sistema experimental, vale lembrar que a Figura (5.8) serve apenas para ilustrar o ensaio, já que as dimensões do bloco T em questão podem ser encontradas no mesmo capítulo na seção 5.2. A estrutura sob teste esta suspensa por fios muito finos que simulam a condição livre-livre. O bloco $\mathrm{T}$ está conectado na estrutura e as medidas são feitas no ponto onde está aplicada a excitação, obtendo assim a FRF de ponto. A excitação é feita via excitador eletrodinâmico o qual esta na extremidade da estrutura no ponto indicado. Para a entrada foi utilizado um sinal aleatório. A banda de freqüências desejável no presente estudo é de 0 a $400 \mathrm{~Hz}$, pois nesta faixa já se pode observar o comportamento da estrutura com as primeiras freqüências naturais. Os sinais gerados pelos acelerômetros lineares conectados ao bloco $\mathrm{T}$ são processados algebricamente via cálculos apresentados no capítulo 3, na seção 3.2, e então se obtém a FRF angular/linear. Estes resultados são comparados com a FRF angular/linear obtida teoricamente, apresentada no capítulo 2. 


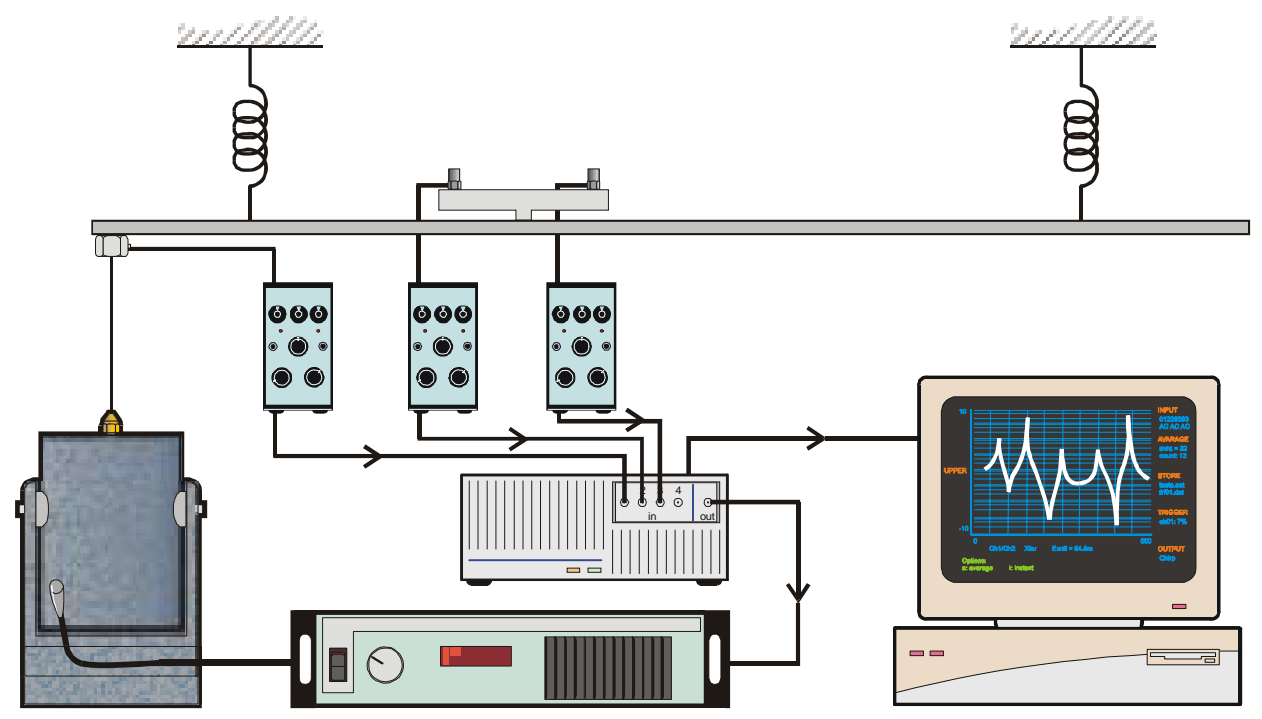

FIGURA 5.8 Aparato experimental da Técnica do Bloco T

O aparato experimental conta com os seguintes equipamentos: (i) Analisador Espectral - TEKTRONIX 2630 Fourier Analyzer; (ii) Acelerômetros B\&K 4375, sensibilidade de 3,11 pC/g (ou 24,9 mV/g) e massa de 2,4g; (iii) Amplificador Condicionador B\&K 2626; (iv) Excitador Eletrodinâmico MB Dynamic e (v) Computador.

A estrutura utilizada para aplicação é a mesma utilizada nos ensaios anteriores.

O ponto de medida foi escolhido por ser um dos locais da viga onde apresentar a maior rotação, como pode ser visto nas Figuras (2.3) a (2.8) do Capitulo 2. Desta medida obtém-se a FRF angular/linear de ponto, apresentada na Figura (5.9).

Para as frequiências entre 0 e $100 \mathrm{~Hz}$ o sinal obtido via bloco T apresenta problemas de ruídos especialmente na vizinhança das anti-ressonâncias. Este comportamento ocorre principalmente por causa do calculo da aceleração angular previamente descrito, no qual os sinais de aceleração são subtraídos um do outro com o objetivo de se obter o movimento angular. 


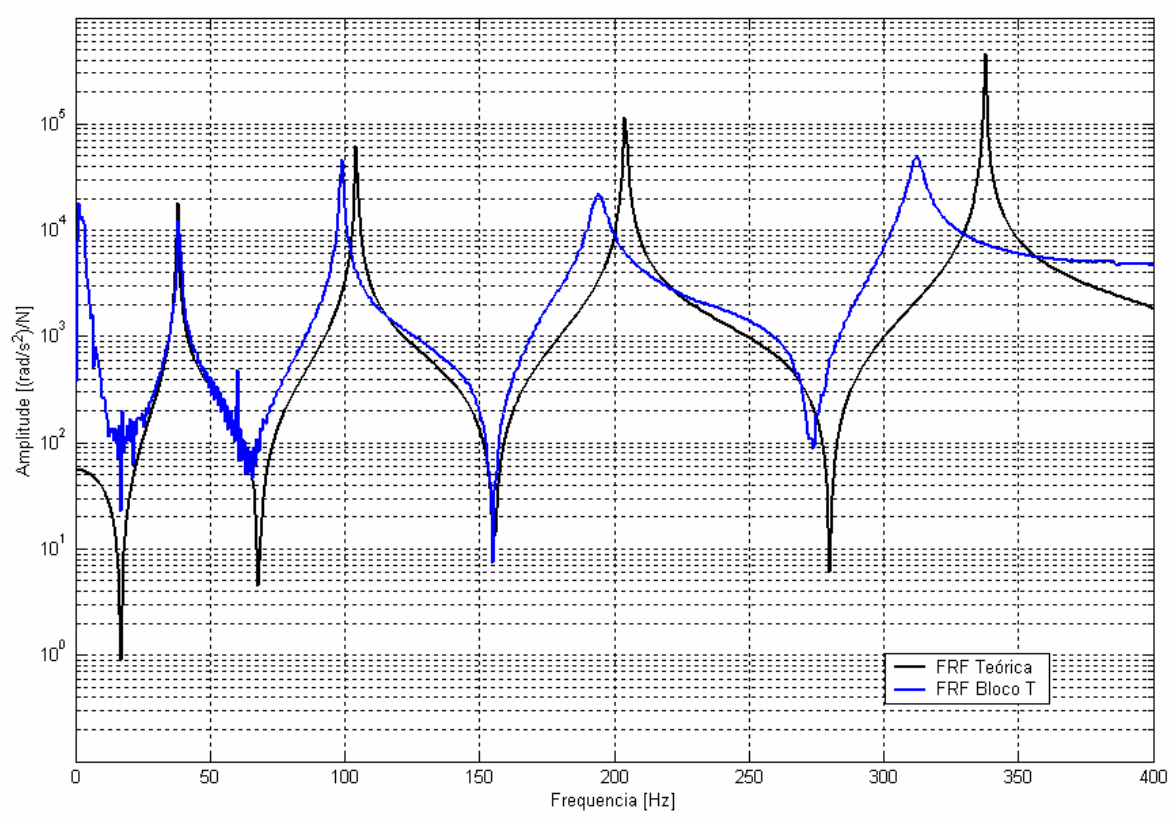

FIGURA 5.9 Medida de FRF de ponto

A curva experimental da Figura (5.9) foi comparada com a curva de FRF teórica do modelo contínuo apresentada no capítulo 2 . Pode-se perceber que a curva experimental apresenta uma boa relação com a curva teórica para a primeira freqüência natural. $\mathrm{Na}$ Figura (5.9) aparecem desvios nas frequiências naturais na faixa de 100 a $400 \mathrm{~Hz}$ entre as curvas apresentadas. A estrutura sob teste, para o caso dos ensaios realizados com o bloco $\mathrm{T}$, esta sujeita ao carregamento de massa imposto pela massa do bloco $\mathrm{T}$ juntamente com a massa dos dois acelerômetros necessários para aplicação da técnica em questão como pode ser visto no capítulo 3 seção 3.2. Logo, para esse caso, esses desvios nas vizinhanças das ressonâncias são devidos a este fenômeno. 


\subsection{Resultados Experimentais Obtidos com o Acelerômetro Angular}

A próxima medida realizada para se obter a FRF angular/linear da viga foi usando um acelerômetro angular piezelétrico. Essa técnica de medidas é a única que possibilita a obtenção de FRF angular/linear diretamente.

A Figura (5.10) esquematiza o aparato experimental. A estrutura sob teste é a mesma dos ensaios anteriores e suas dimensões foram apresentadas na seção precedente. Este aparato experimental contou além dos equipamentos descritos no ensaio precedente com acelerômetros Piezelétrico B\&K 8840, sensibilidade de $34 \mu \mathrm{V} / \mathrm{rad} / \mathrm{s}^{2}$ e massa de $18,5 \mathrm{~g}$ e uma fonte de tensão.

Vale lembrar que a Figura (5.10) é uma figura ilustrativa e suas medidas não correspondem às medidas reais.

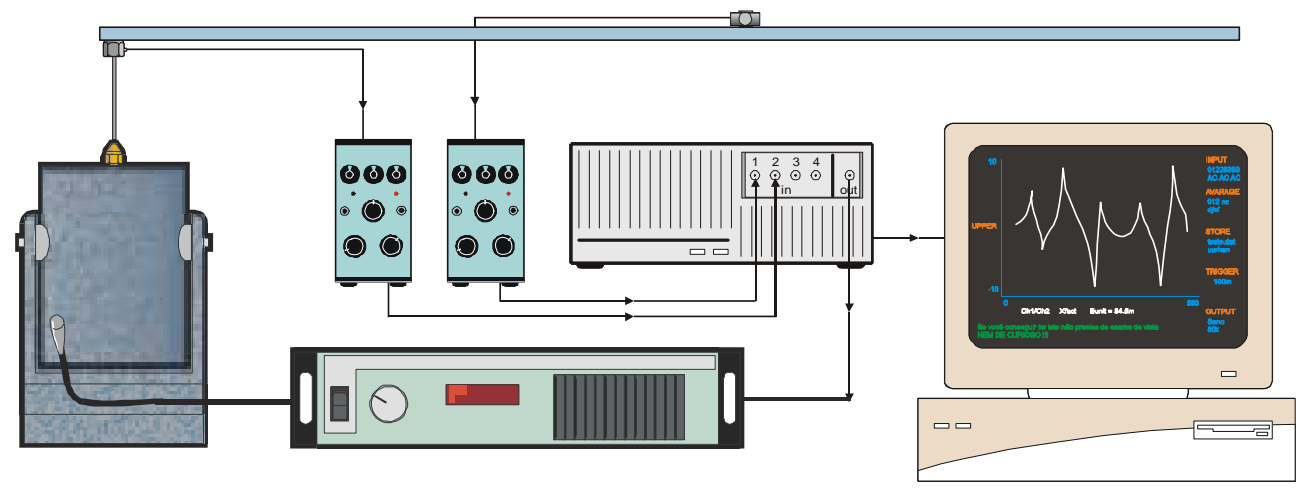

FIGURA 5.10 Aparato Experimental do Acelerômetro Angular

A medida foi feita no ponto localizado na extremidade da viga e coincide com o ponto de excitação. A FRF angular/linear de ponto esta apresentada na Figura (5.11). Pode se perceber que a curva de FRF obtida através do acelerômetro angular apresenta modo de 
corpo rígido introduzido pela suspensão. A curva experimental apresenta boa relação com a curva teórica para a primeira freqüência natural, porém pelo fato do acelerômetro angular ser robusto e apresentar uma massa de $18,5 \mathrm{~g}$, ele também introduziu na estrutura carregamento de massa observado nas freqüências mais altas.

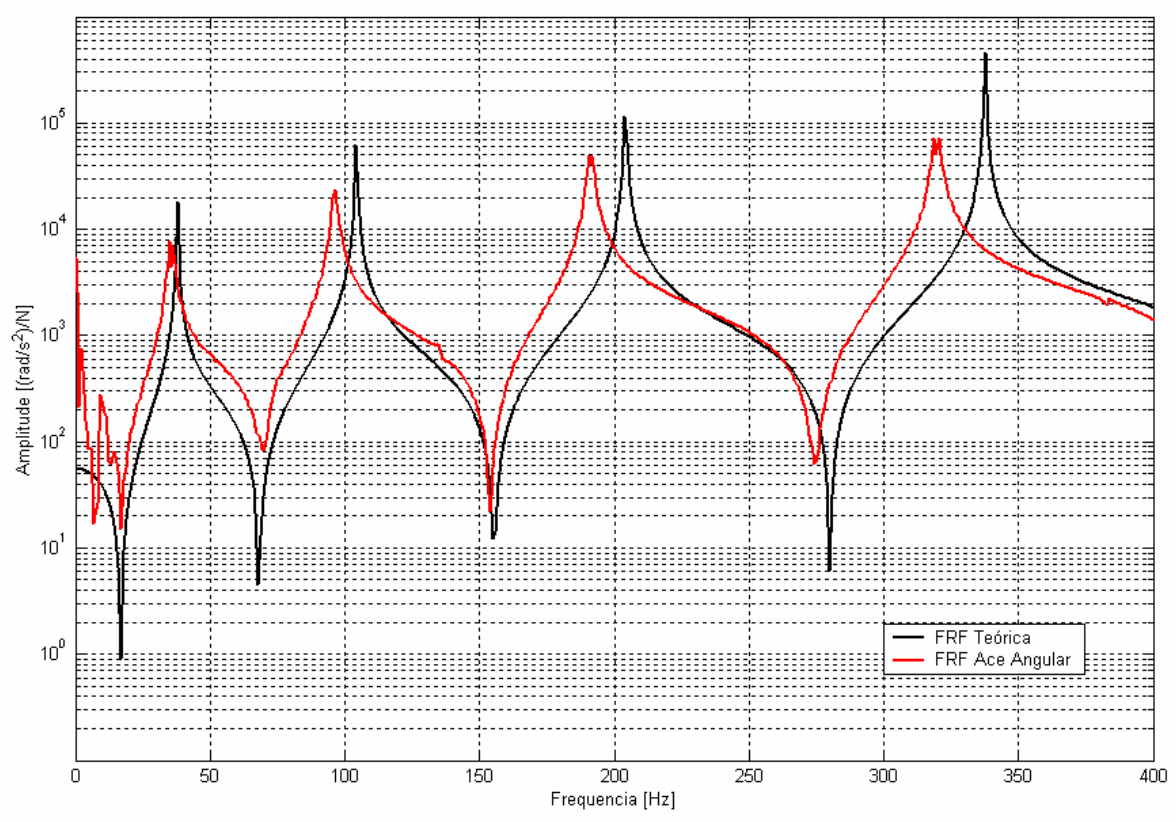

FIGURA 5.11 FRF de ponto do Acelerômetro Angular e do modelo Teórico

A relação entre as curvas de FRFs angular/linear obtidas pelas técnicas de Bloco T e acelerômetro angular está apresentada na Figura (5.12) 


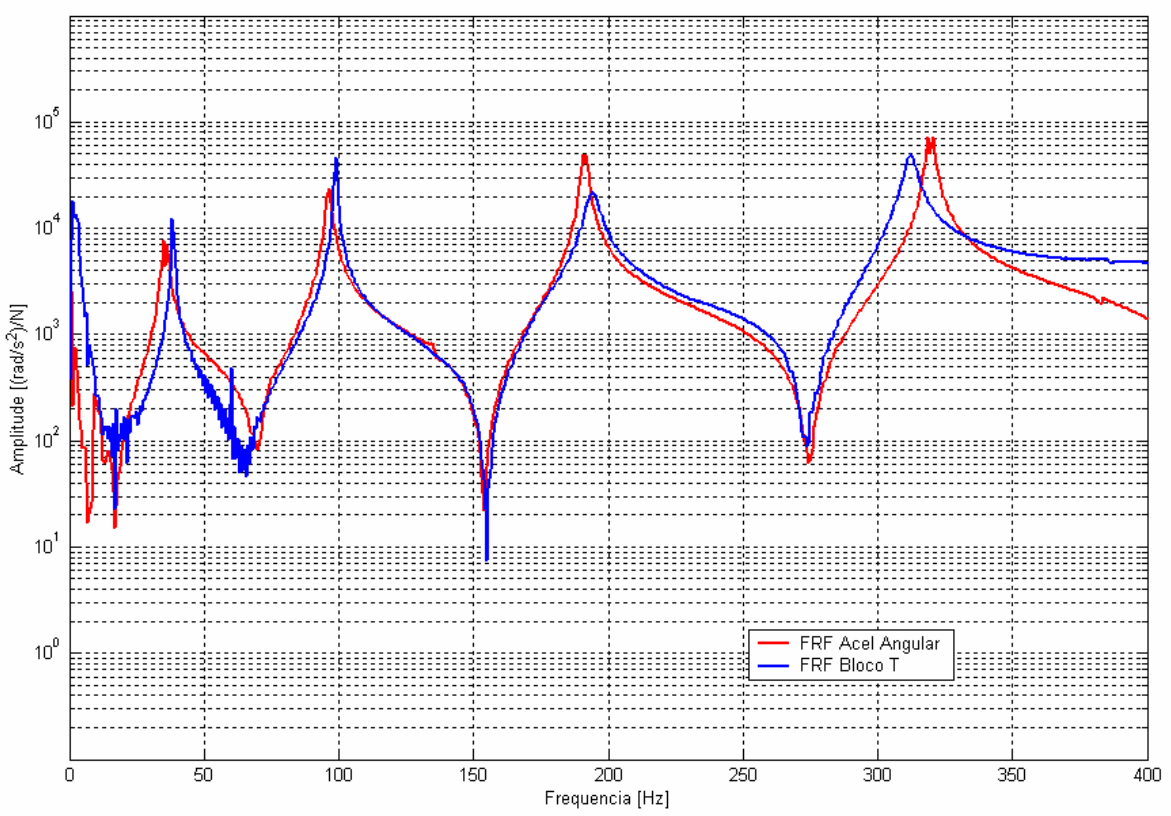

FIGURA 5.12 FRF de ponto do Acelerômetro Angular e do Bloco T

Para a curva da Figura (5.12) pode-se perceber que a relação entra as curvas experimentais obtidas via técnica do bloco $\mathrm{T}$ e via acelerômetro angular apresentaram boa correlação não apenas para a primeira freqüência natural, mas também para as outras freqüências naturais apresentando apenas um desvio na ultima freqüência natural apresentada na faixa de frequiência estudada. Este fato ocorre por ser duas técnicas distintas na maneira de obtenção, ou seja, a técnica de medida com bloco T é uma técnica indireta onde, a partir de medidas de aceleração linear se obtém acelerações angulares passando por cálculos matemáticos, o que não ocorre com técnicas de medidas diretas como é o caso do acelerômetro angular piezelétrico. 


\subsection{Resultados Experimentais Obtidos com a Técnica de Diferenças}

\section{Finitas de $1^{\text {a }}$ Ordem}

Foi realizado um ensaio experimental com o objetivo de aplicar a técnica das diferenças finitas de $1^{\mathrm{a}}$ ordem. A Figura (5.13) esquematiza o aparato experimental. A viga está suspensa por fios muito finos que simulam a condição livre-livre, análogo aos experimentos anteriores. A excitação é feita via excitador eletrodinâmico o qual esta na extremidade da estrutura no ponto indicado, e neste mesmo ponto se encontram os acelerômetros que são necessários para a aplicação da técnica das diferenças finitas. Para essa técnica medem-se as FRFs de ponto e de transferência para os dois acelerômetros usados. Como sinal de excitação foi utilizado um sinal aleatório, pois este excita todas as freqüências. A banda de freqüência desejável no presente estudo é de 0 a $400 \mathrm{~Hz}$, pois nesta faixa já se observa o comportamento da estrutura com as primeiras freqüências naturais. Os sinais gerados pelos acelerômetros lineares conectados na estrutura são processados matematicamente via cálculos apresentados no capítulo 3 na seção 3.3 , e então se obtém todas as FRFs da estrutura onde as relações saída entrada são: linear/linear, angular/linear, linear/angular e angular/angular.

Vale lembrar que a Figura (5.13) é uma figura esquematizada do aparato experimental, onde os equipamentos utilizados e a estrutura sob teste não estão em escala. 


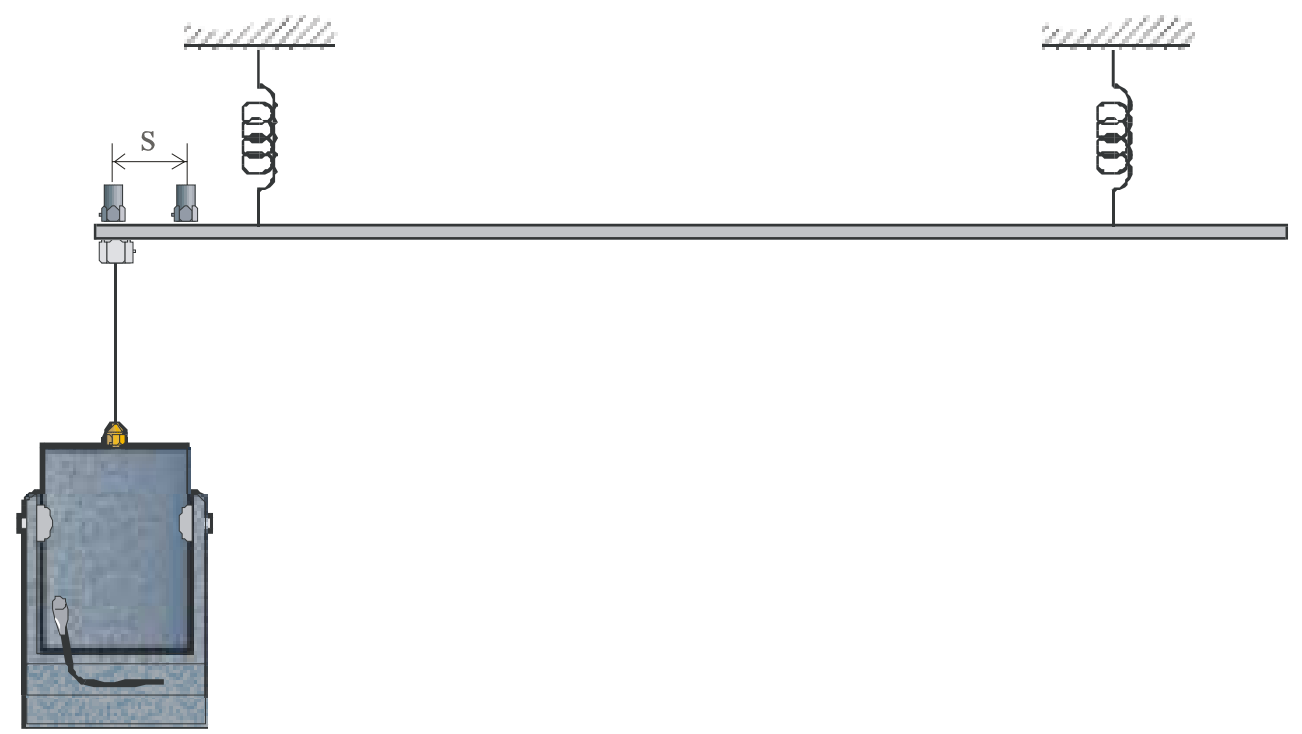

FIGURA 5.13 Aparato Experimental para a Técnica de Diferenças Finitas de $1^{\text {a }}$ Ordem

No aparato experimental, para este caso, o analisador espectral foi substituído por uma analisador Espectral - Agilent VXI 16 canais, os acelerômetros usados para este caso foram os acelerômetros PCB Piezotronics modelo 333B um com sensibilidade de 92,5 $\mathrm{mV} / \mathrm{g}$ e o outro com sensibilidade de $93,8 \mathrm{mV} / \mathrm{g}$, os dois com massa de $5,2 \mathrm{~g}$ e um computador equipado com o software de aquisição e processamento de Análise Modal IDEAS $^{\circledR}$ Test, conectado a um sistema de aquisição de 16 canais Agilent VXI.

Foi utilizada a mesma estrutura dos ensaios anteriores. $\mathrm{O}$ espaçamento entre os acelerômetros foi tomado com sendo de 5\% do comprimento total da estrutura, ou seja, $45 \mathrm{~mm}$.

Na Figura (5.14), estão mostrados os resultados obtidos com a técnica de diferenças finitas de $1^{\mathrm{a}}$ ordem. 


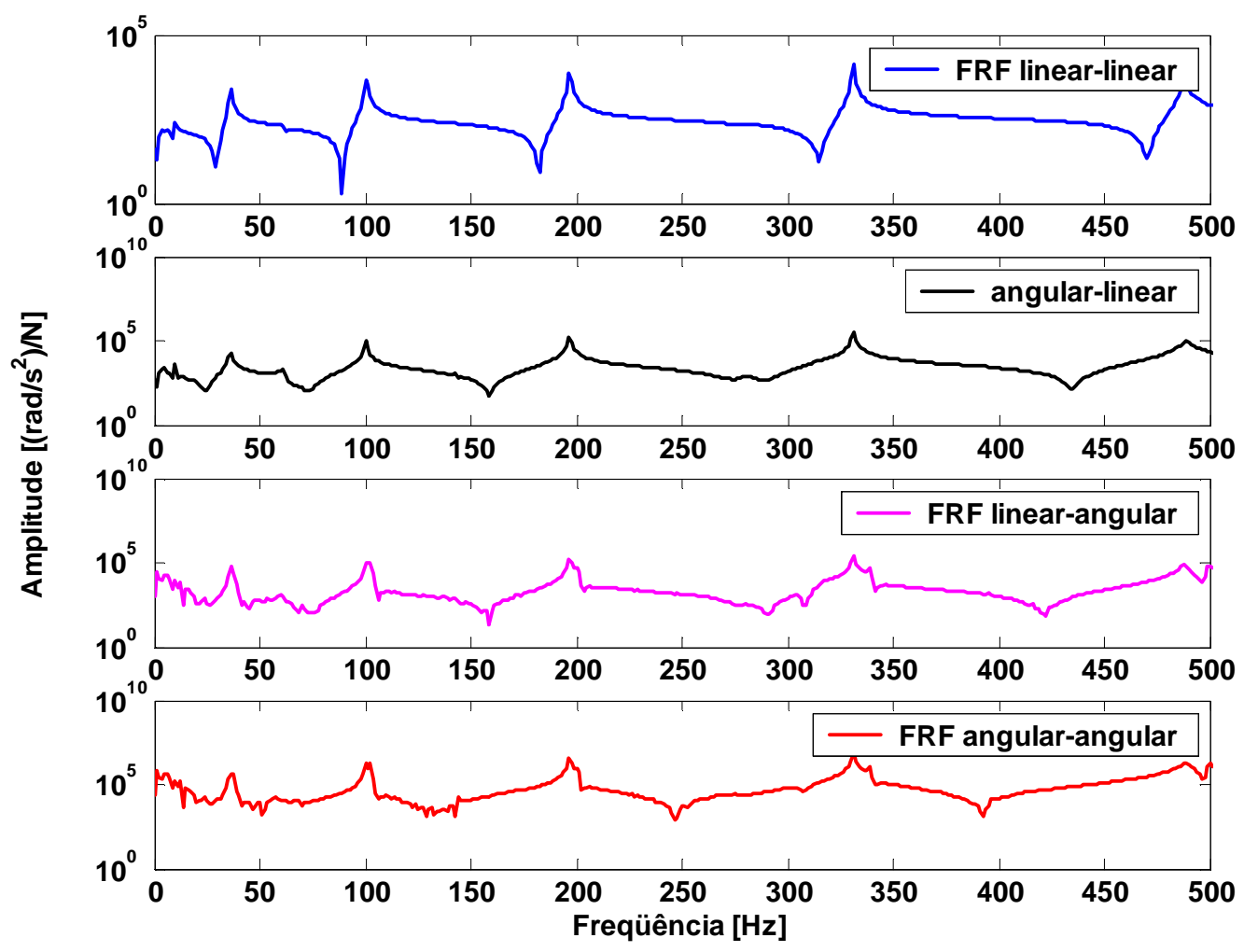

FIGURA 5.14 Resultados das FRFs com todos os Graus de Liberdade via Diferenças Finitas $1^{\mathrm{a}}$ Ordem

Pode se notar que para os dois primeiros casos onde se tem a relação saída entrada como sendo linear/linear e angular/linear, as curvas de FRFs são mais bem definidas do que para os dois últimos casos, principalmente para o caso angular/angular. $\mathrm{O}$ uso de medidas diretas de FRFs envolvendo apenas graus de liberdade de translação para se obter as medidas de FRF envolvendo graus de liberdade angulares normalmente carregam erros adicionais nas medidas. Isto é devido a formulação empregada para se obter essas FRFs, na qual subtraem-se as quantidades medidas e estimam-se as quantidades angulares, como pode ser visto no capítulo 3 seção 3.3. Assim, pequenos erros nos dados medidos podem 
resultar em grandes erros nas curvas de FRFs estimadas. Segundo DUARTE (1996), estes erros tendem a diminuir conforme as freqüências aumentam.

A FRF em questão neste trabalho possui a relação saída entrada como sendo os graus de liberdade angular e linear respectivamente. A Figura (5.15) mostra as curvas de FRF obtida via técnica de diferenças finitas de $1^{\text {a }}$ ordem e obtida via modelo teórico da viga de Euler - Bernoulli.

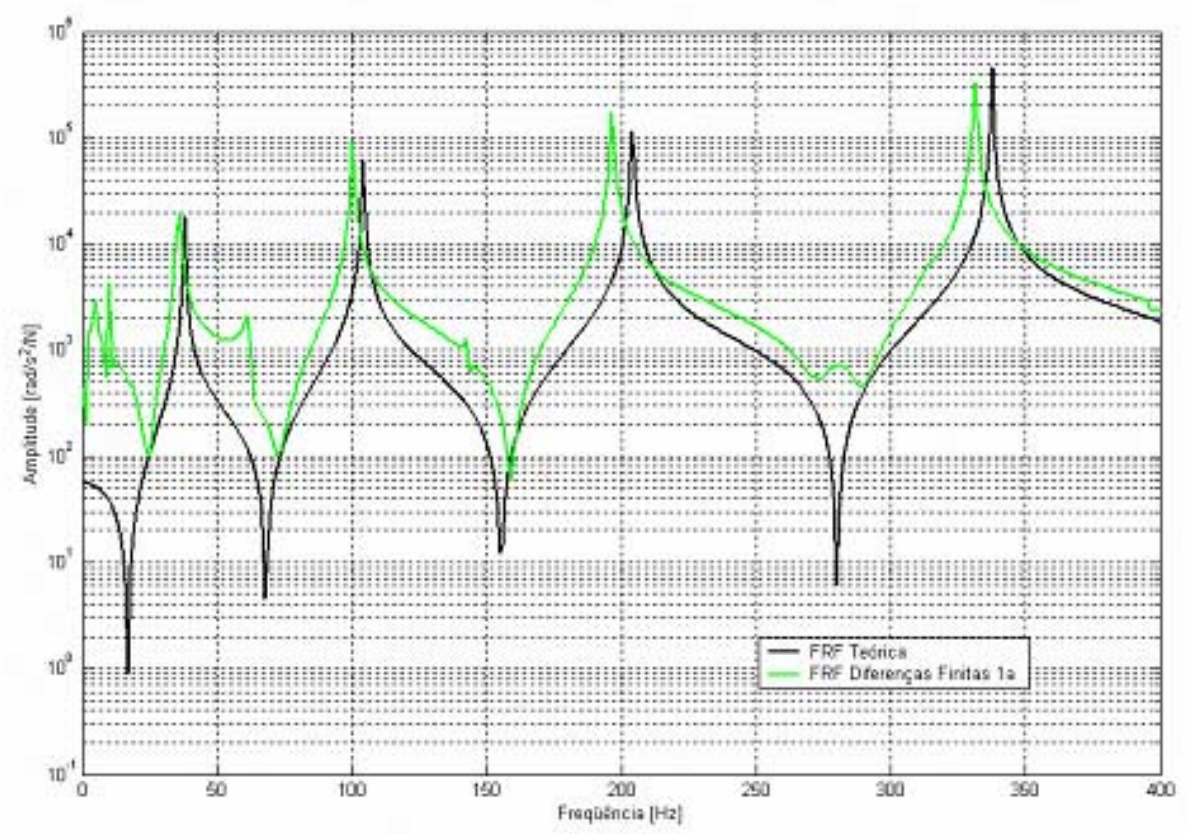

FIGURA 5.15 FRF diferenças finitas $1^{\mathrm{a}}$ ordem e modelo teórico

Pode se perceber que a curva da Figura (5.15) apresenta ruído na faixa de freqüência abaixo de $25 \mathrm{~Hz}$, esse ruído se deve ao modo de corpo rígido. As curvas apresentam boa relação entre as freqüências naturais, porém ainda apresenta o problema de um desvio nas vizinhanças das freqüências naturais na faixa de freqüência de 100 a $400 \mathrm{~Hz}$. Nota-se que, 
para a aplicação da técnica de diferenças finitas de $1^{\mathrm{a}}$ ordem é necessário o uso de dois acelerômetros de medidas de aceleração linear, podendo assim estar contaminando as medidas com o carregamento de massa desses acelerômetros. Outro fator que é válido lembrar é que todas as medidas de FRFs para a técnica de diferenças finitas de $1^{\mathrm{a}}$ ordem passam por um processo de manipulação matemática onde são subtraídas curvas de FRFs.

Na Figura (5.16) mostra a comparação entre os resultados obtidos via diferenças finitas $1^{a}$ ordem com os obtidos via acelerômetro angular.

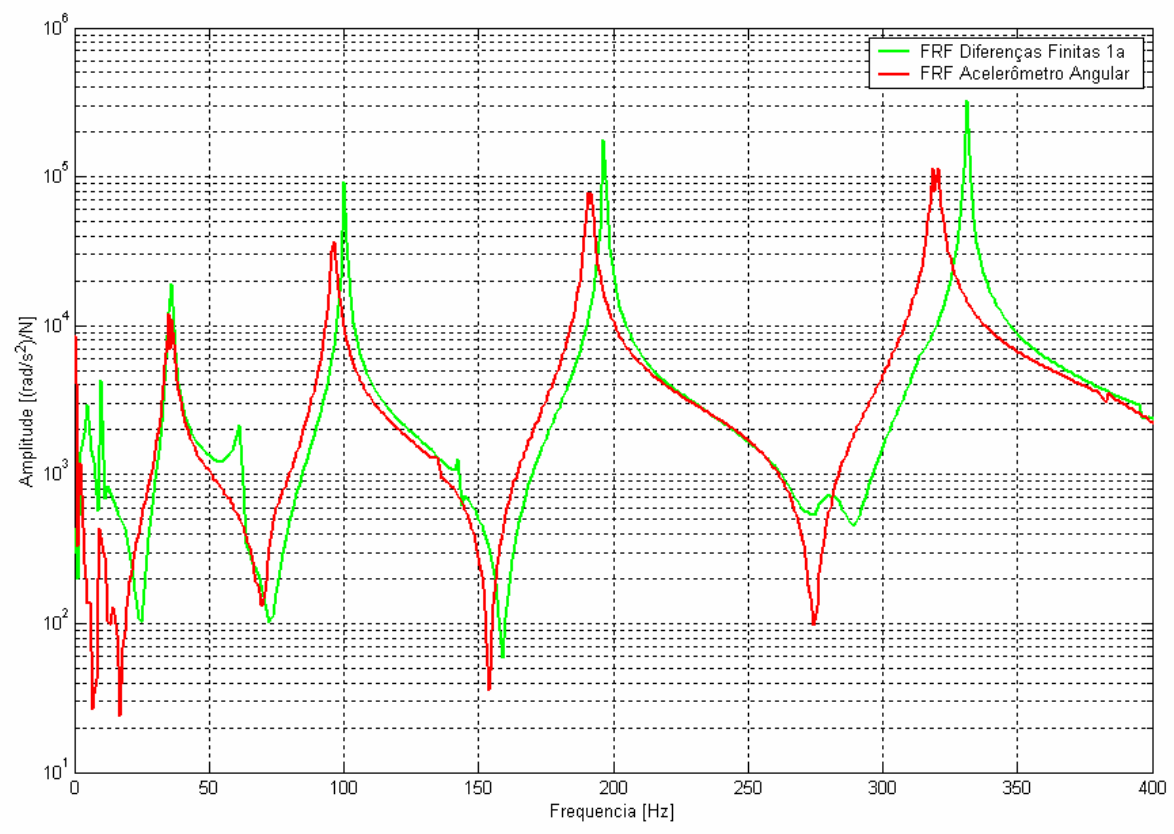

FIGURA 5.16 Comparação dos resultados obtidos via diferenças finitas e Acelerômetro

Angular

Nota-se pela Figura (5.16) que as curvas experimentais obtidas via diferenças finitas de $1^{\text {a }}$ ordem e com acelerômetro angular apresentam uma boa relação. A diferença entre os 
picos de ressonância para as frequiências mais altas que $200 \mathrm{~Hz}$ deve-se ao fato da FRF via diferenças finitas ser derivada de um conjunto de FRFs linear/linear.

Na Figura (5.17) a técnica em questão foi confrontada com a técnica do Bloco T desenvolvida anteriormente neste trabalho.

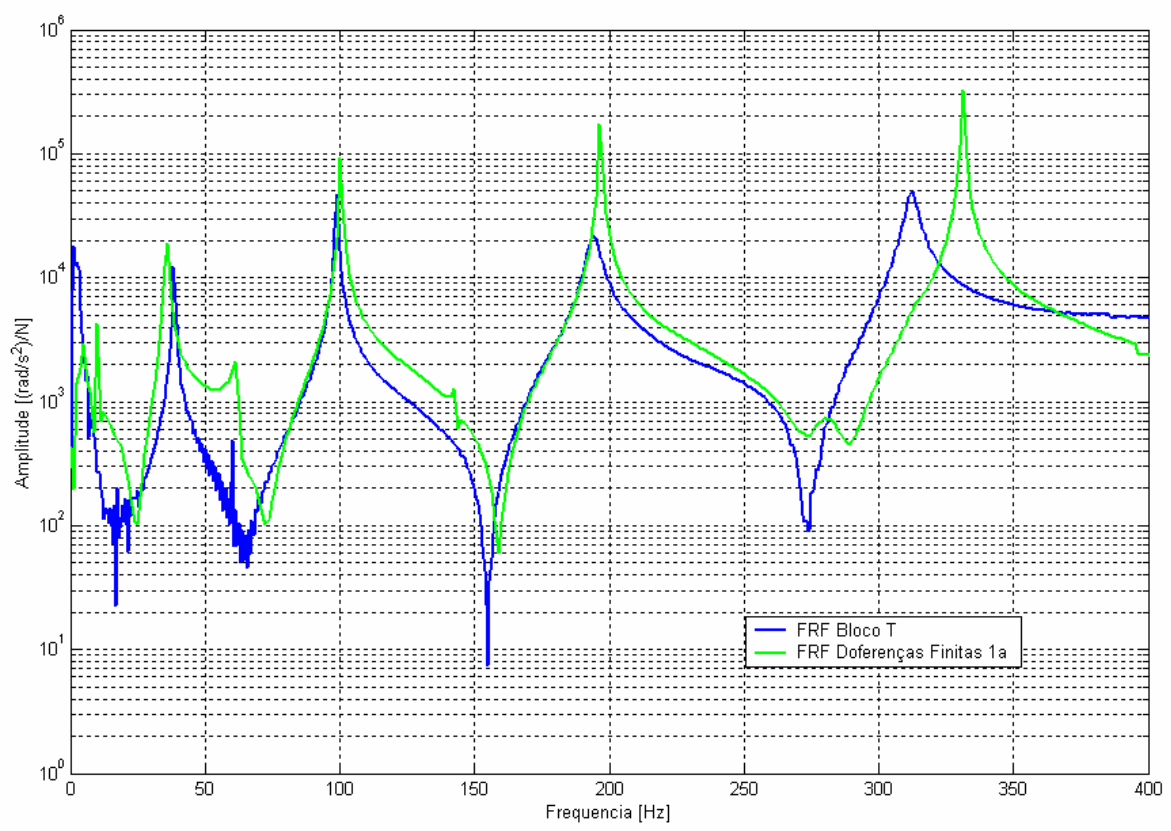

FIGURA 5.17 Comparação dos resultados obtidos via Diferenças Finitas e BlocoT.

Esses resultados apresentaram uma boa comparação para as freqüências naturais. Percebe-se que os picos de ressonância possuem uma boa relação entre as curvas. Porém para as freqüências mais altas, ou seja as freqüências acima de $300 \mathrm{~Hz}$ começam a sofrer um pequeno desvio. 


\subsection{Resultados Experimentais Obtidos com a Técnica de Diferenças}

\section{Finitas $2^{\text {a }}$ Ordem}

Para se aplicar à técnica de diferenças finitas de $2^{\mathrm{a}}$ ordem foi realizado um ensaio experimental esquematizado na Figura (5.18). A excitação é feita via excitador eletrodinâmico o qual esta na extremidade da estrutura no ponto indicado, e neste mesmo ponto se encontram os acelerômetros que são necessários para a aplicação da técnica das diferenças finitas, para essa técnica se utiliza três acelerômetros lineares idênticos. Como sinal de excitação foi utilizado um sinal aleatório, pois este excita todas as freqüências. A banda de frequiência desejável no presente estudo é de 0 a $400 \mathrm{~Hz}$, pois nesta faixa já se observa o comportamento da estrutura com as primeiras freqüências naturais. Os sinais gerados pelos acelerômetros lineares conectados na estrutura são processados matematicamente via cálculos apresentados no capítulo 3 na seção 3.2, e então se obtém todas as FRFs da estrutura onde as relações entrada saída são: linear/linear, linear/angular, angular/linear e angular/angular.

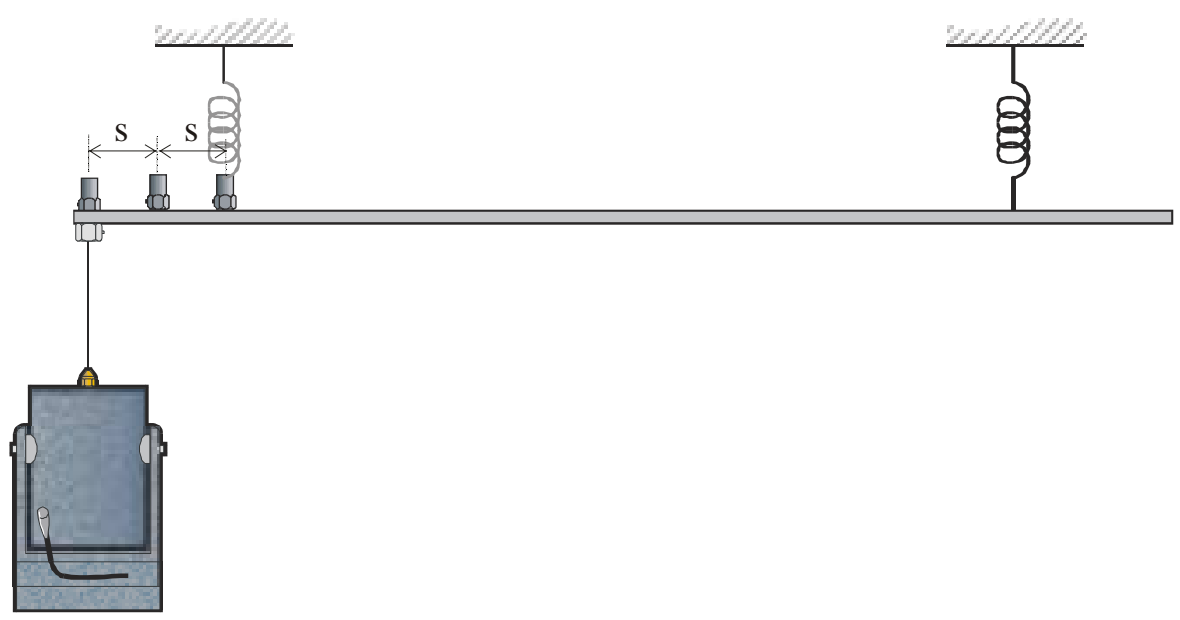

FIGURA 5.18 Aparato Experimental para a Técnica de Diferenças Finitas de $2^{\mathrm{a}}$ Ordem 
O aparato experimental, para este caso, é o mesmo do usado para as diferenças finitas de $1^{\mathrm{a}}$ ordem.

Foi utilizada a mesma estrutura dos ensaios anteriores. $\mathrm{O}$ espaçamento entre os acelerômetros foi tomado com sendo de 5\% do comprimento total da estrutura, ou seja, $45 \mathrm{~mm}$.

A Figura (5.19) apresenta o conjunto de FRFs para todos os graus de liberdade.

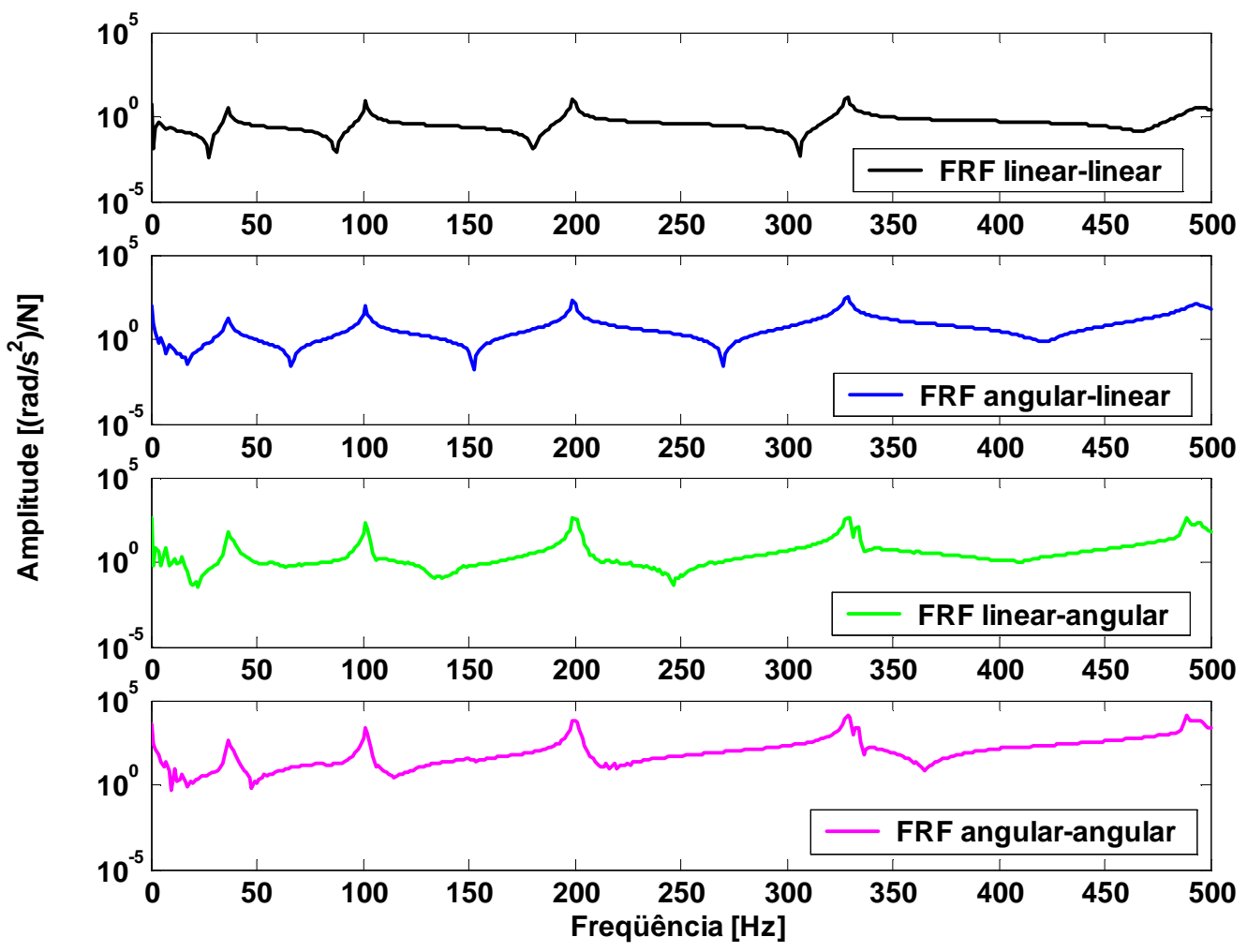

FIGURA 5.19 FRFs Obtidas via técnica Diferenças Finitas 2ª Ordem

Nota-se pela Figura (5.19) notar se que para os dois primeiros casos onde se tem a relação linear/linear e angular/linear as curvas são mais bem definidas. Para os outros dois 
casos onde as relações saída entrada são linear/angular e angular/angular as FRFs apresentam algumas quebras nas curvas. Isto se deve ao método de derivar entradas angulares a partir de FRF puramente lineares.

A Figura (5.20) apresenta a comparação com essa curva obtida com o presente método sendo confrontada com a curva teórica obtida via modelo contínuo da viga de Euler - Bernoulli.

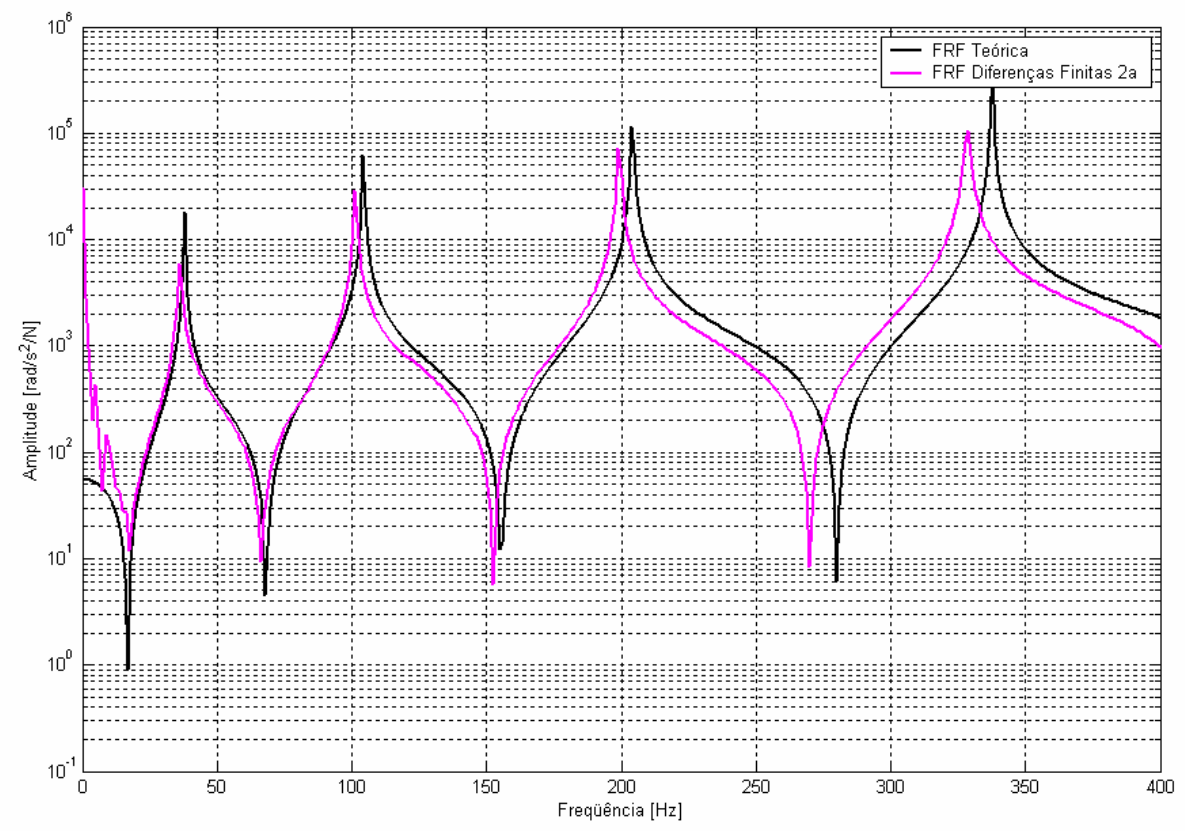

FIGURA 5.20 FRF Diferenças Finitas 2a Ordem e FRF Modelo Teórico

Nota se que Figura (5.20) apresenta uma ótima relação entre as curvas em questão. Os picos de ressonância e anti-ressonância coincidem quase que perfeitamente. As freqüências altas ainda apresentam um desvio nos picos devido à forma de obtenção via cálculos 
matemáticos para o método das diferenças finitas, porém esses desvios são menores que os apresentados nas confrontações anteriores.

A Figura (5.21) mostra as curvas de diferenças finitas de $2^{\mathrm{a}}$ ordem e a de $1^{\mathrm{a}}$ ordem. Nota-se que a curva de diferenças finitas de $2^{\mathrm{a}}$ ordem apresenta melhor comportamento quando comparada com a curva de diferenças finitas $1^{\mathrm{a}}$ ordem. Isto se deve ao fato de que a técnica de diferenças finitas de $2^{\mathrm{a}}$ ordem ser mais precisa que a de $1^{\mathrm{a}}$ ordem.

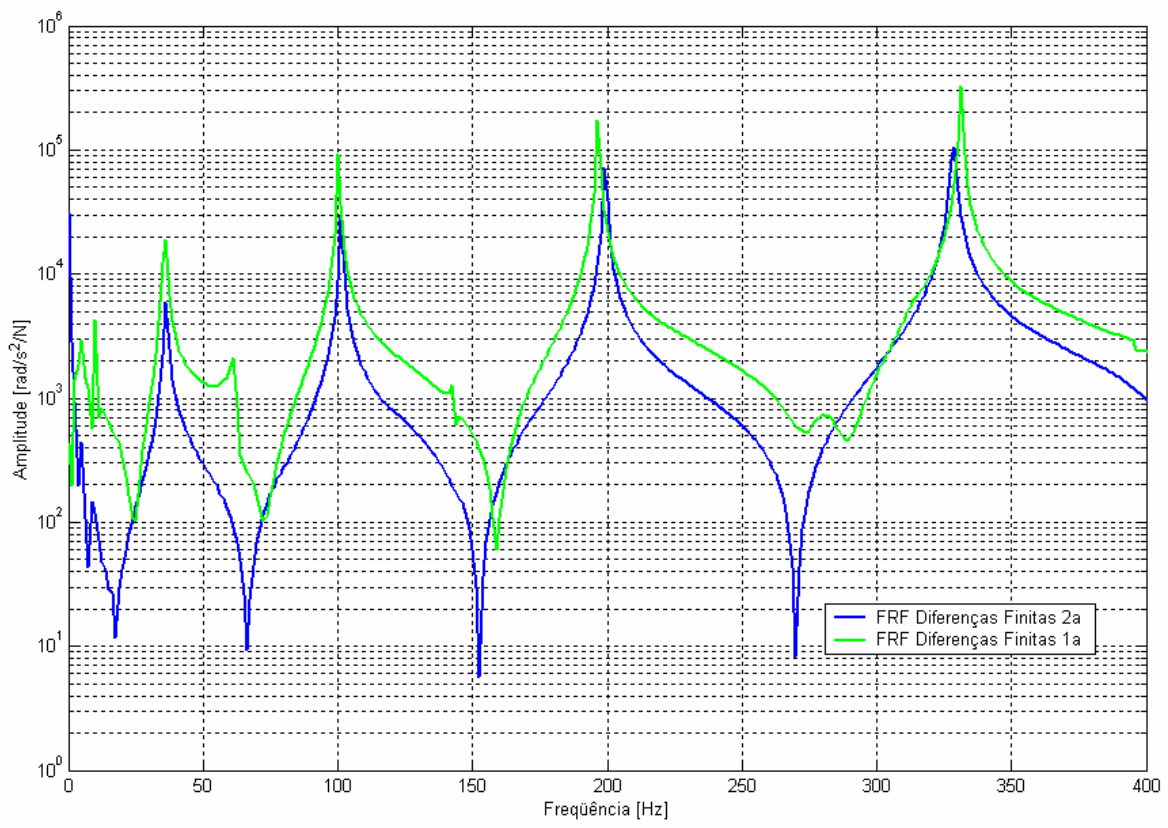

FIGURA 5.21 FRF das Diferenças Finitas de $1^{\mathrm{a}}$ e $2^{\mathrm{a}}$ ordem

A Figura (5.22) traz a confrontação da técnica de diferenças finitas de $2^{\mathrm{a}}$ ordem com acelerômetro angular. 


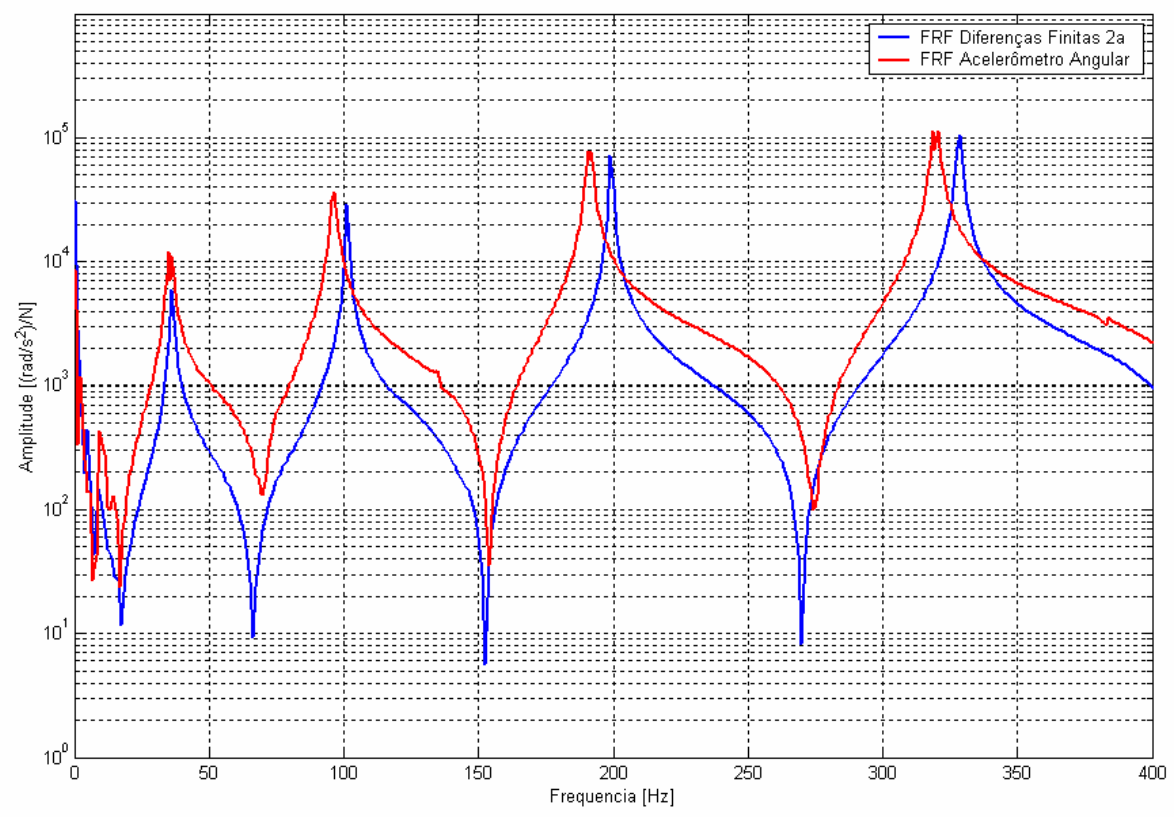

FIGURA 5.22 FRF Diferenças Finitas 2a ordem e FRF Acelerômetro Angular

Nota-se na Figura (5.22) que há uma boa relação entre as curvas para a primeira freqüência natural havendo depois dela um desvio entre as curvas. Vale lembrar que o acelerômetro angular é uma medida direta de aceleração angular enquanto que a técnica de diferenças finitas de $2^{\mathrm{a}}$ ordem usa de curvas de FRFs lineares e manipulação algébrica para se obter as curvas de FRF angular/linear tendo assim sempre o erro de aproximação pelo cálculo.

Na Figura (5.23) tem-se as curvas de FRF obtidas via diferenças finitas e bloco T 


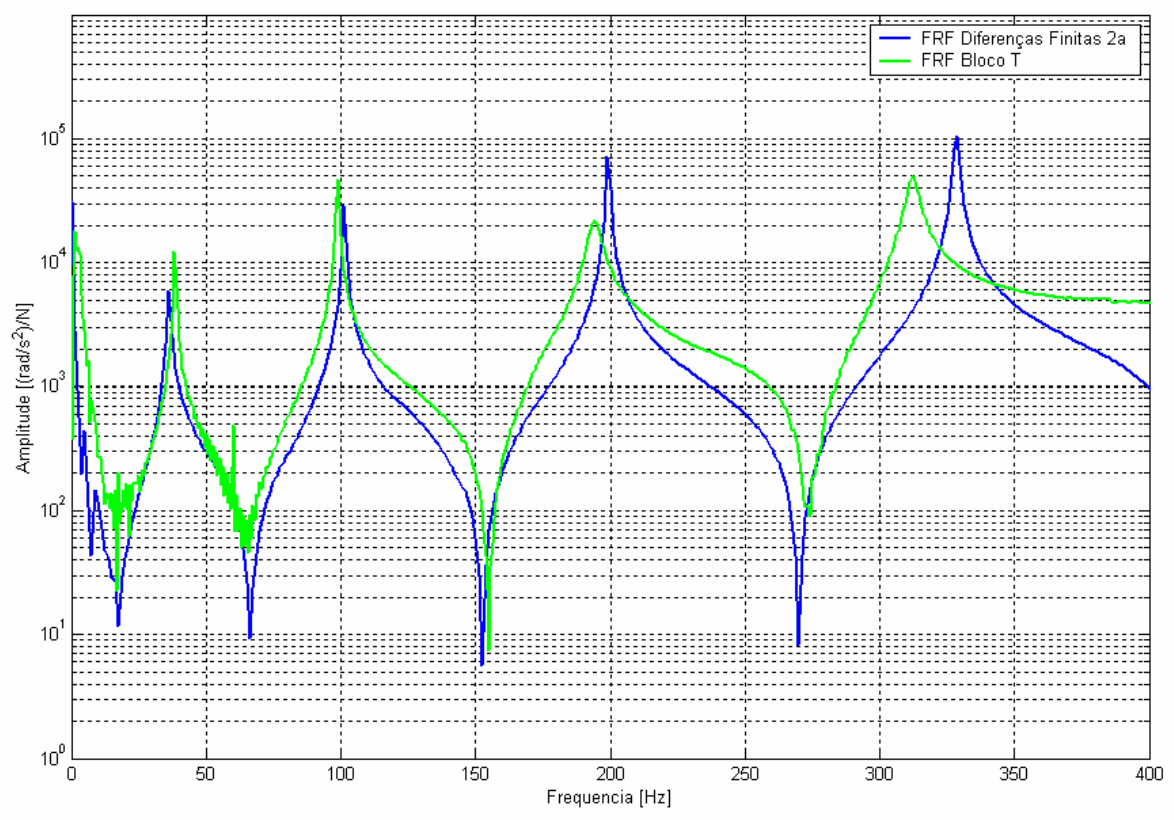

FIGURA 5.23 FRF Diferenças Finitas 2a Ordem e FRF Bloco T

As curvas da Figura (5.23) apresentam-se uma boa relação entre os picos de freqüências naturas até para o segundo modo. Já para as freqüências naturais mais altas, começando de $200 \mathrm{~Hz}$ se observa um desvio entre os picos de ressonância e antiressonância. Vale ressaltar que os dois métodos são indiretos, ou seja, as curvas de FRFs angulares/lineares são obtidas a partir de outras curvas passando por um procedimento matemático. Para a técnica do Bloco T é usado o sinal de aceleração no domínio do tempo dos dois acelerômetros usado, já para a técnica de diferenças finitas o número de acelerômetros aumenta de dois para três e o sinal usado para se derivas as curvas de FRFs angulares/lineares são as próprias FRFs puramente lineares. Vale ainda ressaltar que para a técnica de diferenças finitas não é usado nenhum tipo de bloco adicional assim o único carregamento na estrutura é as massas dos acelerômetros. 
Com o intuito de melhor visualização a TABELA (5.2) apresenta as freqüências naturais obtidas pelas técnicas estudadas nesta dissertação:

TABELA 5.2 Comparação das Freqüências Naturais das Técnicas Analisadas

\begin{tabular}{ccccccc}
\hline $\begin{array}{c}\text { Freq. } \\
\text { Naturais } \\
{[\mathbf{H z}]}\end{array}$ & $\begin{array}{c}\text { Modelo } \\
\text { Teórico }\end{array}$ & $\begin{array}{c}\text { Elementos } \\
\text { Finitos }\end{array}$ & Bloco T & $\begin{array}{c}\text { Acel } \\
\text { Angular }\end{array}$ & $\begin{array}{c}\text { Diferenças } \\
\text { Finitas 1 }^{\mathbf{a}} \\
\text { Ordem }\end{array}$ & $\begin{array}{c}\text { Diferenças } \\
\text { Finitas 2 }^{\mathbf{a}} \\
\text { Ordem }\end{array}$ \\
\hline \hline $1^{\mathrm{a}}$ & 37,82 & 38,10 & 38,12 & 36,25 & 36,25 & 36,25 \\
\hline $2^{\mathrm{a}}$ & 104,25 & 104,99 & 98,75 & 96,25 & 100,00 & 101,25 \\
\hline $3^{\mathrm{a}}$ & 204,35 & 205,84 & 193,75 & 192,50 & 196,25 & 198,75 \\
\hline $4^{\mathrm{a}}$ & 337,81 & 340,25 & 311,88 & 320,65 & 331,25 & 328,75 \\
\hline
\end{tabular}

Neste capítulo pode ser visto os principais resultados obtidos com as técnicas de medidas de aceleração angular sugeridas para este trabalho. Foram discutidos e analisados os resultados das duas técnicas indiretas de determinação de acelerações angulares, sendo a primeira delas a técnica do Bloco $\mathrm{T}$ e, a segunda sendo baseada num procedimento de diferenças finitas de primeira e segunda ordem. Também serão analisados os resultados obtidos com o sensor piezelétrico para medidas diretas de acelerações angulares. Os resultados de todas as técnicas foram confrontados entre si e com os resultados teórico discorrido no capítulo 2. Foram feitas considerações importantes sobre a escolha da geometria do Bloco $\mathrm{T}$ onde se comprovou que dependendo do lugar onde se deseja obter as acelerações angulares a geometria do bloco pode interferir na medida contaminando-a com ruídos. Ainda foi feito um teste sobre a importância de uma correta fixação do Bloco T na estrutura sob teste onde se viu que a má fixação do bloco na estrutura pode contaminar as 
medidas com freqüências naturais fantasmas, ou seja, freqüências naturais não são próprias da estrutura. Este teste comprova duas hipóteses básicas para a utilização da técnica do bloco $\mathrm{T}$, a primeira é que o bloco tem que se comportar como corpo rígido dentro da faixa de frequiência que se esta trabalhando e a segunda hipótese é que o bloco $\mathrm{T}$ não deve influenciar a dinâmica da estrutura introduzindo freqüências naturais que não são próprias dela.

O próximo capítulo conclui o trabalho realizado, com algumas considerações e ainda apresenta propostas de complementação do trabalho como sugestões de trabalhos futuros. 


\section{Capítulo 6}

\section{CONCLUSÃO E TRABALHOS FUTUROS}

Neste capítulo se encerra o trabalho discorrendo as conclusões das aplicações das técnicas para a estimativa de acelerações angulares a partir de dados experimentais aqui relatadas. Foram feitas confrontações entre os resultados dessas técnicas. Lembrando que foram usadas duas técnicas indiretas de determinação de acelerações angulares, sendo que a primeira delas utiliza um dispositivo conhecido como Bloco $\mathrm{T}$ e a segunda sendo baseada num procedimento de diferenças finitas. Foi utilizado também sensor piezelétrico para medidas diretas de acelerações angulares. Todos os resultados desses procedimentos foram confrontados com o modelo contínuo da viga de Euler - Bernoulli. Considerações importantes sobre a fixação do bloco $\mathrm{T}$ na estrutura e a escolha de uma geometria adequada para os ensaios são Algumas sugestões de continuação desse trabalho são sugeridas como trabalhos futuros. 


\section{Conclusão e Trabalhos Futuros}

Este trabalho foi dirigido ao estudo e validação de técnicas experimentais para a obtenção de FRF angular/linear. Para verificar o bom desempenho das técnicas estudadas foi desenvolvido um modelo teórico levando em consideração as grandezas de interesse neste trabalho, grandezas angulares.

A primeira técnica testada foi à técnica do bloco $T$. Esta técnica utiliza acelerômetros lineares para a obtenção de acelerações angulares. Deve-se ressaltar que a técnica em questão é uma técnica indireta de obtenção de FRF angular/linear, ou seja, se deriva grandeza angular a partir de grandezas lineares. Foram testadas várias configurações de blocos $\mathrm{T}$ para se ter uma idéia de qual dos tamanhos se adequaria para que se obtivesse o melhor resultado para as medidas propostas. Embora não de disponha de um critério rigoroso para escolher o bloco $\mathrm{T}$ mais adequado para os demais experimentos (por exemplo baseado em níveis de ruído, sensibilidade do bloco $\mathrm{T}$, etc) procurou-se escolher o bloco cujo resultado fosse o mais limpo em termos de prováveis distorções em termos de amplitudes. Verificou-se que para as FRFs angulares/lineares cujo ponto de excitação e de medida são os mesmos, os blocos que apresentaram melhores resultado foram aqueles que possui o maior comprimento de braço, isto porque a sensibilidade do bloco $\mathrm{T}$ é dependente do comprimento do seu braço, pois este determina a quantidade de rotação que o bloco esta sentindo a partir dos sinais medidos pelos acelerômetros lineares. Entretanto, quando se aumenta o comprimento do braço do bloco T, aumenta-se também sua massa, possibilitando a introdução de outros problemas na medida. Para iniciar as medidas com os blocos T fez-se um teste sobre o modo de fixação do bloco $\mathrm{T}$ na estrutura sob teste e para isto se deve uma atenção especial, pois este pode introduzir erros significantes ao resultado. Depois de se escolher 
o melhor bloco e a forma mais eficiente de fixação iniciam-se os ensaios experimentais com a técnica. Os resultados foram confrontados com a curva de FRF angular/linear obtida via modelo teórico. Nessa confrontação os resultados do bloco T apresentaram um desvio nos picos de freqüências naturais mais altas que $100 \mathrm{~Hz}$, apresentando assim uma boa relação apenas com a primeira frequiência natural. Uma possível explicação para esse desvio nos picos de ressonância entre as duas curvas em questão é o fato de que as medidas feitas com o bloco T carregam a estrutura com uma massa adicional que corresponde a massa do sistema (bloco T mais os dois acelerômetros lineares) assim pode estar carregando a estrutura com o problema de carregamento de massa.

A segunda técnica estudada, é a técnica que usa acelerômetro angular piezelétrico. Essa técnica possibilita a medida direta de grandezas angulares. A curva obtida com essa técnica foi confrontada com o modelo teórico da estrutura e com a técnica previamente discorrida. Para a primeira confrontação verificou-se que as curvas sofreram um desvio nos picos de ressonância. Aqui vale lembrar que o acelerômetro angular é robusto. Esses desvios podem ter acontecido pelo mesmo motivo do desvio ocorrido com a técnica de bloco T, ou seja, pelo carregamento de massa imposto pelo uso do acelerômetro angular. A segundo confrontação que foi com a curva obtida com a técnica do bloco T, para essa comparação se obteve uma boa relação.

Para a terceira técnica estudada, técnica de diferenças finitas de $1^{\text {a }}$ ordem, as curvas de confrontação, além da curva obtida de maneira analítica, foram as curvas dos dois ensaios experimentais anteriormente discutidos. Vale lembrar que as curvas para a técnica em questão são obtidas de maneira indireta. Para a primeira avaliação da técnica que é feita ao comparar os resultados da técnica de diferenças finitas de $1^{\mathrm{a}}$ ordem com a curva do modelo teórico observou-se que há um desvio entre elas porém este desvio é menor se comparado com a curva do modelo teórico em relação às curvas do bloco $\mathrm{T}$ e 
do acelerômetro angular, ou seja, a técnica de diferenças finitas de $1^{\text {a }}$ ordem se aproxima de melhor forma do modelo teórico. Além disso, quando a curva da FRF obtida via diferenças finitas de $1^{\mathrm{a}}$ ordem é avaliada em relação às curvas obtidas via acelerômetro angular e via bloco $\mathrm{T}$ ainda apresenta desvio entre os picos de frequiências naturais mas estes são menores.

A última técnica desenvolvida é a técnica de diferenças finitas $2^{\mathrm{a}}$ ordem. Esta é uma técnica de obtenção de FRFs angulares/lineares indireta. A confrontação dessa técnica foi feita com as curvas já obtidas e pode-se observar que esta técnica é a que apresenta melhor relação com a FRF angular/linear obtida pelo modelo teórico podendo ver que a curva se encaixa perfeitamente até para as anti-ressonâncias. Assim pode-se concluir que a técnica de diferenças finitas de $2^{\mathrm{a}}$ ordem é a técnica que melhor se aproxima do modelo teórico. Além disso a técnica de diferenças finitas de $2^{\mathrm{a}}$ ordem apresenta uma boa relação com as curvas das outras técnicas apresentando pouco desvio com os picos de ressonância. Sendo assim esta é a técnica que apresentou melhor desempenho.

\section{Trabalhos Futuros}

A escolha da geometria do bloco $\mathrm{T}$ é um tema interessante para um futuro trabalho, pois para um melhor desempenho dessa técnica seria ideal que o bloco $\mathrm{T}$ possuísse braços bem compridos, pois este determina a quantidade de rotação que o bloco esta sentindo a partir dos sinais medidos pelos acelerômetros lineares, porém quando maior for o braço do Bloco T, maior será sua massa e esta pode possibilitar a introdução de problemas de carregamento de massa na estrutura. 
É sugerido como trabalho futuro uma aplicação de algumas técnicas de cancelamento de massa e momento de inércia para eliminar possíveis erros introduzidos pelas técnicas de obtenção de grandezas angulares. Além dessa sugestão é possível aplicar as técnicas aqui relatadas em estruturas mais complexas.

Também são sugeridas aplicações das FRFs angulares / lineares, tais como em acoplamentos de estruturas, modificação estrutural, entre outras.

Nesta dissertação se tratou apenas de obtenção de aceleração angulares, ou seja, apenas a saída da FRF, é interessante como trabalho futuro um estudo detalhado de aplicação de grandezas angulares na entrada da FRF, ou seja, excitar a estrutura com um momento e obter a FRF cuja relação saída entrada seja puramente angular. 


\section{Capítulo 7}

\section{REFÊRENCIAS BIBLIOGRÁFICAS E}

\section{Bibliografia Consultada}

Este capítulo apresenta uma lista de toda as referências bibliográficas e bibliografias utilizadas para a confecção deste trabalho. As referências bibliográficas estão dispostas segundo as diretrizes e normas de publicações de dissertações e teses do ano de 2003 da Escola de Engenharia de São Carlos - Universidade de São Paulo. 


\section{Referências Bibliográficas e Bibliografia Consultada}

ANSYS User's Manual. Theory manual. 2000. ANSYS revision 6.0.

ASHORY, M. R. (1999). High Quality Modal Testing Methods. London. Tese (doutorado) - University of London, Imperial College of Science, Technology and Medicine.

BELLO, M., et al. (2000). Dynamic rotation Estimates using low cost PZT's. Proceedings of the International Seminar on Modal Analysis, ISMA25, Leuven, Belgica.

BREGANT, L., SANDERSON, M. (2000), Rotational Degree of Freedom: A historical Overview on Techniques and Methods. Proceedings of the International Seminar on Modal Analysis, ISMA25, Leuven, Belgica

CHAMPOUX, Y., et al.(2000). Moment mobility Measurement using an impact force couple. Proceedings of the International Seminar on Modal Analysis, ISMA25, Leuven,Belgica

CHEN, W. H., CHERNG, J. S. (1985). Modal Synthesis Via Combined Experimental and Finite Element Techniques With Consideration of Rotational Effects. Journal Of Sound and Vibration, 103(1), p 1-11.

CRAIG, R. R. (1981). Structural Dynamics: an introduction computer method. New York, Wiley.

DONG, J. e McCONNELL, K. G. (2002) Extracting Multi Directional FRF Matrices with Instrument Cluster. Proceedings of the $20^{\text {th }}$ International Modal Analysis Conference, IMAC, USA. 
DUARTE, M. L. M. (1996) Experimentally-Derived Structural Models for Use in Further Dynamic Analysis, London, Tese (doutorado) - University of London, Imperial College of Science, Technology and Medicine.

DUARTE, M. L. M. e EWINS, D. J. (2000). Rotational Degree of Freedom for Structural Coupling Analysis Via Finite-Difference Technique Whit Residual Compensation. Mechanical Systems and Signal Processing, 14 (2), p 205-227.

EWINS, D. J. (2000). Modal Testing: Theory and Practice. Letchwork, England, Research Studies Press Ltd

HELDERWEIRT, S., et al (2001). Application of Accelerometer-Based Rotational Degree Of Freedom Measurements for Engine Subframe Modelling. Proceedings of the $19^{\text {th }}$ International Modal Analysis Conference, IMAC 19, p 1298-1304

HEYLEN, W., LAMMERNS, S., SAS, P. (2000). Modal Analysis Theory and Testing. KU Leuven, PMA, Leuven, Belgium

HUEBNER, K. H.; THORNTON, E. A. (1982). The finite element method for engineers. 2. ed. John Wiley \& Sons Inc.

IVARSSON, L; SANDERSON, M. A., TROSHIN, A. G. (2000), Design, Theory and Validation of a Low Mass 6-d.o.f Transducer. Journal of Sound and Vibration, 230(3), p 661-688.

IVARSSON, L. H. (2000). A MIMO technique for measuring mobility matrices. Proceedings of the International Seminar on Modal Analysis, ISMA25, Leuven, Belgica.

LIU, W., EWINS, D. (1999). The Importance Assessment of RDOF en FRF Coupling Analysis. Proceedings of the $17^{\text {th }}$ International Modal Analysis Conference IMAC, Kissimmee, Florida, USA, p 1481-1487 
MAIA, N. M. M. et. al (1997). Experimental Modal Analysis. Taunton, England, Research Studies Press Ltd, John Wiley \& Sons Inc.

MATLAB User's Manual. Theory manual. 2002. Matlab revision 6.0.

McCONNELL, K. G. (2001). Evaluation of an Angular accelerometer. Proceedings of the $19^{\text {th }}$ International Modal Analysis Conference, IMAC, USA, p 14601466.

McCONNELL, K. G. (1995). Vibration Testing, Taunton, England, Research Studies Press Ltd, John Wiley \& Sons Inc.

RATCLIFFE, M. J., LIEVEN, N. A. J., (1996). Measuring Rotations Using a Laser Doppler Vibrometer. Proceedings of the $14^{\text {th }}$ International Modal Analysis Conference, IMAC, USA, p 1002-1008.

RAO, S. S. (1995). Mechanical Vibrations, USA, Addison-Wesley Publishing Company 3 edição.

RORRER, R. A. L., et al (1989). Angular acceleration of a free-free beam. Proceedings of the $7^{\text {th }}$ International Modal Analysis Conference, IMAC, Las Vegas, Nevada, USA, p 1300-1304.

URGUEIRA, A. P.V., (1989) Dymanic Analysis of Coupled Structures Using Experimental Data. London, Tese (doutorado) - University of London, Imperial College of Science, Technology and Medicine.

ZIAEI-RAD, S., MARTARELLI, M., EWINS, D.J., (2000). Measuring RDOFs using laser Doppler vibrometer. Proceedings of the International Seminar on Modal Analysis, ISMA25, Leuven, Belgica.

YOSHIMURA, T., HOSOYO, N., (1999), FRF Estimation on Rotational DOFs by Rigid Block Attachment Approach, Proceedings of the International Seminar on Modal Analysis, ISMA25, Leuven, Belgica. 
YOSHIMURA, T.,HOSOYA, N., (2000). FRF Estimation on Rotational Degree of Freedom by Rigid Block Attachment. Proceedings of the International Seminar on Modal Analysis, ISMA25, Leuven, Belgica.

INSALACO, M. D. The art of fabriting na rotational accelerometer. Kistler Instrument Corp, http://www.sensorsmag.com/articles/0900/114/main.shtml (21 out 2002).

KISTLER INC.(2001) http://www.kistler.com (3 junho 2003). 


\section{ANEXO 1}

\section{Procedimento Para OBTer as Matrizes}

\section{DE TRANSFORMAÇÃo PARA APROXIMAÇÃo}

\section{DE $1^{\text {a }}$ ORDEM DA TÉCNICA DE DIFERENÇAS}

\section{FINITAS}

Como mostrado na FIGURA 1, se a distância $l$ entre as linha paralelas de ação da Força $F_{A}$ e $F_{B}$ é pequena o suficiente, um dado sistema de forças $\left(F_{A}\right.$ e $\left.F_{B}\right)$ pode ser aproximadamente reduzido para um sistema de forças acopladas equivalente num dado ponto $b$, CHEN e CHERNG (1985).

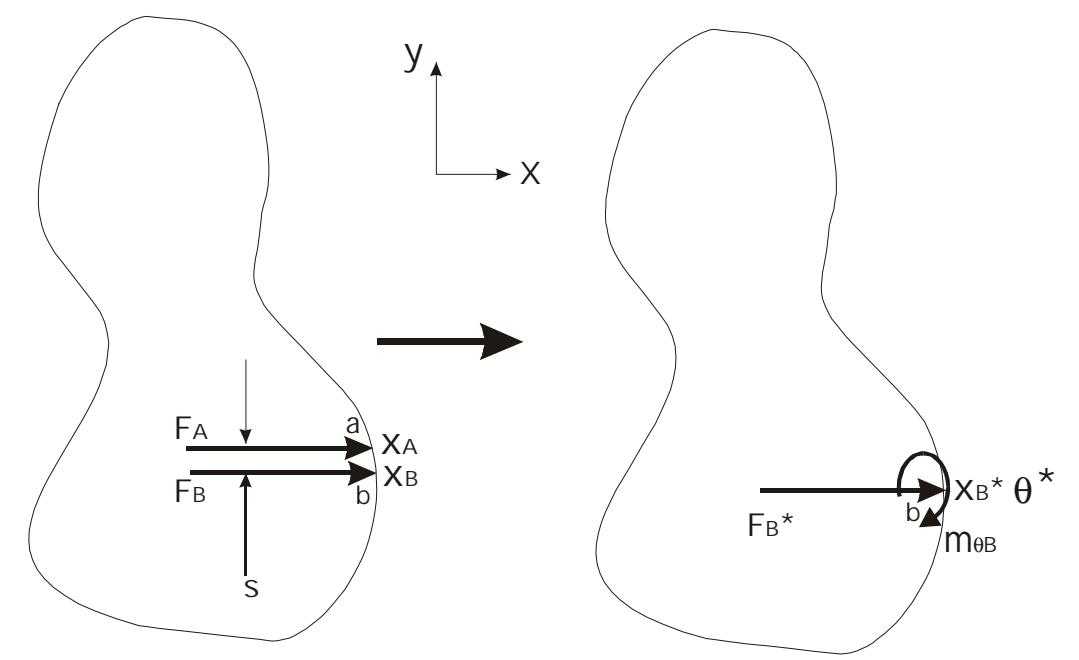

FIGURA 1 Sistema Equivalente 
A força equivalente

$F_{B}^{*}=F_{A}+F_{B}$

e o momento é dado por

$$
m_{\theta B}=F_{A} s
$$

A rotação no ponto $b$ pode ser expressa por

$\theta^{*}(\omega)=\frac{x_{A}(\omega)-x_{B}(\omega)}{S}$

desde que o deslocamento $x_{A}(\omega)$ e $x_{B}(\omega)$ nos pontos $a$ e $b$ sejam escritos como:

$$
\left\{\begin{array}{l}
x_{A}(\omega) \\
x_{B}(\omega)
\end{array}\right\}=\left[\begin{array}{ll}
{\left[H_{A A}(\omega)\right]} & {\left[H_{A B}(\omega)\right]} \\
{\left[H_{B A}(\omega)\right]} & {\left[H_{B B}(\omega)\right]}
\end{array}\right]\left\{\begin{array}{l}
F_{A}(\omega) \\
F_{B}(\omega)
\end{array}\right\}
$$

onde $\left[H_{A A}(\omega)\right],\left[H_{A B}(\omega)\right],\left[H_{B A}(\omega)\right]$ e $\left[H_{B B}(\omega)\right]$ são as mobilidades dinâmicas e, de acordo com a relação de Reciprocidade de Maxwell, $\left[H_{A B}(\omega)\right]=\left[H_{B A}(\omega)\right]$, CHEN e CHERNG (1985).

Então, rearranjando a Equação (2), tem-se

$F_{A}=\frac{m_{\theta B}}{s}$

e da Equação (1) tira-se 


$$
F_{B}=F_{B}^{*}-\frac{m_{\theta B}}{s}
$$

Pela Equação (4), tiramos as seguintes expressões

$$
\begin{aligned}
& x_{A}(\omega)=\left[H_{A A}(\omega)\right] F_{A}+\left[H_{A B}(\omega)\right] F_{B} \\
& x_{B}(\omega)=\left[H_{B A}(\omega)\right] F_{A}+\left[H_{B B}(\omega)\right] F_{B}
\end{aligned}
$$

Substituindo as Equações (5) e (6) e fazendo

$$
x_{A}(\omega)=\theta^{*}(\omega)_{s}+x_{B}(\omega)
$$

tem-se

$$
\begin{aligned}
& \theta^{*}(\omega)_{s}+x_{B}(\omega)=\left[H_{A A}(\omega)\right] \frac{m_{\theta B}}{s}+\left[H_{A B}(\omega)\right] F_{B}^{*}-\left[H_{A B}(\omega)\right] \frac{m_{\theta B}}{s} \\
& x_{B}(\omega)=\frac{m_{\theta B}}{s}\left(\left[H_{A B}(\omega)\right]-\left[H_{B B}(\omega)\right]\right)+\left[H_{B B}(\omega)\right] F_{B}^{*}
\end{aligned}
$$

Substituindo a Equação (10) na Equação (9), tem-se

$$
\theta^{*}=\left(\left[H_{A A}(\omega)\right]-2\left[H_{A B}(\omega)\right]+\left[H_{B B}\right]\right) \frac{m_{\theta B}}{s^{2}}+\left(\left[H_{A B}(\omega)\right]-\left[H_{B B}(\omega)\right]\right) \frac{F_{B}^{*}}{s}
$$




$$
\left\{\begin{array}{c}
x_{B}(\omega) \\
\theta_{B}(\omega)
\end{array}\right\}=\left[\begin{array}{cc}
{\left[H_{B B}(\omega)\right]} & \frac{\left[H_{A B}(\omega)\right]-\left[H_{B B}(\omega)\right]}{s} \\
\frac{\left[H_{A B}(\omega)\right]-\left[H_{B B}(\omega)\right]}{s} & \frac{\left[H_{A A}(\omega)\right]-2\left[H_{A B}(\omega)\right]+\left[H_{B B}(\omega)\right]}{s^{2}}
\end{array}\right]\left\{\begin{array}{c}
F_{B}^{*}(\omega) \\
m_{\theta B}(\omega)
\end{array}\right\} 12
$$

Reescrevendo a matriz da Equação (12)

$\left\{\begin{array}{c}x_{B}(\omega) \\ \theta(\omega)\end{array}\right\}=\left[\begin{array}{cc}0 & 1 \\ \frac{1}{s} & -\frac{1}{s}\end{array}\right]\left[\begin{array}{cc}{\left[H_{A A}(\omega)\right]} & {\left[H_{A B}(\omega)\right]} \\ S y m & {\left[H_{B B}(\omega)\right]}\end{array}\right]\left[\begin{array}{cc}0 & 1 \\ \frac{1}{s} & -\frac{1}{s}\end{array}\right]^{T}\left\{\begin{array}{c}F_{B}^{*}(\omega) \\ m_{\theta B}(\omega)\end{array}\right\}$

onde a matriz

$$
\left[T_{1 f}\right]=\left[\begin{array}{cc}
0 & 1 \\
\frac{1}{s} & -\frac{1}{s}
\end{array}\right]
$$

é a matriz de transformação para aproximação de primeira ordem da técnica de diferenças finitas, CHEN e CHERNG (1985).

Para se obter a matriz de transformação para o ponto atrás do ponto de media o procedimento de cálculo é análogo mudando apenas o ponto de relação. 


\section{ANEXO 2}

\section{Procedimento PARA OBTER as MATRIZES}

\section{DE TRANSFORMAÇÃO PARA APROXIMAÇÃO}

\section{DE $2^{a}$ ORDEM DA TÉCNICA DE DIFERENÇAS}

\section{FINITAS}

A FIGURA 2 apresenta um esquema onde se aplicam forças $F_{A}, F_{B}$ e $F_{C}$ e se a distância $l$ entre as linha paralelas de ação dessas forças é pequena o suficiente, um dado sistema de forças $\left(F_{A}, F_{B}\right.$ e $\left.F_{C}\right)$ pode ser aproximadamente reduzido para um sistema de forças acopladas equivalente num dado ponto $B$.
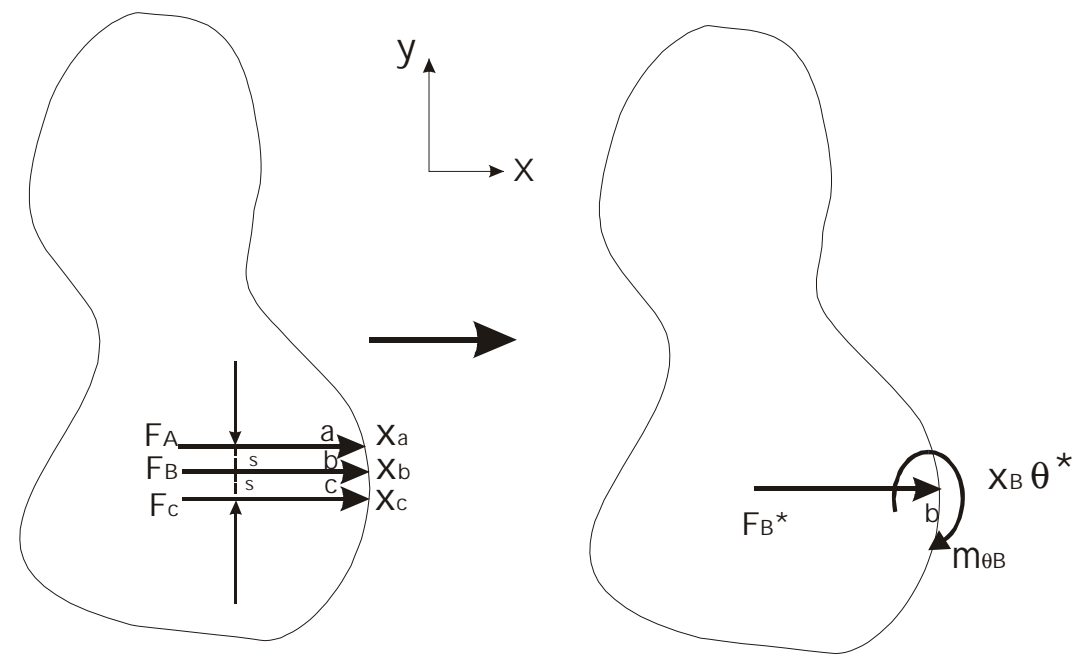

FIGURA 2 Sistema Equivalente para Aproximação de Segundo Ordem para o ponto 
A força equivalente

$$
F_{B}^{*}=F_{A}+F_{B}+F_{C}
$$

e os momentos no ponto $B$, são dados por:

$$
\begin{aligned}
& m_{\theta B}=F_{A} s \\
& m_{\theta B}=-F_{C} s
\end{aligned}
$$

Substituindo as Equações (2) e (3) na Equação (1), tem-se

$F_{B}^{*}=F_{B}$.

A rotação no ponto $b$ pode ser expressa por:

$$
\begin{aligned}
& \theta^{*}(\omega)=\frac{x_{A}(\omega)-x_{B}(\omega)}{s} \\
& \theta^{*}(\omega)=\frac{x_{B}(\omega)-x_{C}(\omega)}{s}
\end{aligned}
$$

O deslocamento $x_{A}(\omega), x_{B}(\omega)$ e $x_{C}(\omega)$ nos pontos $a, b$ e c são escritos como

$$
\left\{\begin{array}{l}
x_{A}(\omega) \\
x_{B}(\omega) \\
x_{C}(\omega)
\end{array}\right\}=\left[\begin{array}{lll}
{\left[H_{A A}(\omega)\right]} & {\left[H_{A B}(\omega)\right]} & {\left[H_{A C}(\omega)\right]} \\
{\left[H_{B A}(\omega)\right]} & {\left[H_{B B}(\omega)\right]} & {\left[H_{B C}(\omega)\right]} \\
{\left[H_{C A}(\omega)\right]} & {\left[H_{C B}(\omega)\right]} & {\left[H_{C C}(\omega)\right]}
\end{array}\right]\left\{\begin{array}{l}
F_{A}(\omega) \\
F_{B}(\omega) \\
F_{C}(\omega)
\end{array}\right\}
$$

Abrindo e expressação matricial da Equação (6), tiramos as seguintes expressões 
$x_{A}(\omega)=\left[H_{A A}(\omega)\right] F_{A}+\left[H_{A B}(\omega)\right] F_{B}+\left[H_{A C}(\omega)\right] F_{C}$

$x_{B}(\omega)=\left[H_{B A}(\omega)\right] F_{A}+\left[H_{B B}(\omega)\right] F_{B}+\left[H_{B C}(\omega)\right] F_{C}$

$x_{C}(\omega)=\left[H_{C A}(\omega)\right] F_{A}+\left[H_{C B}(\omega)\right] F_{B}+\left[H_{C C}(\omega)\right] F_{C}$

Isolando $x_{A}(\omega)$ da Equação (4) e $x_{B}(\omega)$ da Equação (5) e substituindo na Equação (6), pode-se escrever:

$$
\begin{aligned}
& \theta^{*} s+x_{B}(\omega)=\left[H_{A A}(\omega)\right] \frac{m_{\theta B}}{s}+\left[H_{A B}(\omega)\right] F_{B}^{*}-\left[H_{A C}(\omega)\right] \frac{m_{\theta B}}{s} \\
& x_{B}(\omega)=\frac{m_{\theta B}}{s}\left(\left[H_{B A}(\omega)\right]-\left[H_{B C}(\omega)\right]\right)+\left[H_{B B}(\omega)\right] F_{B}^{*} \\
& -\theta^{*} s+x_{B}(\omega)=\left[H_{C A}(\omega)\right] \frac{m_{\theta B}}{s}+\left[H_{C B}(\omega)\right] F_{B}^{*}-\left[H_{C C}(\omega)\right] \frac{m_{\theta B}}{s}
\end{aligned}
$$

Subtraindo a Equação (10) da Equação (12), tem-se a expressão para $\theta_{\mathrm{B} \text { : }}$

$$
\theta^{*}=\frac{m_{\theta B}}{4 s^{2}}\left(\left[H_{A A}(\omega)\right]+2\left[H_{A C}(\omega)\right]+\left[H_{C C}\right]\right)+\frac{F_{B}^{*}}{4 s}\left(\left[H_{A B}(\omega)\right]-\left[H_{C B}(\omega)\right]\right)
$$

As Equações (11) e (13) podem ser rearranjadas na forma matricial ficando:

$$
\left\{\begin{array}{c}
x_{B}(\omega) \\
\theta(\omega)
\end{array}\right\}=\left[\begin{array}{cc}
{\left[H_{B B}(\omega)\right]} & \frac{\left[H_{C B}(\omega)\right]-\left[H_{B A}(\omega)\right]}{s y m} \\
\frac{\left[H_{A A}(\omega)\right]-2\left[H_{A C}(\omega)\right]+\left[H_{C C}(\omega)\right]}{4 s^{2}}
\end{array}\right]\left\{\begin{array}{c}
F_{B}^{*}(\omega) \\
m_{\theta B}(\omega)
\end{array}\right\}
$$




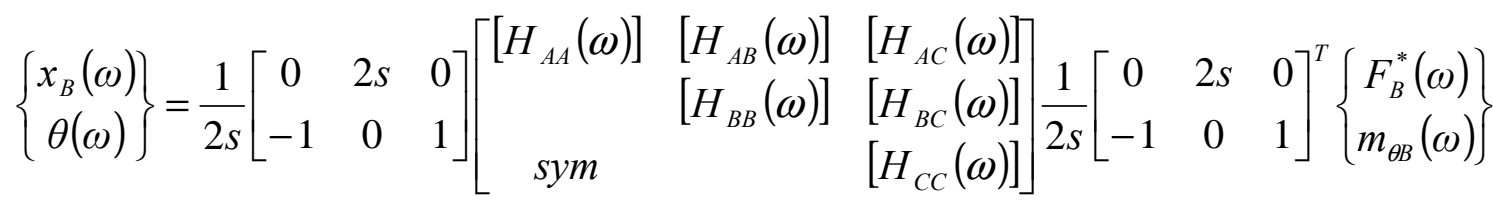

onde a matriz

$\left[T_{2 c}\right]=\frac{1}{2 s}\left[\begin{array}{ccc}0 & 2 s & 0 \\ -1 & 0 & 1\end{array}\right]$

é a matriz de transformação para o ponto central do ponto de medição para aproximação de segunda ordem da técnica de diferenças finitas, CHEN e CHERNG (1985).

Procedimento similar de cálculo é aplicado para os pontos a frente e atrás do ponto de medida obtendo as matrizes de transformação, CHEN e CHERNG (1985). 


\section{ANEXO 3}

\section{Programa Matlab ${ }^{\circledast}$}

\section{Programa Para Cálculo das frF}

\section{ANGULARES OBTIDAS VIA BLOCO T}

Este programa gera as FFT (Fast Fourier Transformer) de todos os sinais colhidos do aparato experimental, calcula a freqüência angular a partir das freqüências lineares obtidas experimentalmente com uso do bloco $\mathrm{T}$, e por fim calcula as FRFs angulares/lineares.

\section{FRF DE PONTO - EXCITAÇÃO E RESPOSTA COLHIDAS NO MESMO PONTO.}

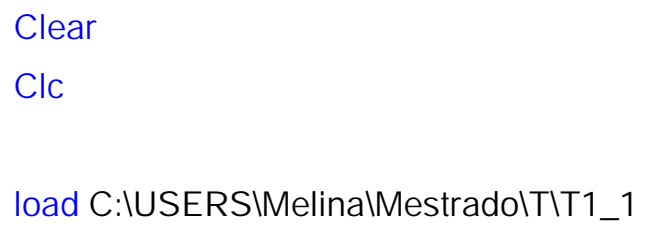

\section{Comprimento do Vetor}

$\mathrm{np}=$ length $(\mathrm{TimeV})$;

Delta da Amostragem no Tempo: 


\section{Freqüiência de Amostragem}

$\mathrm{fa}=1 / \mathrm{dt}$

$\mathrm{df}=\mathrm{fa} / \mathrm{np}$

$f=0: d f:(n p * d f-d f) / 2$

Transformada de Fourier dos sinais no tempo dos dois acelerômetros:

$\mathrm{T} 1=(1 / \mathrm{np}) * \mathrm{ft}(\mathrm{Timei} 1) ;$

Força

$\mathrm{T} 2=(1 / \mathrm{np}) * \mathrm{ftt}(\mathrm{Timei})$;

Acelerômetro

$\mathrm{T} 4=(1 / \mathrm{np}) * \mathrm{ftt}(\mathrm{Timei} 4) ;$

Acelerômetro

\section{Calculo para a Aceleração Angular}

$\mathrm{Tf}=(\mathrm{T} 2-\mathrm{T} 4) / 0.08$

Gyy=Tf.*Tf;

$\mathrm{Gxy}=\mathrm{T} 1{ }^{*} \mathrm{Tf} ;$

\section{FRF}

$\mathrm{FRF} 1=\mathrm{G} y \mathrm{y} . / \mathrm{G} x \mathrm{y}$

Ioad C:IUSER SIM elina\Mestrado|Angular|melina1

\section{Gráfico da FRF}

semilogy (f,(abs(FR F 1(1:np/2))), 'b','F reqV,abs (Xfer21), 'r')

xlabel('F requency $\left.[\mathrm{Hz}]^{\prime}\right)$

ylabel('Amplitude $[\mathrm{g} / \mathrm{N}]$ ]')

legend('FRF do T-Block','FRF do Accelerometer')

title('FRF Angular de Ponto')

grid on 


\section{Programa Para Calcular a FrF}

\section{ANGULAR / LINEAR OBTIDA VIA TÉCNICA DAS \\ DIFERENÇAS FINITAS DE $1^{\text {a }}$ ORDEM}

Comando de entrada
Clear
clc
i=sqrt(-1);
load diferenca1_1.txt
freq1=diferenca1_1(:,1);
real1=diferenca1_1(:,2);
imag1=i*(diferenca1_1(:,3));

FRF de ponto com excitação no extremo da viga

FRF_CC=real1+imag1;

subplot(2,1,1);

semilogy (freq1,abs(FRF_CC), 'b')

axis([0 50010 10 10^5]);

real2=diferenca1_1(:,4);

imag2=diferenca1_1 $(:, 5)$;

FRF de transferência com excitação no extremo da viga

$F R F \_C B=r e a l 2+i m a g 2 ;$

subplot(2,1,2);

semilogy (freq1,abs(FRF_CB), 'r')

axis([0 50010 (10 10^4]); 
figure

semilogy (freq1,abs(FRF_CC), 'b', freq1,abs(FRF_CB), 'r')

load diferenca1_2.txt

freq2=diferenca1_2(:,1);

real_1=diferenca1_2(:,2);

imag_1=i*(diferenca1_2(:,3));

FRF de transferência com excitação a $45 \mathrm{~mm}$ da extremidade da viga

FRF_BC=real_1+imag_1;

subplot(2,1,1);

semilogy (freql,abs(FRF_BC))

axis([0 $50010{ }^{0} 10 \wedge$ 5]);

real_2=diferenca1_2(:,4);

imag_2=diferenca1_2(:,5);

FRF de ponto com excitação a $45 \mathrm{~mm}$ da extremidade

$F R F \_B B=$ real_2+imag_2;

subplot(2,1,2);

semilogy(freq1,abs(FRF_BB),'r')

axis([0 $\left.\left.50010{ }^{\circ} 10 \wedge 4\right]\right)$

figure

semilogy(freq2,abs(FRF_BC), 'b', freq2,abs(FRF_BB),'r')

Programa que calcula FRF angular a partir da técnica de diferenças finitas.

Matriz do espaçamento 's'

$\mathrm{s}=0.045(\mathrm{~m})$

Distância entre os acelerômetros

$T=[0 \quad 1 ;(1 / s)-(1 / s)]$ 


\section{Matriz Estimada das FRFs}

$\mathrm{Hyy}=\mathrm{FRF} \mathrm{CC}_{-}$;

$\mathrm{Hyt}=(1 / \mathrm{s}) *\left(F R F_{-} C \mathrm{C}-\mathrm{FRF} \_\mathrm{CB}\right)$;

$H t y=(1 / S) *\left(F R F \_C C-F R F \_B C\right)$;

$\mathrm{H} t \mathrm{t}=(1 / \mathrm{s}) \wedge^{2} *\left(F R F_{-} \mathrm{CC}+\mathrm{FRF} \mathrm{B}_{-} \mathrm{B}-\mathrm{FRF} \mathrm{F}_{-} \mathrm{CB}-\mathrm{FRF} \mathrm{F}_{-} \mathrm{BC}\right)$;

\section{FRF}

title('Diferenca Finita de Primeira Ordem' )

subplot $(4,1,1)$

semilogy(freq1,abs (Hyy), 'b')

legend('F R F linear-linear')

xlabel('Frequencia [Hz]')

ylabel('Amplitude [N/m]')

subplot $(4,1,2)$

semilogy (freq1, abs (Hyt), 'g')

legend('linear-angular')

xlabel('Frequencia [Hz]')

ylabel('Amplitude $[\mathrm{g} / \mathrm{N}]$ ')

subplot $(4,1,3)$

semilogy (freq1,abs (Hty), 'm')

legend('FR F angular-linear')

xlabel('Frequencia [Hz]')

ylabel('Amplitude [N/m]')

subplot $(4,1,4)$

semilogy (freq1,abs (Htt), 'k')

legend('FRF angular-angular')

xlabel('Frequencia [Hz]')

ylabel('Amplitude [N/m]') 


\section{Programa Para Calcular a FrF}

\section{ANGULAR / LINEAR OBTIDA VIA TÉCNICA DAS \\ DIFERENÇAS FINITAS DE $2^{\text {a }}$ ORDEM}

Comandos de Entrada do programa

clear

clc

close all

$i=\operatorname{sqrt}(-1)$;

load diferenca2_01.txt

freq01=diferenca2_01(:,1);

Excitaçao em C e aceleração em C

real01=diferenca2_01(:,2);

imag01=i*(diferenca2_01(:,3));

FRF de ponto com excitação no extremo da viga

FRF_CC =real01+imag01;

Excitação em C e aceleração em B

real02=diferenca2_01 $(:, 4)$;

imag02 $=$ i* (diferenca2_01(:,5));

FRF de transferência com excitação no extremo da viga

FRF_BC=real02+imag 02;

Excitação em C e aceleração em A

real03=diferenca2_01(:,6); 
imag03=i*(diferenca2_01(:,7));

FRF de transferência com excitação no extremo da viga

$F R F \_A C=$ real03+imag03;

load diferenca2_02.txt

freq11 =diferenca2_02(:,1);

Excitação em C e aceleração em C

real11=diferenca2_02 $(:, 2)$;

imag11=i*(diferenca2_02(:,3));

FRF de ponto com excitação à $45 \mathrm{~mm}$ do extremo da viga

FRF_CB=real11+imag11;

Excitação em C e aceleração em B

real12=diferenca2_02(:,4);

imag $12=i *($ diferenca2_02 $(:, 5))$;

FRF de transferência com excitação à $45 \mathrm{~mm}$ do extremo da viga

FRF_BB =real12+imag12;

Excitação em C e aceleração em A

real13=diferenca2_02(:,6);

imag13=i*(diferenca2_02 $(:, 7))$;

FRF de transferência com excitação à $\mathbf{4 5} \mathbf{m m}$ do extremo da viga

$F R F \_A B=$ real13+imag13;

load diferenca2_03.txt

freq21 =diferenca2_03(:,1);

Excitação em C e aceleração em C

real21=diferenca2_03(:,2); 
imag21=i*(diferenca2_03(:,3));

FRF de ponto com excitação à $90 \mathrm{~mm}$ do extremo da viga

FRF_CA=real21+imag21;

Excitação em C e aceleração em B

real22=diferenca2_03(:,4);

imag22=i*(diferenca2_03(:,5));

FRF de transferência com excitação à $\mathbf{4 5} \mathbf{m m}$ do extremo da viga

FRF_BA=real22+imag22;

Excitação em C e aceleração em A

real23=diferenca2_03(:,6);

imag23=i*(diferenca2_03(:,7));

FRF de transferência com excitação à $90 \mathrm{~mm}$ do extremo da viga

FRF_AA=real23+imag23;

Programa que calcula FRF angular/linear a partir da técnica de diferenças finitas de $2^{a}$ ordem.

Matriz de espacamento S

$\mathrm{s}=0.045(\mathrm{~m})$

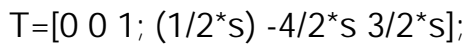

$\mathrm{TT}=[0 \quad 1 / 2 * s ; 0-4 / 2 * s ; 13 / 2 * s] ;$

Matriz Estimada das FRFs

$\mathrm{Hyy}=\mathrm{FRF} \mathrm{CC}_{\text {; }}$

$\mathrm{Hyt}=(1 /(2 * s)) *\left(3 * \mathrm{FRF} \mathrm{C}_{-} \mathrm{C}-4 * \mathrm{FRF} \mathrm{F}_{-} \mathrm{CB}+\mathrm{FRF} \mathrm{F}_{-} \mathrm{CA}\right)$;

$\mathrm{Hty}=(1 /(2 * s)) *\left(3 * F R F_{-} C \mathrm{C}-4 * \mathrm{FRF} \mathrm{F}_{-} \mathrm{BC}+\mathrm{FRF} \mathrm{F}_{-} \mathrm{AC}\right) ; ;$

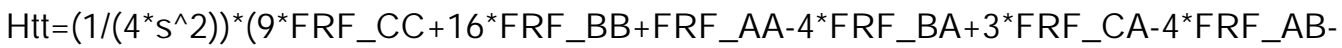

$\left.12 * F R F \_C B+3 * F R F \_A C-12 * F R F \_B C\right)$;

FRFs com todos os graus de liberdade: 
subplot( $4,1,1)$

figure

semilogy(freq01,abs(Hyy), 'k')

legend('F R F linear-linear')

figure

subplot $(4,1,2)$

semilogy(freq01,abs(Hty), 'b')

legend('FRF angular-linear')

figure

subplot( $4,1,3)$

semilogy(freq01,abs(Hyt), 'g')

legend('FRF linear-angular')

subplot $(4,1,4)$

figure

semilogy (freq01,abs ( $\mathrm{Htt})$, 'm')

legend('FRF angular-angular')

\section{FRF que possui a relação Angular/Linear}

figure

semilogy (freq01,abs(Hty),'b')

legend('FRF angular/linear') 
